\title{
Identidades y apelaciones antagónicas de los trabajadores del
espectáculo (1902-1955) trabajadores del
espectáculo (1902-1955)
}

Fecha de recepción: 19/03/2018. Fecha de aceptación: 08/05/2018.

\begin{abstract}
Resumen
En el presente artículo analizaremos las condiciones laborales de los artistas durante las primeras cinco décadas del siglo XX. En el primer apartado, nos centraremos en las características de la organización comercial de las artes del espectáculo, en el surgimiento de las asociaciones y gremios que nucleaban a los diversos agentes del sector y en los conflictos e identidades surgidos en el bienio 1919-1921. Asimismo, profundizaremos en la legislación existente y en el escaso rol cumplido por el Estado, tanto nacional como municipal, respecto de las condiciones laborales de los artistas, y en la incursión de los mismos en la arena política.
\end{abstract}

En el segundo apartado, tomaremos en consideración el imaginario impuesto por el teatro independiente que, en pos de transmitir al público un mensaje emancipador, desplaza las relaciones de producción al exterior de la actividad artística, construyendo la figura del artista como militante. Por el contrario, el primer peronismo intentará privilegiar la dimensión laboral de todas las actividades, inclusive las culturales, apelando a los artistas como trabajadores. Consideramos que en esta disputa subyacen conflictos más profundos, como la mutua influencia entre el Estado y la producción artística, o los vínculos de la cultura y el arte con el mundo del trabajo.

\section{Performing Artists' Identities and Antagonistic Appeals (1902-1955)}

\begin{abstract}
In this paper we will analyze the working conditions of artists during the first five decades of the 2oth Century. In the first section, we will focus on the characteristics of the commercial organization of performing arts, as well as on the emergence of the associations and unions that gathered the diverse agents of the sector and on the conflicts and identities that arose in the biennium 1919-1921. We will also look into
\end{abstract}

\section{Palabras clave}

artistas del espectáculo; mundo del trabajo; identidad; teatro independiente; primer peronismo
Keywords

Artists; Work Studies; Identity; Independent Theatre; First Peronism 
the legislation and the limited role played by the State, both national and municipal, regarding the working conditions of the artists. Finally, we will analyze the incursion of the artists in the political field.

In the second section, we will consider the imaginary imposed by the independent theatre that, in order to transmit an emancipatory message to spectators, displaces the relations of production to the exterior of artistic activity, constructing the figure of artists as an activists. Conversely, the first Peronism tried to privilege the labor dimension of all activities, even cultural ones, thus appealing to artists as workers. We consider that deeper conflicts underlie in this dispute, such as the mutual influence between the State and artistic production, or the connections that culture and arts have with the world of work.

\section{Primer Apartado: Identidades y apelaciones antagónicas. ¿Artistas, productores o trabajadores? (1902 - 1930)}

I.

Desde principios del siglo XX, los espectáculos en vivo presentaron un desarrollo sostenido en la Ciudad de Buenos Aires, llegando a su mayor apogeo entre 1918 y 1926. En efecto, de las cinco compañías nacionales registradas en 1916, para 1928 ya se contabilizan setenta y dos que, en su mayoría, representan géneros identificados con el teatro popular y que actúan en un circuito céntrico compuesto por más de 30 salas, en una ciudad con una población estimada en 2.000.000 de habitantes. ${ }^{1} \mathrm{El}$ año 1925 es aquel en que se registra la mayor asistencia de público (6.740.047 espectadores) y de recaudación (\$10.000.000, cifra a la que se había escalado sostenidamente desde los $\$ 3.000 .000$ registrados en 1919 , lo cual a su vez ya mostraba un importante incremento desde los $\$ 900.000$ indicados para mediados de la década del diez). ${ }^{2}$

Sin contar aún con la competencia de la radio, ${ }^{3}$ del cine sonoro y del espectáculo deportivo, el teatro mantenía su hegemonía como forma masiva de entretenimiento. Esto dio lugar a una amplia disponibilidad de público para una actividad que se volvió sumamente lucrativa y, por consiguiente, muy intensa. Las salas daban funciones continuadas los siete días de la semana de 18 horas hasta la medianoche, aunque también podía comenzarse más temprano.

Por otra parte, a la cantidad de empresarios y empleados que llevaban adelante la administración de las salas teatrales, debemos agregar que cada compañía contaba con un promedio de entre diez y cuarenta integrantes, por lo que se estima qua había cerca de tres mil artistas en actividad. A esto debe sumarse la gran cantidad de nuevos autores que se volcaron a escribir teatro: según los datos recopilados por la Sociedad Argentina de Autores, en 1900 se estrenaron doce obras de autores nacionales, setenta y cuatro en 1918, 193 en 1919, 250 en 1920 y 381 en 1926. También surgieron revistas dedicadas al teatro, como Bambalinas, La Escena, Anuario Teatral Argentino, y Comoedia, que entre 1918 y 1933 editaron cerca de 1700 libretos de obras (González Velazco, 2012).

La década del veinte resulta un período clave para comprender la evolución de las condiciones laborales y de la estructura identitaria de los artistas, matrices que se mantendrán activas a lo largo del siglo hasta nuestros días. La posibilidad de éxito económico promovió el carácter estrictamente comercial de la actividad y la pulsión por obtener el mayor rédito, lo cual conllevó el surgimiento de conflictos. En primer lugar, todos los agentes implicados en la producción de espectáculos se vieron en la
1. Según María Florencia Caudarella, el circuito céntrico poseía capacidad para 26.000 personas, datos que la autora compara con los de las ciudades de Nueva York y Chicago para la misma época (Ver Caudarella, 2016: 19). Por su parte, Rubens Bayardo (1997: 51) señala que para 1910, los teatros de la Ciudad y del gran Buenos Aires poseían capacidad para 33.000 personas, con un promedio de 1 butaca cada 75 habitantes, mientras que para 1976 dicha cifra bajó a 31.000, con un promedio de 1 butaca cada 260 habitantes.

2. Estos y otros datos fueron extraídos de ATA, 1928; Klein, 1988; González Velazco, 2012 y Caudarella, 2016.

3. La primera emisión radial se realizó en 1920 y sólo fue escuchada por pocas personas. 
necesidad de agruparse en sindicatos o asociaciones que defendieran sus derechos y que aún permanecen en actividad. En segundo término, es en este contexto que los artistas ensayan y ponen en práctica dos tradicionales estrategias de lucha de los trabajadores: la huelga y la autogestión como forma alternativa de organización de la actividad.

Del análisis de estas experiencias, surgen una serie de preguntas que guiarán nuestro análisis: ¿cómo actuaron los diversos agentes (artistas, empresarios de sala y de compañía, autores, etc.) en este contexto? ¿Cuál fue la posición del Estado en materia de políticas laborales y culturales? ¿Son los actores productores o trabajadores? Si son productores, ¿qué producen?, ¿para quién producen?, ¿cuáles son las características económicas de aquello que producen? ¿Cuáles son las posibilidades y límites para instaurar una organización de la producción alternativa a la comercial? ¿Fueron viables estas estrategias en el contexto de un mercado en expansión? ¿Qué sucedió cuando sobrevino la crisis?

\section{II.}

Desde finales del siglo XIX, el espectáculo en vivo fue la forma principal de entretenimiento, fundamentalmente en el creciente espacio urbano. Así, el circo criollo, el teatro de texto y los espectáculos de variedades se convirtieron en actividades comerciales de gran dinamismo. En este contexto, las primeras décadas del siglo XX constituyen un largo período de grave precariedad laboral para los artistas, en una actividad con altos niveles de informalidad que aún conservaba los principios organizativos del siglo XIX: el teatro por secciones y el sistema de compañías.

Si bien existía un teatro culto para las élites (conformado mayormente por compañías extranjeras 4 que representaban teatro lírico o de texto), el teatro de mayor desarrollo durante el cambio de siglo fue el denominado género chico. En efecto, el teatro porteño finisecular presenta un gran desarrollo comercial y estético, proveniente de su origen popular en el circo y de su surgimiento por iniciativa de los artistas, quienes compartían su condición social con el público, incorporando formas, procedimientos y contenidos valorados por el mismo.

Pero esto no sólo sucederá con el sainete. También las variedades serán fundamentales en la transición del siglo:

Los espectáculos de variedades pudieron moverse con flexibilidad en un contexto de mutaciones culturales, incorporar la tecnología, conservar la atracción por lo excéntrico o sorprendente, otorgar más lugar al fenómeno del tango -que era popularizado por la industria discográfica-, proyectar más cintas, etc. Es decir, pese a ser un tipo de espectáculo muy antiguo, las variedades fueron las que hicieron lugar más rápidamente a las grandes novedades que atraían la atención del público: el tango, el jazz y el cine (González Velazco, 2012: 40).

La actividad teatral se hallaba organizada en compañías, reunión estable de actores, inicialmente de tipo familiar, que no sólo generaba puestas en escena sino que también funcionaba como espacio para la incorporación y formación de nuevos artistas. La compañía se constituía alrededor de un actor que funciona como cabeza, asumiendo conjuntamente los roles de director escénico y empresario, quien negociaba las condiciones con el dueño de sala. El resto de los integrantes se organizaba a partir de la distribución de roles fijos y de un rígido escalafón, cuya promoción interna se daba por acumulación de experiencia y/o edad. Los roles se aprendían por imitación, ensayo y error. Estas estructuras contaban con una gran solidaridad interna, pero
4. Durante las primeas dos décadas del siglo la mayoría de las compañías eran extranjeras, pero esto se revertirá a fines de los años 10. Si bien la Primera Guerra Mundial impidió el arribo de artistas provenientes de Europa, lo cierto es que existen otras razones para explicar la "nacionalización” de las compañías. El Anuario Teatral Argentino listó para 1925, 118 compañías en todo el país y 20 más de las que no tenía datos. La publicación agrega que 78 de ellas incluían la denominación "nacional", "argentina" o "criolla" en su nombre, aunque no todos los artistas que las integraban eran argentinos. Por tal motivo, debemos entender que si la adscripción de una compañía a una colectividad o país de origen había sido un rasgo valorado por un público eminentemente inmigrante en los años anteriores, llegados los 20 la nacionalidad argentina se evidenció como un rasgo positivo para ese mismo público y para sus hijos. 
también con una extrema dependencia de la tiranía del capocómico, quien poseía atribuciones sobre el quehacer escénico y también sobre los cuerpos de los artistas (son frecuentes los casos de hijos ilegítimos dentro de las compañías, niños que llegaban con los elencos en gira procedentes de Europa de los cuales se desconocía su filiación, ${ }^{5}$ compra de niños por parte de circos, etc.).

El crecimiento del espacio urbano a principios del siglo XX determinó el asentamiento de la actividad y la apertura de teatros estables. De esta forma, surgió el empresario de sala, también conocido en el medio teatral como empresario de paredes. Algunos compraban varios teatros y cines $^{6}$ ubicados en el centro porteño, lo que generó una gran concentración inmobiliaria en el sector (González Velazco, 2012).

El trabajo de autores y actores era escasamente remunerado en relación con las extraordinarias ganancias producidas por la actividad, que eran percibidas por ambas instancias empresariales. La explotación comercial era intensa. El teatro era por secciones: se representaban obras de corta duración para un público golondrina (que entraba y salía de la sala frecuentemente) y pagaba una entrada de pocos centavos, por lo que la ganancia sólo se obtenía realizando hasta seis funciones diarias. La primera función era la matinée, a las 17 horas, y luego podían llegar a ofrecerse tres y hasta cuatro funciones más. Además, se utilizaban números de distinto tipo para amenizar los intermedios, por lo que no había momentos ociosos.

Las salas podían dedicarse a un mismo tipo de obras o combinar diferentes géneros y precios de localidades, para diversificar la oferta. También se incluía publicidad en los volantes y programas de mano, con el objeto de disminuir los gastos de producción. Todas estas prácticas sólo pueden explicarse en un contexto de gran disponibilidad de público y en la necesidad de captarlo.

Esta dinámica comercial se basaba en el recambio constante de espectáculos con el fin de amortiguar los riesgos de la inversión. Si una obra no era exitosa se la reemplazaba de inmediato, incumpliendo contratos y ocasionando denuncias (González Velazco, 2012). También podía suceder lo contrario: si la obra era exitosa, se la programaba en varias secciones, dando de baja las que estaban anteriormente. ${ }^{7}$ Esto no implicaba ni el fin de la temporada ni necesariamente el cambio de compañía, pero sí el esfuerzo extra de ensayar por la noche. En efecto, esta renovación constante de la cartelera obligaba a las compañías a ensayar y estrenar en muy poco tiempo.

Los ensayos se realizaban de madrugada y no eran pagos. Estaban a cargo del capocómico o de su delegado (dado que, en varios casos, el actor principal se sumaba a los mismos a último momento), y consistían en la lectura en voz alta del texto (para memorizarlo o porque algunos actores no estaban alfabetizados), en el agregado de la mímica considerada adecuada y en la marcación de entradas y salidas. No se ensayaba más de una semana por obra y se suponía que el resto surgiría de la improvisación en escena.

El negocio del espectáculo aportaba ganancias significativas para los empresarios y los actores principales, pero no así para el resto de la compañía, registrándose grandes diferencias internas. Para fines de la década del diez el sueldo de un actor de reparto era de aproximadamente \$150 y el de un galán o una primera actriz, de \$800, mientras se calcula que los ingresos promedio de una familia obrera por 48 horas semanales de trabajo eran de \$200 (González Velazco, 2012).

La inexistencia de legislación laboral y de políticas en materia teatral promovía que las condiciones laborales de los artistas quedaran libradas al afán de lucro de los empresarios. La cantidad e impuntualidad en el inicio de las funciones ocasionaban
5. Tal como lo analiza Shirkin, en "El artista de variedades en el Buenos Aires de la primera mitad del siglo XX", artículo que forma parte del presente dossier.

6. González Velazco (2012) señala que muchos empresarios apostaban tanto al teatro como al cine, diversificando su actividad. Sin embargo, el teatro era una alternativa más autónoma porque no dependía de la llegada y distribución de las películas, es decir, del trato con distribuidoras extranjeras.

7. Una práctica similar a la que hemos señalado para las salas alternativas en la actualidad, en el artículo de nuestra autoría, “Entre el mundo del arte y el mundo del trabajo. Herramientas conceptuales para comprender la dimensión laboral del trabajo artístico", en el presente dossier. 
que la jornada laboral se extendiese. No existía día de descanso, licencia por enfermedad, maternidad o accidentes, ni jubilación. Otros aspectos que dan testimonio del alto nivel de informalidad de la actividad son la inexistencia de un contrato único (los contratos eran de palabra y por familia), la asiduidad en el incumplimiento de los compromisos por parte de los empresarios, las rebajas arbitrarias en los sueldos o la suspensión de temporadas en función de la recaudación, las multas injustificadas y el abandono en medio de giras, lo cual obligaba a los actores a procurarse el regreso por sus propios medios. Para evitar despedir a un actor, el empresario podía hacer uso de una claque que lo hostigara en escena, motivando su renuncia. Esto podía generar la práctica inversa: que el artista contratara su propia claque para que lo apoyara, lo cual requería de su inversión.

Por otra parte, los actores debían costearse su propio vestuario. Esta disposición, que sobrevivía desde los tiempos de la colonia, obligaba a los actores a disponer de traje de calle, frac completo, guantes, zapatos de color y negro, mientras que las actrices debían aportar valencianas, charra, gallega, pescadora, soirée, traje de calle blanco, blusa negra, zapatos blancos, negros y de color, medias y pañuelo (Klein: 1988).

En este contexto, la situación de la mujer era aún más grave. González Velazco (2012) da cuenta de que los espectáculos de género ligero estaban ligados a la prostitución $\mathrm{y}$, en algunos casos, compartían el mismo espacio (colocando como ejemplo al Royal Pigall, que era un cabaret en la planta baja y un teatro de género libre en el primer piso). Frecuentemente, eran las mismas mujeres y los mismos empresarios que las ofrecían como artistas de variedades o como prostitutas indistintamente.

Si bien estas condiciones laborales desembocaron en una organización colectiva temprana, la misma no perduró en el tiempo y no tuvo como objeto la confrontación a los empresarios. En efecto, la Asociación de Artistas Dramáticos y Líricos Nacionales funcionó entre 1906 y $1916^{8}$ y tuvo un perfil netamente mutualista, dado que sus miembros eran tanto actores como actores-empresarios y su objetivo, paliar los perjuicios que la enfermedad, la vejez y la muerte causaban entre los actores y sus deudos (aunque también intentaron infructuosamente que se implementara el día de descanso). De hecho, el único legado de esta efímera Asociación fue el aún existente Panteón de Actores en el Cementerio del Oeste (Cementerio de la Chacarita). Esta opción por el mutualismo (en contraposición a un perfil netamente sindical) se mantuvo como una variante constantemente en pugna en el colectivo actoral, provocando rupturas y divisiones cuando los intentos de esgrimir reivindicaciones gremiales entraban en una colisión demasiado directa con el sector empresarial. ${ }^{9}$

El primer conflicto al interior de la actividad teatral fue, de hecho, el protagonizado por los autores. En 1907, Enrique García Velloso impulsa la creación de la Sociedad Argentina de Autores Dramáticos y Líricos mucho antes de que existiera una ley que amparase los derechos de autor. Pero esta iniciativa logrará estabilidad recién en 1910, con la fundación de la Sociedad Argentina de Autores, institución pionera presidida por el propio García Velloso y que años más tarde pasará a denominarse ARGENTORES. La Sociedad exige a los empresarios el 10\% de la recaudación, para lo cual realiza jornadas de lucha y boicot a los teatros, en las que incluso se registran hechos de violencia y heridos (Baranchuk, 2016). Estas protestas cuentan con el apoyo de los actores, el público y la prensa (Kogan, 2012). El 12 de agosto de 1911 los empresarios firman un convenio reconociendo el 15\% de derecho autoral para el estreno y el $10 \%$ para el resto de las funciones.

De este modo, la Sociedad consiguió que los empresarios cumplieran con lo que un mes después dictaminaría la Ley 7092 de 1910, pero que no entraría en vigencia sino hasta la sanción de la Ley 11723 de 1933:
8. Estaba presidida por Miguel $\mathrm{F}$. López, periodista rosarino devenido en primer galán (Baranchuk, 2016)

9. Es así como entre 1920 y 1950 se producen tres divisiones en la AAA. La primera, en 1921, cuando se forma la Unión Argentina de Actores, que nuclea a los actores-empresarios en un afán netamente mutualista. En 1924 vuelven a fusionarse. En 1935 se produce una nueva escisión, cuando el grupo gremialista forma el Sindicato Argentino de Actores. Nuevamente se fusionan en 1937. La tercera separación tendrá lugar en 1946, como consecuencia del surgimiento del peronismo. La fusión, en este caso, será en 1954. Veremos estos casos en profundidad más adelante. 
La ley 7092 fue promulgada el 23 de septiembre de ese mismo año y publicada en el Boletín Oficial un día después. El artículo 3 de la flamante norma, redactada por el entonces director de la Biblioteca Nacional, Paul Groussac, y defendida en el Senado por Joaquín V. González, estableció que el derecho de propiedad de una obra científica, literaria o artística comprende para su autor la facultad de disponer de ella, de publicarla, ejecutarla, representarla y exponerla en público, de enajenarla, traducirla, adaptarla o de autorizar su traducción y reproducirla en cualquier forma. A pesar de que la ley contemplaba acciones civiles, incluyendo medidas cautelares y el derecho a reclamar daños y perjuicios, fue básicamente ineficaz debido a la ausencia de sanciones penales. Actualmente rige la ley 11723 sancionada por el Poder Ejecutivo Nacional el 28 de septiembre de 1933. (Carranza Torres, 2011).

Para 1918, la Sociedad Argentina de Autores contaba con trescientos cincuenta socios y comenzaba a editar su Boletín Societario. La enorme producción teatral de los años veinte promovió la implementación de un sistema de escritura fabril:

Abastecer a los cuarenta teatros céntricos que funcionaban todos los días en secciones continuadas, cubrir los recambios de cartelera y atender a la demanda de un público de seis millones de espectadores al año que se subdividía en varios públicos con intereses distintos requería una producción constante de obras (González Velazco, 2012: 161).

Los autores producían a gran escala y fijaban la cantidad de funciones mediante un contrato con los empresarios, por las que percibían un porcentaje de la recaudación para sí y para la Sociedad, que se veía así fortalecida. De este modo, el éxito en el reconocimiento de la Sociedad de Autores, el apoyo de otros agentes a sus reclamos y la temprana obtención de beneficios, muestra la legitimidad con la que contaba la instancia autoral en el campo teatral porteño de aquellos años, a diferencia de otros sectores de la producción teatral.

\section{III.}

El bienio 1919-1921 estará marcado por las dos huelgas de actores. La primera se produjo en 1919 y se extendió por aproximadamente quince días, entre el 6 y el 23 de mayo. La segunda se produjo entre mayo y junio de 1921 y, si bien duró más, no quedó tan arraigada en el imaginario colectivo como la anterior, hecho que quizá se deba a la cercanía de aquella primera medida de fuerza con los sucesos de la Semana Trágica.

Las huelgas de actores formaron parte de la conflictividad que se vivió en la Ciudad de Buenos Aires por esos años. Según David Rock, durante el primer semestre de 1919 se registraron doscientas cincuenta y nueve huelgas con una participación en las movilizaciones de más de cien mil trabajadores. La tasa de agremiación pasó de un $12 \%$ en 1918 a un $24 \%$ en 1919 (González Velazco, 2012).

Sin duda, esto se hallaba en consonancia con el contexto internacional. Entre 1916 y 1921 se presentan oleadas de conflictividad social en todo el mundo, marcadas tanto por el desarrollo de la Primera Guerra Mundial como por la Revolución Rusa, lo cual había generado un clima de temor en las clases altas (Baranchuk, 2016). En 1919 se funda, además, la Organización Internacional del Trabajo (OIT). ${ }^{10}$

El primer sindicato en la Argentina, es la Unión Tipográfica Bonaerense, surgido en 1877. A principios del siglo XX el nivel de conflictividad aumenta, por lo que en 1904 el Presidente Julio A. Roca le encomienda a Joaquín V. González la redacción
10. Sus antecedentes datan de 1864, cuando se funda la Asociación Internacional de Trabajadores (AIT), primera central sindical mundial en Londres. En 1889 surge la Segunda Internacional, cuyo primer congreso se celebra en París el 14 de julio y se declara el $1^{\circ}$ de mayo como Día Internacional de los Trabajadores en conmemoración a los mártires de Chicago. En 1901, se constituye en Copenhague la Secretaría Internacional de Sindicatos, con participación de asociaciones de Alemania, Bélgica, Finlandia, Gran Bretaña y Suecia (Baranchuk, 2016). 
de un primer proyecto de Ley de Trabajo, mientras que Juan Bialet Massé elabora un informe sobre las condiciones laborales en las provincias. Finalmente, en 1905, se promulgó la Ley 4661, primera normativa laboral, que estableció el descanso dominical. Tres años después, en 1907, se sancionó la Ley 5291, regulatoria del trabajo de mujeres y niños, y se creó el Departamento Nacional de Trabajo, antecedente de la futura Secretaría y actual Ministerio. En 1915 se promulga la Ley 9688 de Accidentes de Trabajo.

La Ley 8871 de 1912, más conocida como Ley Sáenz Peña, habilitó la llegada al poder del partido radical en 1916, el cual mantuvo una relación oscilante con el sector trabajo. Por un lado, propició una normativa protectora (propuesta de salarios mínimos, obligación de pagar a los obreros en moneda nacional, etc.) y, por otra parte, llevó adelante una represión brutal, como la acontecida durante la huelga en los Talleres Vasena en 1919 (hecho conocido como la Semana Trágica) y en la Patagonia en 1921 y 1922 (Baranchuk, 2016).

Mariana Baranchuk (2016) señala que hasta 1919 prevaleció el sindicalismo de tendencia anarquista influenciado por los inmigrantes, que propugnaba el aislamiento del resto de la sociedad, la alta confrontación con el poder, la no aceptación de pautas integradores y que, por consiguiente, ostentó cierta debilidad para influir en la historia del país, debido al trasplante mecánico de estrategias provenientes de luchas proletarias europeas. Este es un dato no menor para tener en cuenta en el análisis de la huelga de los actores. Tampoco lo son las observaciones de Carolina González Velazco (2012), cuando señala que la huelga, el asociacionismo y la participación política muestran los modos en que se planteaban las relaciones entre trabajadores y empresarios por esos años. Y si bien para 1921, los niveles de conflictividad ya habían descendido, la corriente asociacionista tiño la sociedad porteña durante todos los años veinte.

Es así como en 1918 se crea la Sociedad Argentina de Empresarios Teatrales (SADET, actualmente AADET), que nuclea tanto a empresarios de compañía como a empresarios de paredes. Un año antes, no obstante, había habido un intento de unión con motivo de una controversia con el diario Crítica (fundado en 1913), al que los empresarios acusaban de acordar con distribuidoras extranjeras para promover el negocio del cinematógrafo en detrimento del teatro (Kogan, 2012). En dicha oportunidad, el 27 de julio de 1917, los arrendatarios de los teatros San Martín, Comedia, Argentino, Nuevo, Apolo, Buenos Aires, Nacional y Excelsior, elaboraron un acta de intención para la fundación de una sociedad de empresarios de teatro bajo el nombre de "Sociedad de Empresarios Teatrales de la Capital" a la que se invitaría al resto de los empresarios, con el objeto de defender los intereses colectivos relacionados con los negocios teatrales. Lo cierto es que para 1918 se vuelven a reunir en el Teatro Argentino y se formaliza la SADET. El empresario-actor Florencio Parravicini es nombrado como presidente de la entidad, de la que forman parte Enrique Muiño, Roberto Casaux, Elías Alippi, Francisco Ducasse y Luis Vittone, entre otros.

Como contrapartida, en la madrugada del 19 marzo de 1919, se reúnen cerca de doscientos actores y actrices para crear la Sociedad Argentina de Actores, que en principio nuclea a los artistas de teatro nacionales. Sin embargo, son sólo los ciento diecinueve actores varones quienes votan la conformación de una Comisión Directiva y se decide que cada compañía elegirá un delegado. El texto de fundación indica que se tratará de una sociedad de base múltiple, con una labor mutualista, cultural y de reivindicación laboral.

El hecho clave que profundizó el conflicto entre actores y empresarios fue la implementación, de manera unilateral por parte de estos últimos, de la sección vermouth en 1918: 
Se calcula que en diez meses de temporada, una compañía de género chico realiza 320 secciones vermouth con un total de 480 horas de trabajo [...], sin contemplarse retribución alguna. Las empresas percibían sólo por estas secciones un total de dos millones de pesos al año (Klein, 1988: 17).

Además, la inclusión de la función vermouth, que comenzaba a las 18 horas, generó retrasos en el inicio de las funciones posteriores, hecho que prolongaba la jornada laboral.

La primera medida que lleva adelante la Sociedad Argentina de Actores consiste en una multitudinaria marcha en la Avenida de Mayo, en la que ochocientos artistas portaron pancartas donde expresaban sus reclamos. El 4 de mayo de 1919 la Sociedad le presentó un pliego de condiciones al Presidente de la SADET, Florencio Parravicini, emulando los reclamos que estaban realizando las compañías españolas, nucleadas en la Sociedad Internacional de Actores. El pliego exigía un aumento del 1\% sobre el sueldo mensual para todos los asociados de compañías de sainetes, zarzuelas y revistas, para cada una de las secciones vermouth que la empresa realizara; el $2 \%$ de aumento sobre el sueldo mensual de todo asociado de compañías de sainetes, zarzuelas o revistas, para cada función matinée que efectuara la empresa (siempre que no fuera domingo); el $2 \%$ de aumento para los actores de las compañías de dramas y comedias, para cada función diurna que se realizara (aún los domingos), que los aumentos fueran para todos los integrantes de la compañía actuaran o no, que nadie fuera despedido por el petitorio y que se concediera a todas las compañías un día de asueto (indistinto) para ensayar. El pliego, que indudablemente buscaba desalentar la implementación de las funciones por la tarde (Caudarella, 2016), finalizaba con la siguiente advertencia: "Si antes del lunes 5 del actual a las 12 PM no ha sido contestada satisfactoriamente [la carta] será considerada rechazada" "La huelga de los artistas", Última hora, 5/5/1919). Acto seguido, la Sociedad Argentina de Actores publicó el pliego en diversos periódicos.

La SADET responde con una contrapropuesta que intenta limitar las mejoras a los escalafones más bajos de las compañías, otorgando aumentos sólo a los artistas, cuyos sueldos no superaran los \$350. La Sociedad Argentina de Actores la rechaza y el 6 de mayo se inicia la primera huelga de actores que, según Beatriz Seibel (2002), es la primera a nivel mundial. Los afiliados no se presentan a hacer funciones, hecho que se suma a la huelga que venían manteniendo los artistas extranjeros. Rápidamente, se unen a la protesta contra los empresarios los gremios de músicos, maquinistas, utileros, electricistas y operadores cinematográficos, hecho que propicia la conformación de la Federación de Sociedades Teatrales y de Espectáculos Públicos, que asumió la representación de los sindicatos en huelga y la difusión de la misma. De este modo,

Los artistas parecían seguir casi al pie de la letra el libreto de los conflictos laborales que desde fines de 1918 se sucedían sin tregua en la ciudad: fundación de una entidad gremial, presentación de un petitorio con reivindicaciones salariales, alianza con otros gremios, paralización de las actividades (González Velazco, 2012: 113).

La SADET, por su parte, apeló a varias estrategias para hacer fracasar la huelga, además de otorgar aumentos a los escalafones más bajos con el objeto de generar divisiones internas en el colectivo artístico. En primer lugar, optó por no reconocer a la entidad sindical actoral y a la Federación. En segundo término, los empresarios rescindieron los contratos de los huelguistas y organizaron una compañía integrada por artistas que no acordaban con la medida de fuerza y que eran, en su mayoría, primeras figuras o actores-empresarios. Dicha compañía estaba formada por Angelina Pagano, Camila Quiroga, Orfilia Rico, María Esther Podestá, Sabina Vittone, Esperanza Palomero, Matilde Rivero, Blanca Podestá, Manuela Ayerza, Florencio 
Parravicini, Segundo Pomar, Enrique Muiño, Elías Alippi, Pablo Podestá, Roberto Casaux, Enrique de Rosas, José Palmada, Salvador Rosich y Francisco Ducasse, entre otros. Se trataba de primeras figuras dispuestas a compartir cartel, hecho que ejerció una gran atracción ante el público, que agotó las localidades en las funciones realizadas en diversos teatros y cuya recaudación fue donada a sociedades de beneficencia. Luego, los empresarios dieron por finalizada la temporada.

Por otra parte, los empresarios se valieron del apoyo de sectores de la prensa. Los periódicos llaman a los huelguistas proletarios, bolchevistas y antinacionalistas, con las implicancias que dichos epítetos tenían en aquellos años. Además, se atacó a la Federación, buscando deslegitimar la lucha conjunta de diversos gremios que se enfrentaban a la misma patronal. Es así como La Nación publica: "no se concibe qué intereses comunes puede tener una tiple con el utilero, ni una bailarina con el electricista, ni un primer actor con los porteros" (La Nación, 10 de mayo de 1919). Por último, los empresarios publicaron un manifiesto en el que se explicaba la fragilidad de los negocios teatrales (González Velazco, 2012) y en el que se revelaban las ganancias de los artistas:

La Sociedad de Empresarios Teatrales tiene el deber de llevar al conocimiento del público, para evitar que sea sorprendido en su buena fe con colecta y subscripciones, los sueldos que ganan en la actualidad algunos de los artistas que simulan figurar como <<proletarios >> del teatro, y cuyos contratos están en poder de esta Sociedad (“La colecta teatral”, s/d, Cit. en Caudarella, 2016: 94).

Luego de esta declaración, se adjuntaba una lista con los sueldos de las primeras figuras, que en algunos casos llegaban a $\$ 2500 .{ }^{11}$ Mariana Baranchuk (2016) agrega que los empresarios se afiliaron además a la Asociación Nacional del Trabajo, cuyo brazo armado era la Liga Patriótica.

Por su parte, la Federación realizó festivales y funciones a beneficio del fondo de huelga, para lo cual se organizaron compañías en cooperativa. Para ello salieron a conseguir salas y textos dramáticos. Mientras algunos empresarios afines a la huelga cedieron sus teatros, el conflicto sobrevino con la Sociedad Argentina de Autores, que negó la cesión de las obras y publicó un manifiesto en diversos periódicos. En el mismo, se declaraba neutral ante el conflicto y manifestaba que

La Sociedad de Autores [...] no ha podido ser indiferente a las reclamaciones [de aquellos] que constituyen lo que podría llamarse <<proletariado teatral >>. Existe por desgracia entre los artistas una clase que justifica esta clasificación. La forman los coristas, las bailarinas, los partiquines de las compañías de diversos géneros, condenados por la miseria y los emolumentos a una vida de esclavitud en el trabajo y de privaciones en el orden íntimo [...] Junto con esta clase actúa otra, la de los privilegiados del presupuesto teatral que disfrutan de sueldos excelentes [...] La Sociedad de Autores no puede, en conocimiento de estas fundamentales diferencias, confundir en un solo concepto económico, cuando de luchas económicas se trata, esas dos situaciones tan diversas ( "El manifiesto de los autores", Última hora, 8 de mayo de 1919).

Sin embargo, a pesar de la supuesta neutralidad esgrimida y de la negativa a ceder las obras a las cooperativas huelguistas, la Sociedad de Autores permite la representación de sus textos por parte de la compañía de actores-empresarios formada por la SADET, evidenciando una clara alianza con ésta última. Este hecho no pasó desapercibido ni por los actores ni por la prensa: "en el seno de la Sociedad de Actores hay mucho mar de fondo contra los autores, pues creen que estos no debieron intervenir en el conflicto" (Última Hora, 5 de mayo de 1919).
11. Por ejemplo, Lea Conti y “la” Manzini cobraran $\$ 1000$ por mes, Olinda Bozán, \$700, y Ana Adamuz, \$2400 (Última Hora, 5/5/1919). 
Las cooperativas de la Federación deben optar entonces por la representación de otro tipo de materiales (canciones, bailes, improvisaciones), aunque algunos dramaturgos se manifestaron a favor de la huelga y, desobedeciendo a la Sociedad Argentina de Autores, cedieron sus obras. Esto provocó su expulsión de la entidad, tal como es el caso de Pedro E. Pico, quien denunció a la comisión directiva por no respetar los estatutos y apoyar a los empresarios en contra de los actores. Este hecho tendrá repercusiones posteriores, que serán analizadas más adelante.

Lo cierto es que la falta de público y el levantamiento de la medida de fuerza llevada adelante por los actores extranjeros, ocasionaron que la huelga fuera debilitándose paulatinamente. Los actores huelguistas, que no podían sostenerse económicamente, debieron volver a sus antiguas compañías. La actividad teatral se normalizó por completo y la temporada finalizó con cifras de espectadores y de recaudación en aumento, tendencia que continuó en 1920 (González Velazco, 2012).

Con la finalización del conflicto se inicia una discusión significativa acerca del futuro de la Sociedad Argentina de Actores. La misma se refiere al carácter que ésta debe ostentar, que oscila entre el mutualismo y el gremialismo. La vertiente gremialista promueve la participación del gremio en la FORA (Federación Obrera Regional Argentina), de orientación anarcosindicalista, aunque la posición que se termina imponiendo es aquella que defiende la dedicación exclusiva a actividades mutuales y culturales. Según González Velazco (2012) resulta claro el rechazo a acciones de enfrentamiento que equipararan el trabajo de un actor al de un obrero, por lo que la experiencia de la huelga se explica como un exceso ante la urgencia de las reivindicaciones más que como herramienta válida de protesta.

De hecho, es sólo un grupo reducido el que participa de esta discusión, siendo evidente que la mayoría de los actores "vegeta en un preocupante estado de indiferencia para los asuntos societarios" (Klein, 1988: 24). En este sentido, son notorias las acusaciones al interior del gremio que pueden encontrarse en el Boletín Mensual de la Sociedad Argentina de Actores (cuyo primer número se publica en septiembre de 1919), y que van desde la referencia a la masa amorfa que se abstiene de participar, hasta la acusación a aquellos que hacen obra disolvente en los lugares de encuentro de actores, por lo que se intenta concientizar a los afiliados para que no sean influenciados por dichas personas. Por otro lado, se producen en el mencionado Boletín una serie de acusaciones, pedidos y hasta ruegos para que los afiliados paguen su cuota sindical. Esto resulta significativo si tenemos en cuenta que en una publicación que cuenta con cuatro folios (como es el caso del primer número de septiembre de 1919), esta cuestión está mencionada directa o indirectamente nueve veces, es decir, dos y hasta tres veces por página, resultando así señalada en casi todas las notas y apartados. Esto indica que los actores no contaban con el dinero para pagar o por lo menos, no regularmente, o que no tenían aún la suficiente conciencia societaria como para hacerlo.

Una de las estrategias de la Sociedad Argentina de Actores en este sentido va a consistir en el lanzamiento de un carnet que permita acceder a descuentos en varios rubros (que incluyen los de la salud, pero no solamente) a todos aquellos que tengan la cuota al día. Esto implica que el gremio aún necesitaba apoyarse en la acción mutual, beneficio que el afiliado percibe más rápida y claramente. ${ }^{12}$ Lo cierto es que en el Boletín se ejerce una función didáctica sobre los afiliados explicando que abonar la cuota no sólo permite tener descuentos en comercios, sino que eso también contribuye para conformar un Fondo de Socorro (didáctica ejercida en pos de la previsión hacia el futuro en una actividad que depende del día a día o de proyectos muy cortos), para llevar adelante la propia Sociedad, para publicar el Boletín con los balances, etc.
12. Con el tiempo esto va a propiciar la creación de la Obra Social de Actores y la retención obligatoria del $6 \%$ para la misma. 
Otras actividades que se encaran en este sentido son la creación de una bolsa de trabajo para actores desocupados, la apertura de una Biblioteca y la realización de charlas, cursos y festivales a beneficio. Uno de ellos, organizado con motivo de la enfermedad de Pablo Podestá, constituye un claro ejemplo de las tensas relaciones entre actores, empresarios y autores como consecuencia de la huelga.

Pablo Podestá es el actor emblemático del teatro argentino del momento, habiendo representado y estrenado obras de innumerables autores argentinos hasta esa fecha. En julio de 1919, el actor presenta signos de deterioro mental y es internado. Pero antes de ese episodio e inmediatamente después de la huelga, el menor de los Podestá participa en una cooperativa conformada por actores inhabilitados (es decir, aquellos que habían sido despedidos durante la huelga y luego no fueron retomados en sus compañías) para actuar por las provincias. Recordemos que Podestá era un actorempresario, dado que había tenido su propia compañía.

La Sociedad Argentina de Actores publica en este primer Boletín que se puso en contacto con el médico responsable del hospital en el que Pablo está internado para saber qué necesita, y que el Consejo Directivo de la agrupación decidió organizar un Festival en Homenaje para recaudar fondos. Luego se realiza una crónica exhaustiva de lo que se hizo para la organización del evento y de los resultados del mismo.

En primer lugar, se gestionaron sin éxito los Teatros Colón y Coliseo (el Boletín no aclara el motivo del fracaso), pero finalmente se obtiene el Teatro Avenida, que es ofrecido por su empresario. Por otra parte, se gestiona y se obtiene la devolución de los impuestos municipales que se cobren por el Festival. Más adelante se detalla la recaudación y se indica cuál es el importe de este impuesto y que su devolución ya fue acordada. Además, se obtiene la adhesión de algunas compañías (como la de Guerrero - Díaz de Mendoza), y de algunos actores (muchos prometieron ir al Festival y después no lo hicieron, pero enviaron notas explicativas, como es el caso de Florencio Parravicini, presidente de la SADET). También adhieren representantes de la Sociedad Internacional de Artistas. Recordemos que en la huelga de mayo habían pactado primero con los empresarios, retirándose de la medida de fuerza y precipitando así el final de la misma. Pero, como el mismo Boletín publica, Pablo Podestá es tan querido que toda la sociedad está preocupada por él.

Ahora bien, en un párrafo aparte pasa a explicarse que una vez que se habían realizado gran parte de las gestiones organizativas, la Comisión Directiva resuelve enviarle notas de invitación a la Sociedad Argentina de Autores y a la SADET, y se refiere lo siguiente:

se resolvió pasar notas a las sociedades "Argentina de Autores” y "Argentina de Empresarios" invitándolas a enviar delegaciones para armonizar ideas y realizar una acción conjunta; y pensando bien que un llamado a nuestro local podía ofrecer dificultades, para evitar negativas y rozamientos que entorpecieran la realización de nuestros propósitos, se buscó un lugar "neutral”, solicitándose al efecto una sala al "Círculo de la Prensa", que nos fue inmediata y galantemente cedida [...] La Sociedad de Empresarios contestó por nota justificando la inasistencia de sus representantes con resoluciones tomadas por su Comisión Directiva en virtud de las cuales consideraban inoficioso concurrir a la cita. La Sociedad de Autores no envío delegación alguna, ni contestó (Boletín de la Sociedad Argentina de Actores, 1 (1), septiembre 1919: 3).

Si bien resulta comprensible la postura de los empresarios, dado que más allá de que Pablo Podestá había sido uno de ellos, su actitud ante una huelga realizada directamente en su contra puede haber provocado resquemores y, sin duda, una clara incomodidad para realizar una acción conjunta con los actores a tan pocos meses del 
conflicto, la falta de respuesta de los autores ante la enfermedad de un actor que había llevado a escena con éxito gran cantidad de piezas de miembros de su asociación, resulta inexplicable.

En 1920, la Sociedad Argentina de Actores amplía su número de afiliados a seiscientos treinta y ocho. Esto se debe a la incorporación de las mujeres y a la fusión con la Sociedad Internacional de Artistas. Poco después, una reforma en los estatutos permite la afiliación de apuntadores, directores de orquesta, coristas y meritorios, por lo que se llega a novecientos socios (González Velazco, 2012).

En octubre, el gremio presenta nuevos reclamos ante la SADET y en marzo de 1921, se firma el Primer Convenio con los empresarios, denominado Bases de Trabajo. El mismo resuelve el tema de los ensayos, disponiendo el lunes como día de descanso para tal fin, la supresión del ensayo nocturno, el pago si el mismo excede los diez días y su reducción horaria para aquellos que realizan la controvertida función vermouth. Se pauta también el comienzo de las tareas después de las 13.30 horas, un sueldo mínimo de \$165 para el desempeño en la Ciudad de Buenos Aires y pasajes y acarreo en giras a cargo de la empresa, con su correspondiente anticipo y un modo de descuento del mismo rigurosamente estipulado. Se suprimen los contratos globales por matrimonio o familia, en favor de contratos personales y con sueldo individual, y se conviene la licencia con goce de sueldo para categorías a partir de $\$ 300$, contratos no mayores a diez meses y no menores de tres, y el pago por enfermedad. Además, se elimina la figura del agente como intermediario y se designan al autor y director como únicas autoridades a las que el actor debe responder en las representaciones y en los ensayos: "o sea, que en la faz de producción creativa, la estructura de división del trabajo (y de mando entre sectores) se organiza siguiendo lógicas creativas y limitando la participación del capital durante el proceso de creación" (Baranchuk, 2016: 104). Sin embargo, cabe destacar que este documento se firma sin la intervención del Estado, por lo que tiene un carácter estrictamente privado.

A pesar de la firma de las Bases de Trabajo, al año siguiente el conflicto volvió a surgir. Consideramos que para comprender la huelga de 1921 es necesario analizar la conformación de la Federación Gente de Teatro y el rol definitorio que desempeñaron en la misma los autores, liderazgo detrás del cual se situaron otros gremios del quehacer teatral, entre los cuales se hallaba la Sociedad Argentina de Actores.

Coincidimos con Caudarella (2016) cuando afirma que los autores teatrales detentaban una posición clave en el teatro del momento. Al conflicto generado al interior de la Sociedad Argentina de Autores a raíz de la cesión de derechos durante la huelga de 1919, se le sumó el enfrentamiento alrededor de la aplicación del voto calificado entre los afiliados (que le daba más valor al voto de los autores con mayor cantidad de obras estrenadas y, por consiguiente, con más recaudación). Esta disputa fue protagonizada nuevamente por Pedro E. Pico, quien había sido reincorporado luego de su expulsión. Pico propuso reformar el estatuto de la entidad para derogar el voto calificado "cuya atribución repugna el carácter de una entidad civil con tendencia cultural" (Boletín de la Sociedad de Autores, diciembre de 1920). Para la Comisión Directiva de la Sociedad, en cambio, eliminar el voto calificado significaba un "avance del bolcheviquismo" (González Velazco, 2012: 126).

Luego de varios meses de disputa y una votación reñida, el grupo liderado por Pico gana las elecciones del gremio y un grupo de veinte autores (entre los que se encontraban Alberto Novión, Roberto Casamayor, Enrique García Velloso, Luis Bayón Herrera, Gustavo Caraballo, Julio F. Escobar, Federico Mertens, Antonio De Bassi y Alberto Wiesbach) se retiran de la entidad. El 9 de marzo de 1921 fundan el Círculo Argentino de Autores. En la Sociedad Argentina de Autores quedan Pedro E. Pico, 
Belisario Roldán, Claudio Martínez Paiva, Francisco Deffilippis Novoa y Armando Discépolo, entre otros. La escisión, que durará hasta 1929, tomará tal estado público que en 1922 el propio Marcelo T. de Alvear, Presidente de la República, se ofrece como mediador entre ambas entidades.

Lo cierto es que el Círculo pasa a administrar el $66,15 \%$ de los derechos de autor del teatro nacional, debido a que sus asociados eran los autores más exitosos (Caudarella, 2016). Mientras que los afiliados que quedan en la Sociedad representan sólo el 33,84\%, dado que si bien producían más obras obtenían menores ganancias por las mismas.

La Sociedad Argentina de Autores se propuso entonces organizar la Federación de Gente de Teatro, para lo cual iniciaron negociaciones con la Sociedad de Actores. Inicialmente se trató de un pacto entre ambas sociedades, con el fin de constituir una "Federación de todos los obreros y productores del teatro consecuencia de la identidad de propósitos" (Boletín de la Sociedad de Autores, marzo de 1921), para lo cual pautaron la obligación de secundarse sin restricciones en cualquier conflicto que surgiera con las empresas (González Velazco, 2012). Finalmente, la Federación se constituyó el 13 de marzo de 1921 y se sumaron a la misma la Asociación del Profesorado Orquestal, la Federación Musical Argentina, la Sociedad de Maquinistas de Teatro, la Sociedad de Electricistas de Teatros y Espectáculos Públicos, la Sociedad de Utileros Teatrales y la Sociedad de Acomodadores, Porteros y Peones de Teatro.

Sin duda, la Federación ostentó desde sus inicios un perfil fuerte y combativo, con el fin de "defenderse de la inicua explotación de los empresarios" ( $¡ V i v a$ la Federación de obreros del teatro!", La Censura, 21 de marzo de 1921). ${ }^{13}$ Su primera medida consistió en la adhesión a la conmemoración del Día del Trabajador, para lo cual obligó a que se suspendan las funciones matinée y vermouth del $1^{\circ}$ de mayo de 1921 . La SADET reaccionó inmediatamente negándose a reconocer la validez de la Federación, temiendo una politización del medio teatral (Caudarella, 2016). La Federación afirma que "La resistencia de los empresarios hace redoblar el entusiasmo de los trabajadores. Mantendrase firmemente la resolución de paro. La noche del domingo en el Liceo y Nacional se trabaja para la Federación" (Crítica, 29 de abril de 1921), en clara referencia a que los propietarios de dichas salas (Carcavallo por El Nacional y Ducasse por el Liceo) se habían unido a la misma. Finalmente se resuelve el asueto, lo cual marca un primer triunfo de la flamante institución.

Más allá de esta primera iniciativa de carácter simbólico, pronto se tornó evidente cuál era el principal propósito de la Federación Gente de Teatro. El 9 de mayo, dos mil trabajadores del teatro se reunieron en asamblea en el Teatro Nacional para votar por unanimidad la siguiente moción: "conminar a todas las personas que se encuentran al margen de su respectivo grupo gremial a que se incorporen a ellos, acordando un plazo que fenece el día 9 a las 12" "La entusiasta asamblea de anoche", Crítica, 10 de mayo de 1921). Esto implicaba que todos los trabajadores que desearan desempeñarse en el teatro debían estar agremiados y que todos los gremios debían ingresar a la Federación. A tal fin, se envió un comunicado a los empresarios en el que se les exigía que sólo contrataran a trabajadores federados y se les concedía un plazo de cuarenta y ocho horas para reorganizar los elencos y las carteleras. Coincidimos con González Velazco (2012) cuando plantea que el conflicto se desplaza así hacia los propios trabajadores, exigiendo la agremiación a aquellos que se negaban a la misma, y hacia los empresarios que desconocían la legitimidad de la Federación. De este modo, la disputa deja de ser estrictamente laboral o salarial y pasa a situarse en la cuestión de la representatividad de todos los trabajadores.

Los empresarios no aceptaron los términos del comunicado, desconociendo a la Federación. La huelga se decreta el 12 de mayo. Aquellos que pertenecían a alguno de los
13. En una caricatura publicada en La Vanguardia (24/5/1921), puede verse a una mujer con atuendos griegos que porta un cartel con la leyenda “Arte, emoción, belleza”, mientras expulsa del teatro a dos hombres con carteles de "Empresario", "Teatro pornográfico" y un tercer cartel arrojado al piso con la leyenda "Círculo amarillo", en referencia al Círculo de Autores. El epígrafe de la caricatura reza: “Así, a latigazos, la poderosa organización de los trabajadores del teatro arroja del templo del arte y la belleza a los mercaderes y traficantes" 
gremios federados no se presentaron a trabajar en los teatros que tuvieran en cartel obras de autores del Círculo y los autores de la Sociedad retiraron su material de aquellos teatros en que no trabajasen actores y técnicos federados (González Velazco, 2012). Las compañías federadas, por su parte, continuaron trabajando. Aunque el conflicto duró dos meses, rápidamente los empresarios dieron por finalizados los contratos de los artistas en huelga y reorganizaron los elencos con reemplazos.

La Federación organizó nuevas compañías con actores cesanteados y salió a conseguir salas y obtener recursos para alimentar el fondo de huelga. Los elencos actuaron en algunas salas periféricas no controladas por los empresarios nucleados en la SADET e inclusive cedidas por el Concejo Deliberante. El compromiso de la Federación fue que todos los elencos suspendidos fueran reubicados. La Federación pagó el equivalente a cinco días de trabajo a los que ganaban menos de \$200 (Caudarella, 2016). Además, se abrió un registro de todos los que iban quedando sin trabajo, donde se anotaba su puesto y el sueldo que percibían. Otros aportes para el fondo de huelga consistieron en un porcentaje de la recaudación de las compañías federadas que seguían trabajando, la organización de funciones especiales, colectas, donaciones de empresarios aliados, donaciones del Partido Socialista, préstamos de la Sociedad de Actores y de Autores, y cesión gratuita de espacio de los diarios Crítica y La Unión (González Velazco, 2012). El 19 de mayo un grupo de manifestantes impidieron el ingreso del público a algunas salas no federadas y hubo intervención policial.

Como en 1919, la medida impactó a la opinión pública, al punto que tanto el intendente de la Ciudad de Buenos Aires como el presidente Hipólito Yrigoyen debieron dar audiencia a los artistas en huelga. Por otra parte, la Federación recibió las adhesiones de gremios sin relación con la actividad teatral (como los taxistas) y de la FORA. Caudarella (2016) señala, además, que la Federación apeló a mostrar su fuerza convocando a gremios del exterior, para lo cual envió una delegación a Montevideo encabezada por Armando Discépolo. De este modo, se obtiene la adhesión de la Sociedad de Autores Uruguayos.

Si bien inicialmente los recursos fueron suficientes para mantener a la mayor parte de los artistas en huelga, a comienzos de junio se tornó evidente que los recursos mermaban, por lo que los autores propusieron que aquellas compañías formadas por la Federación se convirtieran en cooperativas que gestionaran sus propios contratos y funcionaran de forma independiente (González Velazco, 2012).

El 14 de junio de 1921 surge otro frente de conflicto, cuando 80 actores-empresarios y otros actores que estaban en desacuerdo con la Federación fundan la Unión Argentina de Actores. El Estatuto de la nueva entidad marca su carácter estrictamente mutualista y establece que debe haber al menos tres actores empresarios en su conducción (Baranchuk, 2016). En lo que respecta a los asuntos laborales, se aclara expresamente que "cualquier conflicto por incumplimiento de contratos o violación de las Bases de Trabajo que se establezcan, la Comisión Directiva tendrá amplias facultades para resolver el asunto, siempre por vías diplomáticas" (Boletín del Círculo de Autores, junio de 1921).

La Unión contó con la adhesión inmediata del Círculo de Autores. El tercer socio de esta tácita alianza fue la Sociedad de Empresarios que ya estaba en contacto con el Círculo desde el inicio del conflicto. Las tres entidades trabajaron en conjunto mientras duró la huelga y más tarde firmaron un pacto tripartito en el que se fijaron las pautas de la actividad, cuya organización de tipo empresarial queda sólidamente consolidada, al establecerse arbitrajes propios ante los conflictos y la obligatoriedad de pertenecer a alguna de estas agrupaciones para poder desempeñarse en el teatro 
(Baranchuk, 2016). Ante la posibilidad de no ser contratados, algunos actores optan por el pasaje de un gremio a otro, mientras que otros mantienen la doble afiliación, con el aporte monetario que eso implicaba.

Lo cierto es que para fines de junio la huelga está debilitada. Las compañías que funcionan en cooperativa no tienen los resultados esperados. Según González Velazco (2012), la Sociedad Argentina de Actores fue la primera que planteó la necesidad de revisar el curso de la huelga, dado que sufría una constante merma de asociados que renunciaban a su afiliación y volvían a sus compañías.

El 4 de julio se realizó una reunión de todos los gremios federados en la sede de Actores para analizar la situación. Aunque los autores desean mantener la huelga, se resuelve levantarla:

considerando que es indispensable mantener la estabilidad de los gremios federados, resuelve dar por terminada la huelga que en 60 días de lucha ha evidenciado el espíritu y la capacidad societaria de los que en ella han participado dejando en libertad a cada gremio para la resolución de sus conflictos parciales ("El conflicto teatral”, Crítica, 5 de julio de 1921).

A partir de ese momento los artistas podían ser contratados por cualquier empresario para cualquier obra, por lo que el objetivo principal de la Federación (y la razón de su existencia) quedó desactivado. Esto precipitó su rápida desintegración.

Si bien la Federación sostuvo que logró que "el año teatral se eche a perder para los capitalistas grandes y pequeños que viven de la escena nacional" ("El Consejo Federal a los dos meses de resistencia da por terminado el movimiento", Crítica, 5 de julio de1921), González Velazco (2012) matiza esta afirmación. La autora plantea que dado que los empresarios se reorganizaron rápido, el efecto de dejar a Buenos Aires sin espectáculos duró sólo un par de días. El teatro funcionó con cierta normalidad para el público (aunque con carteleras paralelas que se publicaban en los diarios), pero el sector se dividió en dos: la parte federada y la parte no federada.

Por nuestra parte, consideramos que resulta significativo que ambos grupos incluyeran en su seno diversos agentes (autores, actores y empresarios) con roles significativamente disímiles dentro del proceso productivo, en un clivaje que se explicitaba como de tipo ideológico-estético, pero en el que la jerarquía simbólica y económica de los autores acabó por marcarle al pulso al conflicto. ${ }^{14}$

\section{IV.}

Luego de exponer los hechos que caracterizaron el proceso de conflictos que tuvo lugar en el bienio 1919-1921, consideramos oportuno analizar en profundidad algunos aspectos reveladores que se presentaron durante el mismo.

En primer lugar, la adopción de la huelga como estrategia de lucha sólo es comprensible en un contexto de bonanza económica para el sector de las artes del espectáculo. Sin duda, la explotación comercial del mismo, único modo de organización de la actividad vigente en esos años, impulsaba la obtención de ganancias cada vez mayores. Tal como lo analizamos anteriormente, la única forma de lograrlo era aumentar la cantidad de funciones ofrecidas al público. González Velazco (2012) afirma que los bajos sueldos y la incorporación de más funciones en el mismo día sin modificar el monto estipulado en los contratos de los actores eran el camino para aumentar la ganancia de los empresarios. Frente a esta situación la huelga era la modalidad para provocar un golpe en la recaudación.
14. Por otra parte, el paro terminó beneficiando a los cines (Caudarella, 2016), lo cual permite comprender la posición del diario Crítica durante el conflicto. Caudarella sostiene que el periódico cubrió los conflictos gremiales en el teatro durante toda la década con su estilo sensacionalista y un lenguaje que mostró la radicalización del enfrentamiento en términos de clase, denominando “amarillos" a los autores del Círculo por su alianza con la SADET. Si bien la Federación reconoció a Crítica por esta cobertura, no es un dato menor que el germen de la reunión de los empresarios y de la propia SADET había sido dar respuesta a los ataques que el diario Crítica le realizaba al teatro argentino, supuestamente en pos de imponer el cinematógrafo. De hecho, en 1924, el periódico publica una encuesta titulada "¿Por qué es verdaderamente malo el teatro nacional?" (González Velazco, 2012: 161) 
Tal como señalamos anteriormente, la estrategia empresarial consistió en poner en evidencia las diferencias en los sueldos de los actores. En este sentido resultan significativas las declaraciones del actor Rogelio Juárez: "y en esta cuestión de la huelga, he ido, y creo lo mismo los otros sueldos grandes, por solidaridad y a que quiten si se puede la función vermouth" "Los artistas no son antinacionalistas", La Montaña, 8 de mayo de 1919). Por un lado, Juárez pone de manifiesto en qué medida la solidaridad interna entre los artistas jugó un rol importante en el conflicto. En segundo término, evidencia que el mismo no se limitaba sólo a los sueldos, sino que también incluía las condiciones de trabajo. En efecto, la función vermouth (a lo que podemos sumar la cuestión del día de descanso y los ensayos nocturnos), eran situaciones que afectaban a todos los actores, independientemente de la jerarquía que ostentaran dentro de la compañía. Por último, no es un hecho menor que los artistas que más ganaban lo hacían en virtud de que eran aquellos que generaban la mayor afluencia del público; por lo tanto, la función vermouth los afectaba aún más en términos económicos que a los que ganaban menos, dado que no se les pagaba nada por lo que ellos mismos generaban. Esto responde a la misma lógica económica por la cual los autores defendían a rajatablas sus ingresos y sus derechos desde 1910. En este sentido, la diferencia que el campo cultural le atribuyó a la legitimidad del reclamo de los autores en detrimento de la legitimidad del reclamo de las primeras figuras, sólo puede entenderse en función de una visión jerárquica del hecho escénico, que aún está vigente en la actualidad.

Un aspecto que los estudios sobre el conflicto coinciden en señalar, es que la huelga obligó a explicitar las posiciones en el quehacer teatral. Mientras Caudarella sostiene que "lo que la huelga general de actores sí dejó esbozado fue el mapa de roles de cada uno de los sectores que componían a la realización teatral nacional" (2016: 81), González Velazco (2012) va más allá al afirmar que las huelgas organizaron el mundo de los artistas con otras coordenadas. Según la autora, la pertenencia a la compañía quedó diluida en función de un colectivo, más allá de las diferencias internas que existían en el mismo. Si bien la compañía era la instancia de organización de los artistas, después de las huelgas se redefinieron las identidades y pertenencias. Muchos actores empezaron a verse como un colectivo en sí, más allá de las compañías en las que estuvieran o el sueldo que ganaran y enfrentados a los empresarios, dueños de sala o directores de las compañías.

Por nuestra parte consideramos que las condiciones en las que se desarrollaba la actividad a inicios de los años veinte, marcadas por la organización de tipo comercial y la alta disponibilidad de público en el espacio urbano, contribuyó a la definición de los grupos en función del lugar que ocupaban en el proceso productivo, que paulatinamente sustituyó a la organización semi-familiar propia de una actividad itinerante y para un público reducido. Esto se evidencia ya antes de las huelgas, con la constitución de la propia Sociedad Argentina de Actores, pero más aún con la organización previa del colectivo empresarial en la SADET, en parte como una medida preventiva ante la inminencia de posibles conflictos.

Con la huelga de 1921 estas identidades fueron puestas en tensión nuevamente, aunque, si en 1919 la iniciativa había sido de los actores, en esta oportunidad los términos en que se planteó el conflicto fueron totalmente delineados según los intereses de los dramaturgos que habían quedado en la Sociedad Argentina de Autores. En efecto, el Círculo de Autores reunía a los dramaturgos más famosos y que más obras representaban. La estrategia de los autores de la Sociedad consistió entonces en inducir u obligar al resto de los agentes del sector a no representar las obras de los del Círculo, para lo cual era necesario contar con el apoyo de los demás gremios. Para ello, promovieron la organización de un colectivo que diluyera las pertenencias de compañía y que se posicionara como el único interlocutor para la 
contratación de artistas y oficios frente a los empresarios. De hecho, la Federación manifestó que no tenía problemas con los empresarios como colectivo, sino con aquellos que no la reconocían.

Los actores percibieron esto y lo debatieron en asamblea. Aunque finalmente se votó por gran mayoría la adhesión a la Federación (ciento cincuenta votos contra treinta y cinco), algunos afiliados denunciaron que la misma era en realidad una necesidad de los autores a raíz de su propio enfrentamiento interno y que el gremio actoral, ajeno a ese conflicto, debía mantener las negociaciones directas con los empresarios como lo habían hecho meses antes con las Bases de Trabajo. También los empresarios percibieron la estrategia de los dramaturgos, cuando con motivo de la exigencia de contratar sólo trabajadores federados enviaron una nota en la que manifestaban: “¿La Sociedad de Autores está segura que su producción es suficiente para abastecer la cartelera de toda la república?" (Boletín de la Sociedad de Autores, mayo de 1921).

Esto explica que, más allá de la cuestión por el asueto del $1^{\circ}$ de mayo, no hubiera negociaciones ni petitorios anteriores, ni ningún hecho puntual que anticipara el conflicto. Según González Velazco, la lectura que debe hacerse es la inversa: "dada esa realidad colectiva que se acababa de crear -la federación-, inexorablemente debería surgir un conflicto con quienes por diversas razones no la integraran, no la reconocieran o se opusieran a ella" (2012: 127). La conmemoración del $1^{\circ}$ de mayo fue, entonces, la ocasión propicia para que la Federación hiciera su presentación pública: "La Federación de Gente de Teatro, emanada de los trabajadores que integran el complejo dinamismo del arte teatral, da un paso adelante, reclamando su puesto en las filas del pueblo" ("Frente al $1^{\circ}$ de Mayo", Boletín de la Sociedad de Autores, mayo de 1921).

Es por ello que la Sociedad de Autores presentó el conflicto en términos ideológicos y estéticos, más que laborales o sectoriales, lo cual hacía más convincente y legítima su convocatoria. La Federación es presentada entonces como una gran asociación de trabajadores del teatro para encarar las luchas sindicales en un momento en el cual "hay ideas que están haciendo estremecer al mundo por un porvenir más digno" (Boletín de la Sociedad de Autores, mayo de 1921), haciendo mención a un clima general que no se vinculaba estrictamente con el teatro. Para González Velazco (2012), la adopción de un lenguaje de clase se presentó como el modo de interpelar identidades contrapuestas.

Consideramos que el clivaje elegido fue, entonces, la división entre productores directos e intermediarios que se beneficiaban comerciando con lo que aquéllos generaban:

La adquisición de un derecho en calidad de salario por toda función productiva, obliga al creador de lo bello o de lo útil a defender su situación de productor frente a las fuerzas inertes que se multiplican a expensas de la actividad ajena (“Manifiesto de la Federación”, Boletín de la Sociedad de Autores, marzo de 1921).

La única fuerza la constituye el productor, el que escribe, el que interpreta, el que mueve la vida mecánica del teatro, y todo esto que es tan fuerte, está aquí, en la federación [...] lo otro era lo estéril, lo inútil, lo inservible, lo que medraba y prosperaba a costa del trabajo ajeno (Boletín Informativo. Órgano de la Federación Gente de Teatro, mayo de 1921).

Los medios se hicieron eco de la utilización de este lenguaje de clase para dar cuenta del conflicto, induciendo a los lectores a interpretar los hechos desde una mirada propia de la época, marcada por el temor ante la Revolución Rusa. Así, "denunciaban que no podían ser proletarios quienes cobraban sueldos tan elevados y que si 
había algún reclamo posible, este les cabía sólo a las categorías más bajas" (González Velazco, 2012: 117). Otros se sorprendían de que a los artistas se les hubiera ocurrido plantear un conflicto en esos términos, reproduciendo formas que no les eran propias:

Pierrot ha dejado su traje y enarbola la bandera roja que tan mal le sienta ("La huelga en el teatro", Idea Nacional, 8 de mayo de 1919)

[La Federación] se ha visto alguna vez en cuestiones muy violentas producidas por otras causas, entre obreros manuales, pero nunca entre agremiaciones en las que la cultura y el ideal estético deben tener un altar (La Nación, 20 de mayo de 1921).

No son obreros ni proletarios, ni pueden constituir federaciones de ninguna clase ciertos ácratas que ganan miles de pesos mensuales (La Montaña, 13 de mayo de 1921).

Por su parte, los actores buscaban desligar su movimiento de aquellos vinculados con objetivos revolucionarios, encuadrándolo en el ámbito económico, justamente para evitar el vínculo con la Revolución Rusa (González Velazco, 2012). Así, un actor declara: "Mistifican los que quieren hacernos aparecer ante la opinión como elementos disolventes y sectarios. Nosotros no tenemos que preocuparnos de tales cosas. Luchamos por un mejoramiento económico. Nada más" "Los artistas no son antinacionalistas", La Montaña, 8 de mayo de 1919). De hecho, la Sociedad Argentina de Actores publica en el primer número de su Boletín:

No escapará al criterio de nuestros consocios, las dificultades de diversa índole que ha sido necesario vencer a fin de levantar el espíritu de la mayoría, que a raíz del movimiento del mes de Mayo ppddo. había quedado un tanto deprimido: decepcionados de la obra societaria unos y por temor a represalias otros, de los que pretendieron destruir nuestra Asociación a la que únicamente imaginaban como incubadora de conflictos, que si en un momento determinado pudieron producirse, no era ese precisamente el objeto con que se constituyó. De una vez por todas, vaya nuestro lema, para que no haya confusiones ni malentendidos de ninguna especie: la Asociación de Actores Argentinos ha sido fundada para la elevación intelectual, moral y material de los actores; su misión es estrechar vínculos entre la familia teatral sin odios, rencillas, ni prevenciones para nadie. No puede tener nuestra sociedad un carácter de resistencia obrerista, en el sentido más lato de la palabra, por cuanto nuestras condiciones de trabajo difieren de las del obrero manual; múltiples factores de diversa índole contribuyen a especializar nuestras reivindicaciones que si en un momento determinado pudieron traducirse en un movimiento huelguista, nunca puede ser este nuestro medio más habitual de lucha (Boletín de la Sociedad Argentina de Actores, 1 (1), septiembre 1919).

No obstante, los artistas no sólo habían apelado a la huelga en los conflictos de 1919 y 1921. En efecto, la otra estrategia implementada fue a autogestión, aspecto que no produjo tanta repercusión en la opinión pública de la época como el cese de actividades, pero que, en definitiva, más influencia ejerció en el futuro del sector. En efecto, en ambas oportunidades los artistas optaron por organizar compañías en cooperativa, no sólo para contribuir al fondo de huelga y a la manutención de los trabajadores, sino también como ensayo para una forma alternativa de organización de la actividad.

Sucede que más allá de los hechos concretos que desataron cada una de las huelgas, el objetivo final de los artistas consistía en la lisa y llana eliminación del empresario de compañía y su sustitución por un sistema de cooperativas que gestionaran por sí mismas una actividad que debía volcarse al bien común y a la transmisión de valores culturales (lo cual se identificaba con dar a conocer la dramaturgia culta europea, en detrimento de la popular y nacional en auge por aquellos años), rotar los roles 
protagónicos para evitar la formación de "prerrogativas jerárquicas" (Klein, 1988: 32) y repartir las ganancias entre sus miembros. La cooperativa planteaba una práctica teatral bajo formas de organización gestadas por los propios actores en posesión de sus medios de trabajo, en una triple independencia del Estado, de la burguesía y de las grandes figuras (Bayardo: 1990).

Se suponía que la mera eliminación del componente capitalista (al que se identificaba con el empresario de compañía en tanto intermediario pero no tanto con el dueño de sala) mejoraría las condiciones de los trabajadores de la actuación, por lo que el cooperativismo resguardaría a los actores y al arte teatral como bien común. Se partía del presupuesto de que el apartamiento del empresario teatral implicaría el reemplazo instantáneo del afán de lucro por las pretensiones estrictamente artísticas de los propios creadores: "Los derechos que tiene el contratante convierten al contratado en un simple instrumento del empresario. Para ellos todo es negocio [...]. Hay que dignificar la clase [...] no todo ha de depender del sueldo ni sacrificarse a éste, la libertad individual, la dignidad profesional." (Renovación, Revista de la Sociedad Argentina de Actores, 1920).

Esto también se hallaba en clara consonancia con un clima de época. En efecto, desde fines del siglo XIX se desarrolló en la Argentina un amplio movimiento cooperativista estimulado por los inmigrantes europeos que se insertaron en el medio agrario e intentaron replicar algunas de las formas de acción colectiva que habían conocido en sus lugares de origen: “...italianos y españoles que se destacan en el mutualismo, alemanes del Volga y judíos promotores del cooperativismo [...] Doctrina inglesa, experiencia alemana e ideología socialista constituyen los tres pilares fundantes del movimiento cooperativo argentino" (Mateo, 2013: 82). Esto había desembocado en la creación de numerosas cooperativas de diverso tipo (escolares, de consumo, de construcción, de seguro y ahorro y, en menor medida, de producción), que intentaban subsanar los aspectos o regiones desatendidos por el gran capital y por el Estado. En este sentido, "la literatura reconoce la gran influencia de la prédica socialista en el desarrollo del cooperativismo argentino, también propiciado por sectores de la dirigencia liberal y por el radicalismo" (Mateo, 2013: 81). Mateo y Carreras Doallo (2013) agregan que la reiterada demanda de los cooperativistas y la intensa labor parlamentaria socialista contribuyeron a redefinir la agenda estatal. No es casual entonces, que en 1926, durante la presidencia de Marcelo T. de Alvear, se sancione la Ley 11388 o Ley General de Cooperativas, basada en el proyecto del socialista Juan B. Justo, que se inspiraba a su vez en la famosa cooperativa inglesa de Rochdale. Sin duda, para inicios de los años veinte estas influencias habían permeado en la dirigencia del gremio actoral, que decidió afrontar las huelgas organizando elencos en cooperativa.

El inconveniente surgió cuando el público no concurrió a ver estos espectáculos. En la falta de éxito de estos intentos se evidenció la división entre actores famosos y actores de reparto: simplemente, los espectadores no asistieron a las obras de las cooperativas, porque los actores más reconocidos no estaban. No deja de resultar paradójico el hecho de que estos elencos se anunciaran como ex-compañia Parravicini o ex-compañía Vittone-Pomar, con el objeto de obtener el reconocimiento del público apelando a aquello que querían eliminar, esto es, a las jerarquías internas. Sin embargo, los espectadores no respondieron a esta interpelación, por lo que los huelguistas se vieron obligados a volver a sus trabajos sin obtener casi ninguna de las reivindicaciones por las que peleaban.

La historiografía tradicional considera este dato como una muestra de la ignorancia o falta de compromiso político y social del público:

Pese a todos los esfuerzos, el movimiento fracasa. Atrincherados en sus reductos céntricos y sustentados por la innegable popularidad de los capocómicos y algunas 
otras figuras, las empresas logran regularizar definitivamente sus temporadas [...] No alcanza el público para costear temporadas de alguna extensión, vinculado al hecho de carecer de figuras de renombre. [El público está] sometido en cierto modo al prestigio de los nombres consagrados (Klein, 1988: 30-32)

Consideramos, en cambio, que estas experiencias tornan evidentes las diferencias que la especificidad de la actividad artística genera respecto de otras áreas del mundo del trabajo, aspectos sobre los que la reflexión resulta insoslayable a la hora de implementar estrategias de lucha tradicionales como la huelga y la autogestión. En este sentido, la extrapolación de las experiencias de otros trabajadores al caso de los artistas, sin tener en cuenta la especificidad de su tarea, no sólo provocó que las medidas implementadas por el colectivo actoral fracasaran, sino que además impidió que el mismo consolidara su identidad como parte del mundo del trabajo y contribuyó a que la problemática laboral en el sector se mantuviera en el tiempo.

Pero, ¿cuál fue el motivo por el cual estas cooperativas fracasaron?

En su análisis sobre las primeras experiencias cooperativistas internacionales (específicamente los bazares de trabajo impulsados por Robert Owen en Inglaterra en 1832/33), Emilio Bottini señala que el "exceso de artículos existentes con relación a la demanda y la falta de su exacta avaluación fueron las causas que determinaron el descrédito y el cese de tales bazares" (1950: 157-158). Por tal motivo, identifica el posterior éxito de la cooperativa de Rochdale, a la que califica como la primera cooperativa exitosa de la historia, con el desarrollo de la producción "pero para el consumo organizado. Tenían suficiente experiencia para pensar que podrían producir para el mercado abierto. El destino que les hubiera esperado habría sido el fracaso, a semejanza de las anteriores fundadas sobre la misma base" (160).

Por su parte, en su caracterización de la doctrina de la economía social propugnada durante el primer peronismo (aspecto sobre el que nos centraremos más adelante), José María Rivera plantea que

Lo fundamental para que el hombre pueda emprender y concluir exitosamente un ordenamiento voluntario del proceso económico, es el conocimiento de sus leyes [...] No es pues por violentar las leyes económicas, sino por ignorarlas, que fracasan muchos ensayos inspirados en los mejores propósitos. [Es necesario] un $<<$ hacer inteligente $>>$, que conduzca al cumplimiento y no al fracaso de los objetivos propuestos (1950: $134 \mathrm{y} 140$ ).

Por consiguiente, podemos concluir en que, según estos autores, la implementación de formas de producción alternativas, tal como la organización en cooperativas, requiere de un hacer organizado, basado en el conocimiento profundo de las leyes económicas específicas de la actividad y de la preservación de la producción a una apertura indiscriminada al mercado.

Ahora bien, a la luz de estas observaciones, ¿cuáles fueron las características de las cooperativas implementadas por los actores huelguistas en los años veinte? ¿Por qué aún en un momento de gran demanda de espectáculos teatrales estas cooperativas fracasaron? Ante todo, ¿son los actores productores o trabajadores? Y si son productores, ¿qué producen? ¿Cuáles son las características económicas de aquello que producen?

Si tomamos como ejemplo cualquier producto manufacturado, llegaremos a la conclusión de que dicho producto fabricado en cooperativa o en una organización fabril empresarial no presenta diferencias sustanciales. Pero no sucede lo mismo con el arte. ¿Podemos afirmar que un personaje interpretado por Florencio Parravicini o 
Enrique Muiño era idéntico que el interpretado por un actor desconocido, que inclusive rotaba ese rol con sus compañeros? Si consideramos que el arte es una actividad donde la creatividad y la subjetividad generan valor, no puede sostenerse al mismo tiempo que el público no fue a ver las obras de los actores huelguistas por su incultura. Este argumento constituye la negación de la posición del arte. La negación de la especificidad del teatro.

Como ya lo señalamos, la actuación es una actividad definida por su extrema dependencia de la mirada ajena. Esta necesidad constante de obtener el favor del público se halla en la base de las jerarquías internas. Así lo entendía la prensa de la época:

El actor es una psicología que, por complicada individualmente, es simple si es vista en el conjunto colectivo de individuos. ¿Cómo podrían permanecer coaligados los cómicos si cada uno tiene a un enemigo en el compañero? Por otra parte, en todos los cómicos hay un empresario en perspectiva y mal pueden hacerse huelgas de firmes resoluciones con obreros que están, como los cómicos, a un día de ser patrones (“El conflicto entre obreros y empresarios", La República, 15 de mayo de 1919).

Y de hecho, el propio historiador oficial de la Asociación Argentina de Actores indicará que la asociación sindical constituye la "experiencia inédita de sustituir la característica competencia propia del oficio, por la libre asociación con sentido colectivo" (Klein, 1988: 14).

Esta característica de la actuación y, por consiguiente, del teatro, constituye una de aquellas leyes económicas específicas de la actividad que no pueden soslayarse ni simplemente sortearse mediante la exigencia de un compromiso ético o moral por parte de los espectadores. En la estrategia adoptada por los actores huelguistas subyacía una lectura de la actividad en la que el empresario teatral (que coincidía con el actor principal o capocómico) era sólo una figura parasitaria que explotaba el trabajo del resto de los actores y que, por lo tanto, podía simplemente eliminarse o someterse a la rotación de papeles y al reparto equitativo de ganancias. Al público, destinatario y consumidor del hecho escénico, sólo le cabía responder afirmativamente a una interpelación meramente ética, que pasaba por alto los componentes estéticos o artísticos del teatro. Por el contrario, consideramos que para llevar adelante una organización de la producción alternativa a la comercial, las cooperativas de teatro debían ser capaces de resolver económicamente las paradojas generadas por esta especificidad de la actividad: ¿cómo sustituir al capocómico? ¿Cómo obtener la mirada del público? De lo contrario, sus trabajadores no encontrarían los medios económicos para su subsistencia, debiendo regresar a sus anteriores compañías, lo que de hecho sucedió. La estrategia implementada por estas cooperativas fue salir a competir abiertamente a un mercado que, aun con una gran cantidad de público disponible y con el teatro comercial paralizado por la huelga, no respondió a su oferta.

\section{V.}

Favorecida por la prosperidad del teatro, hasta 1928 la situación se mantuvo estable. Es así como, en $1924 \mathrm{y}$, al calor de las mejoras producidas por el aumento de los ingresos en la taquilla, que lentamente se reflejaron en los sueldos de los actores, la Sociedad y la Unión se fusionaron una vez más en la nueva Asociación Argentina de Actores, cuyo estatuto refrendó el carácter mutualista en detrimento de la acción gremial. Para 1927, la Sociedad Argentina de Actores contaba con un alto número afiliados. ${ }^{15}$ Sin embargo, lo firmado en las Bases de Trabajo no se aplicaba. En efecto, dicho acuerdo había sido realizado entre empresarios y actores, pero no

15. Según declaraciones de Florencio Parravicini (Caudarella, 2016: 74), éstos ascendían a 400o. González Velazco (2012), en cambio, consigna 1800 . 
contemplaba el arbitraje de una instancia externa que garantizara su cumplimiento y que aplicara sanciones si el mismo no se respetaba. Es decir, no contaba con la intervención del Estado.

Hasta el momento, el rol del Estado como promotor de la cultura en general había sido mediocre (Sigal, 2002), situación que se profundizaba en el caso de las artes del espectáculo. Esto se manifestó en la inexistencia de políticas teatrales públicas, por lo que la intervención estatal se redujo a la regulación sobre los contenidos y al cuidado de las formas en escena. Por su parte, muchos intelectuales, que se encontraban desempeñando roles decisorios en el Estado, se limitaban a reclamar porque el teatro no se desarrollaba en el sentido que ellos pretendían.

No obstante, hacia mediados de los años 20 comenzó a vislumbrarse la necesidad de una política estatal en materia de teatro que se asemejara a la emprendida en los países europeos, aunque se entendía que la misma debía abocarse inicialmente a la creación de una escena oficial que, a la manera de la Comedia Francesa, complementara lo que hasta el momento sólo incluía al Teatro Colón (Caudarella, 2016). Sin embargo, este proyecto no logrará plasmarse hasta bien entrada la década siguiente.

Poco era, por su parte, lo que existía hasta el momento en materia de legislación. En efecto, el ámbito municipal contaba con la Ordenanza General de Teatros (más conocida como OGT), aprobada el 9 de diciembre de 1910 por el Concejo Deliberante. Además de los teatros, dicha ordenanza incluía también a cine-teatros, cinematógrafos, cafés cantantes, salones sociales, cafés, circos, quermeses, fiestas al aire libre, salas de patinaje, gabinetes ópticos y panorámicos (Caudarella, 2016). Dadas las modificaciones sufridas desde su sanción, la Ordenanza constituía para 1918, un cuerpo de 262 artículos en gran medida contradictorios entre sí.

Los mismos se dirigían fundamentalmente a arbitrar la relación entre los espectáculos y el público, limitándose a cuestiones edilicias y de seguridad e higiene de las salas (dimensiones y espacios con los que debían contar las mismas, materiales que debían utilizarse para construirlas, medidas de las butacas, pasillos, etc.), a normativas respecto de la suspensión de las funciones y, en menor medida, a la moralidad, buscando regular los contenidos de los espectáculos y el comportamiento de los espectadores. Los empresarios debían tramitar una autorización en la Municipalidad donde constara que la sala se adecuaba a lo exigido por la Ordenanza. Sin embargo, muchas salas funcionaban con habilitaciones precarias que se prorrogaban durante años.

Esto se debía a los inconvenientes en la aplicación de la OGT. Por tal motivo, en 1922 se agrega el $1^{\circ}$ Capítulo con el objeto de crear una Comisión Superior de Teatros (CST), luego denominada Inspección General de Teatros, encargada de autorizar los espectáculos. La misma estaba presidida por el Secretario de Obras Públicas, Higiene y Seguridad del Departamento Ejecutivo, y compuesta por el Presidente de la Comisión de Interpretación y de Obras Públicas y Seguridad del Concejo Deliberante, el Jefe de Policía, el director de la Administración Sanitaria y Asistencia Pública, el director general de Instalaciones Eléctricas, Mecánicas y Alumbrado, el Jefe del Cuerpo de Bomberos, el Ingeniero Jefe de las Obras Sanitarias y el Jefe de la Inspección de Teatros (González Velazco, 2012). Sin embargo, y dado que no lograba reunirse con suficiente asiduidad, la Comisión fue disuelta en 1927.

En definitiva, el gobierno municipal nunca pudo garantizar la aplicación de la normativa aduciendo la escasez de recursos materiales y humanos, "pero sobre todo, un factor que dificultó su cumplimiento fue la permanente astucia y adaptación que desarrollaron los empresarios teatrales para evadir multas y clausuras" (Caudarella, 2016: 209). 
En efecto, el medio teatral rechazaba de plano la intervención del Estado. Desde el punto de vista empresarial, la normativa era una injerencia en el ámbito privado, cuyo único objetivo era censurar los contenidos de las obras:

las inspecciones municipales, con el argumento de constatar la higiene de las salas, la seguridad o el cumplimiento de los horarios de ensayos o si había o no menores de edad, en realidad buscaban presionar para que se modificaran algunos textos o escenas por considerar que eran "inconvenientes" o que "atentaban contra la moral” (Kogan, 2012: 124).

La estrategia empresarial consistió entonces, en denunciar sistemáticamente la arbitrariedad de clausuras o allanamientos, que conllevaban además la pérdida de puestos de trabajo y de manifestaciones culturales, utilizando los medios gráficos para tal fin. Citaremos dos casos que se reproducen en Los Productores, dado que constituyen ejemplos significativos de los argumentos utilizados por la entidad durante las primeras décadas del siglo pasado y que resultan refrendados por lo que constituye la historia oficial de la Asociación Argentina de Empresarios Teatrales.

El primero es una nota publicada por Fray Mocho (24 de enero de 1913), a raíz del cierre de los teatros Apolo, Nacional, Avenida, Mayo, Comedia, Royal y Casino, debido a lo que la nota califica como imposición del intendente Anchorena:

Cierto es que las butacas no estaban de acuerdo con las disposiciones municipales, pero, según la gente de teatro, las disposiciones municipales tampoco le acordaban autoridad para clausurar así, de golpe y zumbido, los teatros. Cuando más a aplicarles multas, siempre según la gente de teatro [...] ¿Qué le importa al doctor Anchorena que el pueblo se quede sin su favorita distracción? (Kogan, 2012: 35).

Más abajo se reproduce la foto de una mujer con gesto sombrío y el epígrafe "Una actriz pensando en la reducción de su sueldo debido a la prolongación del cierre" (35).

El segundo es un volante que la SADET imprime en 1925 con el título "Al público", con motivo del arresto de cuarenta y ocho artistas en varios teatros de la Ciudad por no contar con documentos de identificación personal. El texto arguye que la legislación que se invoca para las detenciones de mujeres y niños no está reglamentada y que, por lo tanto, se desconoce si corresponde su aplicación al ámbito de la cultura (Kogan, 2012: 14).

De este modo, si bien sólo 3 de los 262 artículos de la OGT hacían mención a los contenidos o características de los espectáculos e indicaban que se prohibían los que afectaran la moral y las buenas costumbres (González Velazco, 2012), los empresarios leían y denunciaban la totalidad de la normativa y, por defecto, la intervención estatal en clave de persecución moral o ideológica. Sin embargo, resultan más acertadas las interpretaciones que vislumbran en el súbito interés que el Concejo Deliberante muestra por las artes del espectáculo durante los años veinte, el objetivo de asegurar el cobro de los impuestos devengados de una actividad ostensiblemente lucrativa. De hecho, recurrentemente se discutían medidas para controlar de manera más efectiva la venta de localidades, dadas las reiteradas denuncias de que los empresarios revendían entradas a mayor precio o agregaban sillas sin numerar (González Velazco, 2012).

Sea como fuere, el Concejo Deliberante mostró por esos años una sostenida preocupación por dos cuestiones vinculadas directa o indirectamente con las condiciones laborales de los artistas: el cumplimiento de los horarios de las funciones y los ensayos nocturnos. En efecto, la OGT fijaba horarios para cada sección y preveía multas por su incumplimiento, aspecto que se había agravado desde 1918 con la incorporación 
de la función vermouth, pero las mismas no se aplicaban. Con respecto a los ensayos nocturnos, los mismos respondían a motivos comerciales (tal como lo hemos señalado), al tiempo que constituían una costumbre fuertemente arraigada entre los propios artistas.

Dado que la legislación en materia laboral era potestad del Congreso Nacional, por lo que estaba fuera de la órbita del Concejo Deliberante, éste intentó una serie de artimañas para aplicar normativas que impactaran indirectamente en la jornada laboral de los artistas. Así, en 1922, los concejales socialistas Antonio Zaccagnini, Alejandro Castiñeiras y Manuel González Maseda impulsan el aumento a una frecuencia semanal en las desinfecciones obligatorias de las salas, que el Digesto Municipal vigente fijaba cada dos meses:

En esta forma, procuraremos también un día de descanso a todo el personal de los teatros, que en la actualidad, yespecialmente en los teatros nacionales por secciones, tienen la jornada de trabajo que he mencionado [...] Debemos preocuparnos de la situación del personal que trabaja en los teatros, que no tiene ningún descanso, que vive en ese ambiente antihigiénico, que representa un peligro físico, e intelectual también, desde el momento en que no se puede trabajar artísticamente, sin un solo día de descanso en la semana (discurso de Antonio Zaccagnini, Versiones taquigráficas del HCD correspondientes al $2^{\circ}$ período y prórroga de 1922).

Como contrapartida, los concejales radicales Horacio Casco y Saturnino García Anido, además de Leonardo Costas, rechazaron la propuesta. Casco propuso que se desligara la cuestión de la desinfección del día de descanso y García Anido manifestó que el día de descanso no tenía relación con las condiciones artísticas. Agregó que el cierre de los teatros dañaba económicamente a los empresarios y también a la misma Comuna, dado que cuatro días al mes sin actividad, equivalían a cuarenta y ocho días al año, y propuso que la desinfección se hiciera en horas de la madrugada (Caudarella, 2016). La SADET sostuvo exactamente el mismo argumento mediante una carta que envió al Concejo. Finalmente, se aprobó la desinfección de madrugada.

En 1925, se presentan en el Concejo Deliberante dos proyectos vinculados con la actividad artística. Uno prevé la reforma de la Ordenanza General de Teatros con el objetivo de disminuir la presión ejercida sobre las salas. Es así como el Secretario de Obras Públicas, Antonio Barrera Nicholson, manifiesta que no existía en Buenos Aires ninguna sala que no estuviera en contravención y que "no podemos dejar a la Ciudad de Buenos Aires sin ningún teatro" (Versiones taquigráficas del HCD correspondientes al $2^{\circ}$ periodo de 1925). El otro proyecto, presentado por el concejal Carlos Manacorda, tenía por objetivo elevar el nivel artístico mediante un premio a las compañías teatrales que representaran obras de alto contenido artístico, consistente en el reintegro de los impuestos de la temporada.

En 1926, se produce un hecho altamente significativo para nuestro análisis, que es la incursión política del colectivo artístico mediante la creación del partido Gente de Teatro, que se presenta a las elecciones municipales de ese año, obteniendo sorpresivamente una banca como concejal para el actor-empresario Florencio Parravicini, durante el bienio 1926-1928.

El partido se reivindicaba como representante de actores, autores y empresarios, por lo que incluía en su lista a personalidades como Enrique Muiño y Roberto Casaux (actores-empresarios al igual que Parravicini) y a los autores Enrique García Velloso y Alejandro Berruti, mientras que su comité funcionaba en una casa que había sido la sede de la Unión Argentina de Actores y que luego de la fusión había pasado a la Asociación Argentina de Actores (González Velazco, 2012). 
La plataforma del partido explicitaba la condición apolítica del mismo y la búsqueda de un elector independiente, y enunciaba un programa de medidas tendientes a promover la actividad teatral (mediante la reducción de impuestos, la facilitación de las habilitaciones y trámites, y la modificación de los criterios para definir lo que se consideraba moral), a vincular el teatro con la sociedad (a través de la creación de un teatro infantil, de una escuela de teatro para niños, de la organización de funciones gratuitas en los barrios y de la apertura del Teatro Colón a todos los ciudadanos), y a desarrollar acciones mutuales que beneficien a los artistas (como la cooperación municipal para la construcción de una Casa de Descanso, un sanatorio y un campo de deportes).

Respecto de la reunión de sectores hasta hace poco tiempo en conflicto, González Velazco considera que el ámbito de la política municipal "se presentaba como una instancia de articulación que permitía refundar la idea <<familia teatral >>” (2012: 104). Sostiene que una organización de estas características responde a las particularidades de la vida política porteña de los años veinte, en la que fueron creados un elevado número de partidos pequeños de diverso origen u organización, estimulados por el sistema de representación proporcional de la Ciudad, que pasaron a coexistir con las grandes estructuras socialista y radical. De este modo, considera que Gente de Teatro recogía las tradiciones municipalistas que proponían una representación sectorial para asegurar la defensa de intereses particulares y retomaba los argumentos que sostenían que el ámbito municipal era una instancia administrativa y no política.

Algo similar plantea Baranchuk (2016), cuando afirma que durante los enfrentamientos de la Semana y la Patagonia Trágica de principios de los años 20, el anarquismo fue cuasi aniquilado, siendo sustituido por una corriente sindical socialista. La estrategia de la misma consistió en ampararse en un marco legal, y desde allí bregar por la mejora en las condiciones laborales mediante la obtención de conquistas graduales. Esto requería de la acción estatal y, por consiguiente, de conseguir tener representantes parlamentarios.

Lo cierto es que Gente de Teatro reunía a grupos que, además de haber estado en conflicto durante las huelgas, ocupaban distintos roles en el proceso productivo. Por tal motivo, los consensos acerca de las reivindicaciones a esgrimir terminaron decantando hacia los intereses de los sectores más poderosos (los empresarios) o que detentaban roles jerárquicos en la producción teatral (los autores), tal como había sucedido en la huelga del 21. De hecho, Parravicini había sido el primer presidente de la SADET. De este modo, Gente de Teatro consistió en un partido sectorial, no gremial, con fuerte presencia de dirigentes y de objetivos propios de los empresarios, que apelaron a la idea de familia teatral para obtener el voto de todo aquél vinculado de alguna manera con el mundo del espectáculo.

De hecho, Los Productores, historia oficial del colectivo empresarial, reivindica al partido Gente de Teatro como propio:

No parece casualidad esta incursión de los empresarios en el mundo de la política. Además de tratar con actores y escritores, de crear espectáculos y de intentar colmar sus salas, a ellos les tocó desde siempre lidiar con las distintas autoridades administrativas para solucionar problemas diversos: desde los horarios y la cantidad de funciones diarias y semanales al funcionamiento de las boleterías; desde la discusión de gravámenes a la publicidad callejera hasta el logro de una condición fiscal menos onerosa teniendo en cuenta la relación de su tarea con la cultura popular; desde clarificar los objetivos de los teatros oficiales hasta su vínculo con los gremios; desde la obtención de tarifas preferenciales en el consumo de electricidad por el uso de marquesinas hasta las condiciones de seguridad dentro 
de las salas; desde la naturaleza de los contratos laborales hasta dejar satisfechos a los distintos poderes con cada uno de sus espectáculos (Kogan, 2012: 123)

La auténtica vocación del Partido no pasó desapercibida en el propio Concejo Deliberante. En efecto, el concejal comunista José Penelón acusó a Gente de Teatro de retrotraer la política a la Edad Media, en la que los patrones y los obreros abogaban por intereses corporativos conjuntos. Este tipo de asociación resultaba inconveniente ya que era imposible "unir los intereses de una profesión determinada, cuando hay diferencias de clases que son fundamentales" (Versiones taquigráficas del HCD correspondientes a las sesiones de convocatoria y ordinarias del $2^{\circ}$ periodo de 1927).

Aunque la actividad y presencia en el recinto de Parravicini fueron muy escasas, hecho reconocido incluso en la época, sus intervenciones no dejaron de ser significativas.

En 1926, resurge la cuestión de los ensayos nocturnos. El concejal comunista José Penelón y el radical alvearista Nicolás Coronado, con el apoyo del Secretario de Obras Públicas, elevan un proyecto que propone prohibirlos y multar a quienes incumplan la medida. Esto es debatido en el recinto, manifestándose en contra concejales del sector yrigoyenista y el propio Parravicini, quienes aducen la supervivencia económica del circuito (Caudarella, 2016).

Parravicini sostiene que para garantizar la afluencia de público es necesario ensayar una nueva obra que suplante aquella que hubiera fracasado y recurre a la especificidad de las tareas de los artistas para fundamentar la existencia de los ensayos nocturnos:

La labor de los artistas de teatro no puede ser equiparada a la de ningún otro oficio o profesión. El zapatero, el carpintero, el músico, tienen mil recursos de trabajo [...] El artista que queda sin trabajo gracias al fracaso de una temporada, sufre las peores indigencias porque no puede ocuparse cuando quiere y donde quiera. $Y$ a veces, para solucionar este problema, tiene que trabajar más de lo frecuente y aún más de lo lógico, muy a pesar suyo y de sus empresarios. Y que conste que no me refiero solamente a los elementos subalternos, sino también a las primeras figuras (Versiones taquigráficas del HCD correspondientes al 1ํㅡㄹ período de 1927).

El concejal de Gente de Teatro se mostró así en contra de que el Concejo Deliberante intentara establecer directa o indirectamente mejoras en la calidad laboral de los teatros. Consideró que era impropio que el Concejo confundiera la legislación sobre espectáculos públicos con el derecho laboral:

No es el Concejo Deliberante quien debe reglamentar el horario ni los salarios. Esto es cuestión de una ley. Y sería lamentable que el Concejo tomara una determinación que pasara esta ordenanza porque tendría muy en breve que borrar con el codo lo que escribió con la mano (Versiones taquigráficas del HCD correspondientes al ${ }^{\circ}$ período de 1927$)$.

Luego del debate, el proyecto pasó a las comisiones de Obras Públicas y Presupuesto y regresó al recinto con una modificación, mediante la cual se permitiría ensayar la noche anterior al estreno. Esto ocasionó una nueva discusión en el Concejo, que llevó cinco días. Durante la misma, los concejales que defendían el proyecto apelaron a la ampliación del concepto de higiene al control, cuidado y atención del individuo. El concejal Carlos Manacorda sostuvo que "el objetivo del socialismo con este proyecto era prestar auxilio a los obreros del teatro, un gremio que, según él, no había sabido comprender y defender sus derechos, lo que los convertía en presa fácil de los empresarios" (Caudarella, 2016: 79). 
Finalmente, el 4 de octubre de 1927 se sancionó la prohibición de los ensayos nocturnos, pero se flexibilizaron las multas respecto del proyecto original. Parravicini manifestó que su acuerdo sólo estaba motivado en evitar que el Concejo siguiera perdiendo tiempo e ironizó: "Si con esto se ha de salvar la patria, que ella se salve, aunque para ello sea necesario suprimir los ensayos nocturnos y el teatro mismo" (Versiones taquigráficas del HCD correspondientes a las sesiones de convocatoria y ordinarias del $2^{\circ}$ periodo de 1927).

Durante el mandato del concejal por Gente de Teatro no sólo fue tratada la cuestión de los ensayos nocturnos. En 1926, el concejal alvearista Nicolás Coronado y los concejales Roberto Lavin y Saturnino García Anido solicitaron al Congreso de la Nación y al Intendente la sanción de una ley que regule el trabajo en las salas considerando las particularidades de artistas y técnicos. Como fundamento, exponen los bajos sueldos y las condiciones precarias de trabajo, que ejemplifican mediante la descripción de camarines pequeños y pestilenciales en los que se agrupaban cuatro o cinco artistas, la finalización en altas horas de la noche de jornadas de entre doce y diecisesis horas, la alimentación deficiente, etc. Afirman que ningún otro trabajador del país se halla en peores condiciones:

Los proletarios del teatro realizan tareas no comparables a las de ningún otro. Los días hábiles trabajan por la tarde en los ensayos, luego en la sección vermouth y por la noche en tres secciones distintas. Los días feriados, mientras todo el mundo tiene derecho al descanso, la actividad de estas personas se duplica de manera pavorosa: las compañías de revistas ofrecen al público hasta siete secciones y los de comedia tres secciones: matinée, vermouth y nocturna. Enorme labor que se efectúa a cambio de una retribución insignificante, salvo las primeras figuras de las compañías teatrales (Discurso de Nicolás Coronado y Ángel Giménez, en Versiones taquigráficas del HCD correspondientes al 1ํㅜ período de 1926).

Consignan además que las malas condiciones de trabajo ocasionan enfermedades en las vías respiratorias y tuberculosis. Giménez caracterizó a los empresarios teatrales como "verdaderos traficantes de carne humana, que están al margen de la ley, que bajo el aspecto de empresarios realizan tareas innobles" (Versiones taquigráficas del $H C D$ correspondientes al $1^{\circ}$ periodo de 1926)

Estas denuncias tuvieron un fuerte impacto en el Concejo y propiciaron un profundo debate, además de reacciones en el sector empresarial. En primer término, la SADET exigió la inmediata retractación en los dichos de Giménez. Es así como el concejal manifestó que había dos tipos de empresarios, aquellos que trabajan por el arte y la educación y aquellos que paralelamente a los negocios teatrales mantenían cabarets, los cuales eran "extranjeros felizmente" (Versiones taquigráficas del HCD correspondientes a las sesiones de convocatoria y ordinarias del $2^{\circ}$ periodo de 1927).

En segundo término, Parravicini salió al cruce defendiendo el monto de los sueldos de los trabajadores del teatro, que rondaban entre 180 y 3000 pesos, ${ }^{16}$ aduciendo que no eran tan bajos como denunciaba el partido socialista y que superaban a los pagados en fábricas y talleres (Caudarella, 2016). Agregó que los empresarios debían afrontar estos pagos, más el alquiler de la sala, lo que explicaba la infinidad de quiebras de compañías por temporada. A modo de ejemplo, Parravicini denunció que las empresas de los teatros Ateneo, Odeón, San Marín, Mayo, Victoria y Buenos Aires habían terminado en bancarrota por los altos impuestos de la Municipalidad. Además, el concejal se vio obligado a consignar que, según datos de la Sociedad Argentina de Actores, los enfermos pulmonares eran sólo 6 de los 4000 que se encontraban afiliados: "tres internados en el sanatorio Santa María, otro en Córdoba y dos en España" (Versiones taquigráficas del $H C D$ correspondientes a las sesiones de convocatoria y ordinarias del $2^{\circ}$ periodo de 1927).
16. Para 1924, el sueldo de una familia tipo rondaba los $\$ 150$ y un empleo de mucama podía pagarse \$70 según el periódico. Un kilo de pan costaba \$o,6o, un litro de leche $\$ 0,20$, un kilo de fideos $\$ 0,50$ y un kilo de carne o,6o. Mientras que la entrada a un teatro de primera línea costaba entre $\$ 1$ y $\$ 3$, y uno más modesto $\$ 0,30$, el cine costaba \$o,20 y la Revista Bambalinas o La Escena \$o,20 (González Velazco, 2012) 
En lo que respecta a estrechar los lazos entre el teatro y la sociedad, Parravicini presentó un proyecto para extender la órbita del teatro infantil más allá del Labardén. Fundado en 1918, el Teatro Infantil Labardén (TIL) constituía un programa de educación por el arte, en el que niños de entre 6 y 14 años se formaban para realizar funciones barriales durante los fines de semana. Cabe destacar que los niños no cobraran y que la movilidad corría por su cuenta:

Como lo describieron en 1929, los concejales Francisco Turano, Ricardo Muscio, Eduardo Catán y Raúl Savarese, los "actorcitos" del Labardén eran niños pobres que sacrificaban sus domingos y algunos días hábiles, "restándoles ratos a sus juegos, en homenaje a sus congéneres, en cuyas almitas lograron infiltrar un soplo de alegría" (Caudarella, 2016: 187).

De hecho, Caudarella consigna que el TIL contaba con escasos recursos, que se destinaban principalmente a los sueldos del Maestro Director, del Maestro Secretario y de los demás docentes, encargados de instrumento y ordenanzas. Para 1925, el Labardén contaba con 49 niños y 37 niñas, ofrecía una obra semanal en promedio ( 31 funciones ordinarias y 21 extraordinarias), muchas de las cuales se organizaban en beneficio de la copa de leche, el pan escolar y las bibliotecas infantiles, es decir, de bienes y servicios que debían ser garantizados por el Estado.

El proyecto de Parravicini proponía estimular el ingreso y el compromiso de los niños mediante el otorgamiento de becas de entre \$30 y \$60 (recordemos que el escalafón más bajo de una compañía cobraba \$180). Durante una sesión, el concejal manifestó que el niño,

especialmente el perteneciente a las clases populares, con toda su inteligencia natural, su imponderable salud física y su poderoso don asimilativo que le hace uno de los más interesantes tipos sociales del mundo, es por aquellas mismas razones y a carencia de organizaciones de esta naturaleza, de suyo grosero en sus modales y lenguaje, refractario al orden colectivo e impermeable casi a la conducta social que se nota en los niños de otras ciudades (Versiones taquigráficas del HCD correspondientes a las sesiones de prórroga del $2^{\circ}$ período de 1927).

En efecto, el TIL tenía como objetivo apremiante substraer a los niños de lo que se consideraba dos amenazas latentes: la calle y el cinematógrafo. Es curioso que este imaginario, que combinaba la legitimación de un tutelaje cultural ejercido hacia las clases populares con el carácter sacrificial y/o misional de la actividad artística, intentara imponerse a los niños. En cierto sentido esto contribuía a perpetuar las condiciones del ejercicio de las actividades artísticas, postura frente a la cual el partido Gente de Teatro no sólo no presentó una alternativa, sino que avaló.

Por último, en su carácter de concejal, Parravicini asistió en representación de la Municipalidad en el acto de colocación de la piedra fundacional de la Casa del Teatro, el 12 de febrero de 1928. El presidente Alvear quería asegurarse la puesta en marcha de la Casa del Teatro antes de que terminara su mandato, por lo que un año antes, el 19 de agosto de 1927 conformó una asamblea presidida por su esposa, Regina Pacini, en la que participaron miembros de la Asociación Argentina de Actores, de las dos asociaciones de autores y de la SADET, con el objeto de elegir la Junta Directiva de la futura entidad. Un mes después el Poder Ejecutivo de la Nación le otorgó la personería jurídica. La Casa del Teatro tendría como objetivo suministrar a los actores, empresarios y elementos afines a la gente de teatro, de edad avanzada o imposibilitados físicamente, un albergue, manutención, asistencia médica y farmacéutica. Los socios de la Casa del Teatro serían de dos tipos: benefactores (que aportarían fondos y no recibirían beneficios) y los beneficiarios, que estarían eximidos de la cuota mensual (Caudarella, 2016). 
En febrero de 1928 se colocó la primera piedra, que contaba con la leyenda "Casa del Teatro, levantada a iniciativa de la señora Regina Pacini de Alvear". En octubre, dos días antes de que finalizara la presidencia de Alvear, se aprobaron los planos del edificio (que tendría cuartos, comedor, salón de encuentro, sala de lectura, salón de fiesta en el que también se podrían hacer espectáculos, enfermería, gimnasio, etc.). No obstante, la Casa del Teatro se inauguraría recién diez años después, el 5 de enero de 1938, día del cumpleaños de Regina Pacini.

Cumplido el mandato de Parravicini, Gente de Teatro se disolvió. Según José González Castillo, el partido decidió no volver a presentarse a elecciones en 1928, argumentando "no poder explicar al electorado la conducta de su representante" (Comoedia (49): 36). Sin embargo, el papel jugado por Parravicini en el Concejo fue estratégico, convirtiéndose en la voz de los empresarios teatrales en el recinto. Aun así, sus colegas esperaban mejores resultados de esta incursión directa en la política. Es así como en 1927, Ivo Pelay cuestiona al concejal porque su actitud "no había sido lo suficientemente severa con su colega de bancada Coronado, que impulsó unos ampulosos allanamientos en varios teatros con el propósito de constatar si en esas salas se seguían realizando ensayos nocturnos" (Kogan, 2012: 123). Esto explica la efímera trayectoria del partido. En efecto, González Velazco (2012) identifica como una de las causas el hecho de que las asociaciones del ámbito artístico buscaban relacionarse directamente con el poder ejecutivo salteando la instancia legislativa, y que los propios miembros de las asociaciones tenían relaciones con personalidades políticas. En definitiva, estos vínculos resultaron mucho más productivos que la participación política directa.

\section{VI.}

En el presente artículo hemos analizado las condiciones laborales de los artistas del espectáculo durante las primeras tres décadas del siglo XX, en un contexto signado por la organización comercial. La gran disponibilidad de público y la pulsión por obtener el mayor rédito posible promovieron la máxima extracción de la plusvalía generada por los artistas, no sólo mediante sueldos bajos sino por medio de largas jornadas laborales sin día de descanso.

Para fines de los años diez, los diversos agentes que intervenían en el proceso productivo de las artes del espectáculo vislumbraron la inminencia del conflicto, motivo por el cual se organizaron en asociaciones y sindicatos que se mantienen activos hasta hoy. El temprano antecedente fue el caso de los autores, que reclamaron un porcentaje de la recaudación a inicios de la década. En segundo término lo hicieron los empresarios, no sólo de cara a los propios autores y a los artistas, sino como modo de actuar conjuntamente ante la prensa y eventualmente, ante del Estado. No deja de ser significativo que los actores hayan sido los últimos en formalizar su agrupamiento (aunque el intento previo, si bien de carácter estrictamente mutualista, da cuenta de la rápida percepción de las necesidades de los mismos).

Cuando los conflictos surgieron, en el bienio 1919-1921, el gremio actoral adoptó dos actitudes disímiles y contradictorias. Discursivamente intentó alejarse de todo conflicto ideológico o de clase que pudiera vincular su reclamo con objetivos políticos de corte revolucionario, para lo cual se manifestó explícitamente ajeno a las luchas obreras y reivindicó la especificidad de la tarea artística en contraposición al resto de los trabajadores. Pero, por otro lado, optó por las estrategias de lucha tradicionales del movimiento obrero: la huelga y la autogestión, sin percibir que justamente la especificidad de la tarea artística dificultaría la aplicación de las mismas, haciendo fracasar el reclamo, lo que de hecho, sucedió. 
Cabe destacar que, mientras las reivindicaciones de los autores contaron con el apoyo de los artistas, no sucedió lo mismo a la inversa, cuando los dramaturgos no cedieron los derechos a los actores huelguistas y sí lo hicieron con los empresarios. Asimismo, hemos analizado cómo el intento de armar un frente conjunto mediante la Federación Gente de Teatro puede explicarse (y de hecho así lo fue en su época y en los estudios posteriores) en función de la división interna entre los autores, y cuyo éxito dependía forzosamente de que otros gremios se involucrasen. Si bien los dramaturgos no ocupaban el mismo lugar que los actores en el proceso productivo, la Federación eligió como estrategia plantear el conflicto en términos ideológicos, apelando al clivaje productores/intermediarios, y agrupando entre los primeros a los creadores (autores y artistas, la verdadera gente de teatro), mientras los segundos fueron caracterizados como elementos parasitarios. Sin embargo, el intento fue económicamente insostenible.

Tanto en 1919 como en 1921, las diferencias internas entre actores de reparto y primeras figuras fue un elemento que no pudo pensarse ni resolverse. Se lo evaluó (y se lo evalúa aún hoy) como una mera expresión de la explotación capitalista de las artes del espectáculo, objeto de manipulación por parte del capital amparado en la ignorancia y falta de compromiso ideológico del público y no como una de las características específicas de las artes escénicas y, por consiguiente, la base de las leyes económicas que rigen su comercialización (ya sea mediante un modelo capitalista, autogestionado o cooperativista).

De hecho, la conformación de dos temporadas paralelas durante el conflicto de 1921, resultó un anticipo de lo que se plasmaría durante la década siguiente, permaneciendo activo hasta la actualidad: dos circuitos paralelos, uno de los cuales apela a la fidelidad del público en términos éticos y extra-artísticos, y se evidencia y/o se esgrime explícitamente como económicamente inviable.

Luego de las huelgas, la situación permaneció inamovible, propiciada por el éxito de público del espectáculo en vivo. Para 1926, los empresarios ensayaron un nuevo modo de vincularse con el Estado, mediante la actuación política directa en el ámbito municipal, espacio en el que se dirimían las cuestiones impositivas y edilicias, que afectaban directamente el negocio teatral. Para ello, crearon un partido político al que también denominaron "Gente de Teatro" en un intento de apelar a la idea de "familia teatral" (González Velazco, 2012), como un grupo específico y con necesidades específicas, en el seno de la sociedad y, sobre todo, frente al Estado. La utilización reiterada de la expresión gente de teatro, muestra hasta qué punto estas iniciativas necesitaban esconder que en las mismas se hallaban reunidos diferentes sectores del proceso productivo. Esto fue posible porque la autopercepción de los propios artistas como trabajadores era difusa.

Mientras tanto, la precariedad de las condiciones de trabajo continuó sin modificaciones. Y hacia el final de la década se agravó, debido a la decadencia del teatro como actividad comercial. No obstante este cambio de escenario y el fracaso de las experiencias anteriores, el gremio actoral mantendrá su versión del cooperativismo como objetivo último de su lucha, articulando las demandas según un lenguaje de clase y una ideología de izquierda, conforme al clima de época, tal como lo analizaremos en próximos artículos del presente dossier. 


\section{Segundo Apartado: Identidades y apelaciones antagónicas. Los trabajadores del espectáculo entre el modelo militante y el modelo sindicalista (1930 - 1955)}

\section{I.}

Los veinticinco años transcurridos entre 1930 y 1955 resultan centrales para comprender las condiciones laborales de los trabajadores del espectáculo en la Ciudad de Buenos Aires. En efecto, lo acontecido durante dicho período delineó las coordenadas que organizarían los campos cultural y artístico durante el resto del siglo y en lo que va del presente, debido a sus consecuencias en el terreno laboral, ideológico y estético.

En un contexto de cambio en los hábitos de consumo cultural de la mayoría de la población, que desembocará en el irreversible abandono del espectáculo artístico en vivo como forma privilegiada de entretenimiento, hacen su aparición el movimiento de teatro independiente, en primer término, y el peronismo, años después.

Con el teatro independiente, se explicita y consolida un modelo de teatro culto, organizado a partir de una propia y particular versión del cooperativismo, en la que las relaciones de trabajo son desplazadas fuera de la actividad artística y en la que los sujetos que la ejercen son interpelados como militantes, cuya misión se contrapone a la retribución económica.

Por su parte, y en un contexto internacional orientado hacia la planificación estatal de la cultura, el peronismo buscará intervenir en las artes del espectáculo. Por un lado, mediante la apelación a los artistas en tanto trabajadores, con el objeto de poner de relieve la dimensión laboral de su actividad. Por otro lado, organizando la escena oficial y los medios de comunicación.

Ambos modelos entrarán en colisión directa, no sólo en el campo cultural en general, sino al interior del propio colectivo artístico. Además de las ostensibles diferencias ideológicas entre ambos sectores, lo que subyace en dicho conflicto es la concepción de los vínculos entre el arte y la cultura, y el Estado y el conjunto de la sociedad.

Si bien el golpe de estado de 1955 interrumpirá violentamente el panorama político, el modelo del teatro independiente, en consonancia con los sectores intelectuales, no sólo tendrá continuidad, sino que terminará por convertirse en hegemónico, dominando el campo cultural y sorteando las (débiles) disputas presentadas por otros modelos de arte y cultura, hasta nuestros días.

Consideramos que la centralidad del ideal del teatro independiente sumirá la problemática laboral del arte en una invisibilidad que aún pesa sobre ella. En efecto, el proceso de constitución de la identidad de los artistas como trabajadores no llegó a cuajar, en parte porque el modelo impuesto por el teatro independiente funcionó como factor retardatario en este sentido.

\section{II.}

Según lo desarrollado anteriormente en el presente dossier, ${ }^{17}$ podemos establecer que, si bien los artistas se asumen por vez primera como trabajadores finalizando la segunda década del siglo XX, esto no sucede sin conflictos ni ambigüedades. Las características específicas de la actividad constituyeron un desafío para la organización entre

17. En el artículo de nuestra autoría “Identidades y apelaciones antagónicas I ¿Artistas, productores o trabajadores? (1902 - 1930)" pares, que por aquellos años no pudo afrontarse, lo cual impidió que el posicionamiento de los artistas como trabajadores se consolidase. 
A estas dificultades se le sumó una fuerte interpelación ejercida por el campo intelectual que bregaba por la asunción de una misión netamente cultural por parte de los artistas. En efecto, desde principios de siglo los intelectuales habían observado con recelo el desarrollo de la mayor parte de las artes del espectáculo, contraponiéndole el proyecto de un teatro producido a partir de textos dramáticos de importancia que, en lugar de expresar las formas y preocupaciones propias del público, lo eduque. Fundamentalmente, la intelectualidad aspiraba a un teatro desligado del afán comercial, al tiempo que exigía del artista su total subordinación a la comunicación del texto dramático al público, asignándole de este modo, una función social a su desempeño artístico.

No obstante, este proyecto demoró en imponerse. En primer lugar, sectores intelectuales intentaron promover una dramaturgia nacional de calidad, basándose en la creencia de que a partir de la misma la escena en su conjunto se elevaría. En cierto sentido, muchos de los dramaturgos del teatro popular pertenecían al campo intelectual o pretendían integrarlo. De todos modos, el ritmo frenético dictado por las ganancias de la actividad terminó imponiéndose en la escritura dramática de las primeras décadas del siglo XX. Sin embargo, los años 30 traerían cambios significativos, que desembocarían en el establecimiento de la preponderancia de la dimensión ética del espectáculo, largamente reclamada.

No es posible comprender el surgimiento del movimiento de teatro independiente sin tener en cuenta la paulatina diferenciación, operada en el seno de le élite, entre una cultura culta dominante y una variante denominada "intelectual", ${ }^{18}$ como resultado del desplazamiento de los intelectuales de la clase dirigente y su reemplazo por una clase netamente política (Sigal, 2002). Surgirá entonces una creciente distancia entre una visión cultural conservadora y otra progresista, vinculada con el ámbito universitario y con posiciones políticas de izquierda. No obstante, esta divergencia estético-ideológica se reduce en lo que respecta a la posición de tutelaje cultural que ambas vertientes se atribuyen y, más específicamente, a la función social, política y educativa (en tanto divulgación de valores universales, que van desde la moral, la religión, el mercado, la propiedad privada o la revolución) que los productos culturales y artísticos deben ejercer en una categoría compleja, definida como pueblo. En este sentido, es funcional el concepto de vanguardia, es decir, la idea de un grupo esclarecido que actúa como guía para el resto: "el pueblo no forja una cultura por sí mismo: son los intelectuales que representan al pueblo los encargados de fraguar la nueva cultura" (declaraciones de Héctor Agosti, en Sarlo, 1984: 22). Esto supone que los sectores populares son únicamente receptores incapaces de producir cultura, por lo que la izquierda debe asumir un "paternalismo misional" (Sarlo, 1984) que impida que dichos grupos sean captados por la hegemonía burguesa.

$\mathrm{Al}$ respecto, Ford (1985) señala que en esta postura persiste el concepto burgués de cultura como bien universal al margen de la historia, es decir, la idea de una cultura única, que acepta no obstante, dos vertientes: la elitista (diferenciadora y apropiadora) y la reformista (es decir, distributiva y, por lo tanto, imponible a otros). Conforme a esto, los intelectuales argentinos surgen en la "difusa zona cruzada por la herencia liberal y la expansión de las izquierdas" (Sigal, 2002: 62), adoptando formas de inserción en lo público típicas de los intelectuales latinoamericanos, priorizando la función social por sobre la función crítica y atribuyéndole una misión a la universidad, una misión al pueblo, a la nación, a la clase obrera y, podemos agregar por nuestra parte, a los artistas.

Uno de los exponentes fundamentales de la tendencia descripta fue el movimiento de teatro independiente, iniciado en 1930 con la fundación del Teatro del Pueblo por Leónidas Barletta. ${ }^{19}$ Poseyendo estrechas relaciones con el Partido Comunista, el
18. Distinción evocada en Sarlo (1983), Sigal (2002) y AA.VV. (1983).
19. No obstante, no fue el único proyecto de un teatro no comercial en la época. González Velazco (2012) señala que a lo largo de la década del 20 aparecieron entre veinte $y$ cuarenta cuadros filodramáticos, según se desprende de las autorizaciones de representación de obras solicitadas al Círculo de Autores. Estas solicitudes dan cuenta de que no se trataba de representaciones privadas, dado que los textos dramáticos estaban disponibles en las revistas de la época. 
Teatro del Pueblo tomó su denominación de la propuesta de Romain Rolland en su libro homónimo, y planteó la concreción de un teatro culto desligado del afán comercial y organizado en cooperativas, pero no ya para eliminar al empresario como intermediario, tal como lo habían planteado los huelguistas de los años 20 , sino para producir un teatro de corte mensajista con una función exclusivamente didácticopolítica hacia el público popular. En este sentido, el movimiento fracasó, dado que nunca llegó a ese público: en efecto, los espectadores del Teatro del Pueblo y del teatro independiente en general pertenecían a sectores medios que ya compartían su ideología política y cultural. No obstante, su ideario y modo de organización ejerció una enorme influencia en el campo cultural, al funcionar como modelo organizativo y plantear un patrón de conducta que, con los años, se tornará exigible en los artistas.

En el contexto porteño, el ideal de producir un teatro culto se identificaba con la difusión de dramaturgias consideradas valiosas (específicamente los clásicos universales y el realismo de izquierda), como modo de contrarrestar la influencia perniciosa del teatro popular. El fin último era la ilustración del espectador, tanto en el terreno cultural como político. A la puesta en escena de estas obras, se le sumaban otras actividades, como la realización de debates con el público y el dictado de conferencias. Por otra parte, Barletta desarrolló una profusa actividad de difusión y crítica a través de su prolongada labor en la revista Conducta.

Es notable que, en el afán por transmitir un teatro que fomentara la conciencia política en las clases obreras, los actores debieran responder a una apelación que los constituía como militantes y no como trabajadores. En efecto, la caracterización de la actuación como parte del mundo de la cultura y, por consiguiente, la exigencia de su total identificación con la misión que se le adjudicaba a la misma, tornaban imposible cualquier asimilación de su tarea con la de los trabajadores a los que se pretendía emancipar.

Debían subordinarse a dicho objetivo todos los componentes del hecho escénico, fundamentalmente el actor, baluarte de las formas desvaloradas de teatro que, según esta perspectiva, ejercían una influencia perniciosa en el público. Esto se evidencia en la organización interna del Teatro del Pueblo, que luego sería replicada en las agrupaciones independientes surgidas posteriormente en todo el país. Dicha estructura constaba de un director personalista en el centro, alrededor del cual se disponían los anónimos actores. La tarea de estos quedaba reducida al compromiso militante con la función atribuida al teatro, para lo cual debían comunicar el texto dramático con parquedad, ignorando los gustos del público y respetando las decisiones del director. ${ }^{20} \mathrm{El}$ resto de los deberes del actor consistía en llevar adelante todos los trabajos que demandaba el mantenimiento de la sala: limpiar, confeccionar la escenografía, el vestuario, etc.

De este modo, la condición del artista en el seno del Teatro del Pueblo era extremadamente precaria, dado que no se consideraba prioritaria su formación técnica (metodológicamente, se utilizaba la Declamación, aunque sin contar con una formación especializada en la misma, con los consiguientes resultados), los roles eran rotativos (por lo que se ignoraban las aptitudes personales y las preferencias del público) y estaba terminantemente prohibido ganar dinero con la actuación, por lo que no se le permitía profesionalizarse y, por consiguiente, sindicalizarse. Así, en un contexto signado por la precariedad laboral y los obstáculos de un arduo proceso de sindicalización, el movimiento de teatro independiente no le planteó al trabajador de la actuación otra alternativa más que el abandono de la actividad profesional en pos de una militancia de tipo político-cultural.

Resulta significativo que el Teatro del Pueblo adoptara como características organizativas tres de las estrategias utilizadas sin éxito por los actores huelguistas en 1919 y
20. El personalismo y didactismo de Barletta se manifiesta también en su Manual del Actor, en el que, además de brindar gráficos con posturas, gestos y expresiones que el actor debía ejercitar diariamente, se incluyen consejos morales y hasta de higiene. 
1921: el cooperativismo, la supresión de jerarquías internas "desde arriba" (es decir, propiciando una horizontalidad desde la instancia enunciativa del hecho escénico, aunque mantuvo la supremacía del director, pasando por alto el efecto producido por la mirada del público), y el desdén por cualquier tipo de intervención estatal en su actividad.

No obstante, debemos hacer una salvedad en este último punto, dado que en $1937 \mathrm{el}$ Concejo Deliberante cedió a los insistentes reclamos de Barletta, concediéndole el uso del recientemente expropiado Teatro Nuevo, por el prolongado plazo de veinticinco años. Si bien el mismo no llegó a cumplirse, ${ }^{21}$ el otorgamiento de la sala por parte del Municipio no deja de ser significativo. Según Bayardo (1990), esto se explica por la acción de los concejales socialistas, quienes promovieron la sesión de locales a los primeros grupos de teatro independiente. No obstante, el ideal cultural del Teatro del Pueblo se hallaba en consonancia con otros sectores de la intelectualidad, no sólo vinculados con la izquierda. Ejemplo de ello son los elogios que Victoria Ocampo le dedicó desde Sur, objetando sólo los precarios medios materiales y estéticos con los que contaban su sala y sus puestas en escena. Incluso Ocampo fue invitada por Barletta a dictar algunas conferencias en el marco del vasto programa cultural del Teatro del Pueblo.

Por otra parte, uno de los argumentos más socorridos para abogar por la implementación del trabajo asociativo en el teatro, desde principios del siglo XX, había consistido en que la exclusión del empresario como organizador de la actividad liberaría al teatro del afán de lucro y lo dejaría sólo a merced de los elevados intereses artísticos de los creadores. Así, para la dirigencia de la temprana Sociedad Argentina de Actores, la eliminación de la instancia capitalista en el mundo del espectáculo, junto con una postura de férrea autonomía ante el Estado, garantizaría la decisión libre y emancipada de los artistas para conformar y gestionar cooperativas organizadas según el modelo de otros trabajadores, mediante las cuales obtener los medios para su subsistencia.

Sin embargo, el modelo de cooperativa adoptado por el teatro independiente se apartó de la norma y fue sumamente singular. ¿En qué consistió dicho modelo?

Llegados a este punto, creemos oportuno recurrir a la caracterización realizada por el cooperativista Emilio Bottini (1950). Entre los principales objetivos del cooperativismo, el autor destaca, por un lado, la generación de recursos económicos:

[Las cooperativas] tratan de conseguir que cada grupo o categoría de personas asociadas se baste a sí mismo [...] El cooperativismo es un movimiento social tendiente a procurar a quienes lo practican ventajas económicas inmediatas y a mejorar sus relaciones morales (1950: 156 y 163).

Por otra parte, la neutralidad política y religiosa:

El cooperativismo encierra un fin en sí mismo, en el sentido de que no es un medio para allegar recursos o reunir adeptos para diversos fines de propaganda política, religiosa o de nacionalidad. En este sentido los cooperadores sostienen la neutralidad, porque sus propósitos son amplios y generosos, pues aspiran a comprender a toda la población [...] La ley 11388, sobre el régimen legal de las sociedades cooperativas, ha establecido que éstas no podrán tener por fin principal ni accesorio la propaganda de ideas políticas, religiosas, de nacionalidad o regiones determinadas (Bottini, 1950: 156 y 162).

Según la caracterización realizada por el autor, las cooperativas del teatro independiente no cumplían con ninguna de estas dos características principales, dado que
21. Dado que en 1943 el gobierno de facto de Pedro Pablo Ramírez ordenó el desalojo del Teatro del Pueblo, en parte por cuestiones ideológicas y en parte por el proyecto de instalar allí el Teatro Municipal, que se abrió en 1944 y que constituirá el germen del Teatro Municipal General San Martín. 
no sólo no buscaban la generación de recursos económicos para que sus miembros se bastasen a sí mismos, sino que además lo prohibía (expulsando a los actores que incumplían esta exigencia). Por otra parte, su fin explícito era la transmisión de contenidos ideológicos al público.

Sin embargo, ésta es la concepción del cooperativismo adoptada por el Teatro del Pueblo y que luego se impuso en el resto del movimiento independiente. Este tipo de organización cooperativa nunca se plantó como objetivo generar recursos económicos para distribuir entre sus miembros, cuya manutención debía ser garantizada mediante actividades extra artísticas. Estas cooperativas eran de carácter informal, no estaban registradas y no formaban parte del movimiento cooperativista existente en el país. Y si bien, en teoría, estas agrupaciones contaban con una conducción de tipo asambleario, en los hechos la toma de decisiones estaba fuertemente dominada por el director. Por otra parte, la gratuidad del trabajo era agravada por la exigencia de anonimato, lo cual le escamoteaba a los artistas la posibilidad de acceder a una retribución simbólica por su labor (con la que sí contaban el responsable de la puesta en escena, los dramaturgos y aquellos artistas visuales que decidían colaborar con las agrupaciones, como es el caso de reconocidos escenógrafos). Por último, consideramos que el desdén por la formación metodológica específica también constituye un importante indicador de precariedad laboral.

Merced a la enorme difusión y prestigio que alcanzaron tanto el Teatro del Pueblo como las agrupaciones independientes que le siguieron, en nuestro campo cultural, la renuncia a la generación de recursos económicos desarrolló un persistente imaginario en el que las relaciones de producción son desplazadas al exterior de la actividad artística. Según el mismo, no hay relaciones de clase dentro del teatro, dado que las mismas se hallan en el ámbito exterior. El artista es un militante que debe ofrendar su desempeño a la educación y emancipación de los sectores de la sociedad afectados por esas relaciones de clase, lo cual crea claramente una división entre un nosotros emancipado y un ellos sometido.

\section{III.}

El éxito en la imposición del ideal ético en el teatro no sólo se debió al surgimiento de la escena independiente, sino también a los cambios operados en los gustos y en el horizonte de expectativas del público (Jauss, 1976). Estos cambios fueron consecuencia directa del ascenso social de la nueva generación, lo que se tradujo en la constitución de una clase media, alejada ya de la experiencia inmigratoria de sus padres. La conformación de la clase media se sustentó en el acceso a la educación, como consecuencia directa de la Reforma Universitaria de 1918, y, paulatinamente, a la vivienda propia. Por otra parte, y aún con la crisis económica como factor retardatario, diversas conquistas laborales beneficiaron notablemente a algunos trabajadores, al tiempo que aumentó el número de propietarios de pequeños comercios.

En efecto, varias son las mejoras en las condiciones laborales, fundamentalmente para los trabajadores calificados. En 1929 se aprueba la ley de jornada laboral de ocho horas, en 1932 se implementa el sábado inglés y en 1934 el Sindicato de Comercio logra las vacaciones pagas para su sector (González Leandri: 2001). No obstante, esto beneficia sólo a unos pocos gremios. En la mayoría, la falta de convenios colectivos seguía propiciando conductas unilaterales por parte de la patronal (Baranchuk, 2016). Por otra parte, la crisis del 30 ocasionó el derrumbe del modelo agro-exportador y el inicio de la sustitución de importaciones concentrada en la Ciudad de Buenos Aires, lo que ocasionó la afluencia de mano de obra rural sin experiencia sindical. 
En este contexto, y luego de varios intentos, se logra crear la Confederación General del Trabajo (CGT), que agrupa a todos los gremios. Su programa de 1931 incluye por primera vez al Estado en las relaciones laborales con una presencia desconocida hasta entonces (Baranchuk, 2016). Entre sus puntos figura la vigilancia por parte de los sindicatos de la aplicación de la legislación social, la jornada de trabajo de ocho horas en trabajos diurnos y seis en trabajos nocturnos e insalubres, el ciclo semanal de cinco días como máximo, las vacaciones pagas con goce de sueldo, el seguro social, de desocupación, enfermedad, vejez y maternidad, el salario mínimo y la extensión de la ley de accidentes de trabajo a todos los asalariados indistintamente.

En 1940 comienzan a dictarse estatutos especiales (como el bancario, el del trabajo a domicilio, etc.), y entre 1941 y 1946 se desarrolla la concentración sindical por ramas. Si bien hasta mediados de los años 30 el movimiento obrero estuvo hegemonizado por socialistas y comunistas, para 1943 la CGT se divide: La CGT ${ }^{\circ}{ }_{1}$, que constituye un neosindicalismo con propuestas reivindicativas de tipo gremial y prescindencia de partidos políticos, manteniendo relaciones afables con el gobierno de turno (Baranchuk, 2016), y la CGT $\mathrm{N}^{\circ}$, que promueve el involucramiento en la política nacional e internacional y el apoyo comunista.

Lo cierto es que se estima que los sectores medios pasaron a constituir el $46 \%$ de la población de la Ciudad de Buenos Aires. El abandono del conventillo y el pasaje a la vivienda unifamiliar, promovió el desarrollo de barrios alejados del centro y propició nuevos modos de convivencia. Así, los vínculos establecidos en el barrio reemplazaron a los establecidos en el patio del conventillo o en el pueblo de origen. Se inició una marcada inquietud asociativa (en principio para subsanar las faltas del barrio a través de acciones colectivas), que creó lazos de solidaridad, al tiempo que favoreció la generación de jerarquías y tensiones, la formación de estereotipos sociales y de élites barriales.

Las modificaciones experimentadas por los sectores medios no sólo repercutieron en su forma de vida y de socialización, sino también en sus modos de esparcimiento, lo cual influenció directamente en sus gustos, preferencias y prácticas de consumo cultural que, en gran medida, se hicieron eco del ideal cultural propuesto por la élite intelectual. Como corolario, se produjo un paulatino declive del teatro como forma popular de entretenimiento, pasando a competir, ahora sí desventajadamente, con el cine, la radio y el espectáculo deportivo, e inclusive con un nuevo estilo periodístico de corte sensacionalista. Coincidimos con González Leandri (2001) cuando plantea que también desde el Estado se inició un proceso de conversión de las clases populares en público, favoreciendo las formas de participación imaginaria propias del consumo de las industrias culturales en una sociedad de masas.

Esto perjudicó directamente a las artes del espectáculo, dado que dificultosamente pueden encuadrarse en parámetros industriales. Así, mientras Caudarella (2016) afirma que entre 1925 y 1927 la audiencia teatral se redujo un $16 \%$ y la recaudación, un $42,82 \%$, Klein (1988) sostiene que el número de espectadores descendió de siete millones registrados en 1928, a aproximadamente la mitad para 1933.

Las condiciones laborales, por consiguiente, empeoraron drásticamente: se incumplen contratos, se rebajan salarios y se interrumpen temporadas. Según González Velazco (2012), lo que estaba en retirada era un tipo de funcionamiento (por secciones) y un tipo de género (el género chico), dado que surgieron nuevas propuestas, como la comedia y la revista, y otro tipo de organización. El mismo tendía a las funciones estrictamente nocturnas (por consiguiente, sólo se hacían una o a los sumo, dos por día), para un público que se desplazaba especialmente desde los barrios al centro para asistir al teatro. 
Por consiguiente, entre 1930 y 1933 muchas compañías se disolvieron y se produjo un sostenido éxodo y/o la dedicación paralela de los actores en los nuevos medios, fundamentalmente la radio, que se masificó y cuyas emisiones se sostenían a través de la publicidad de anunciantes. También surgieron los teatros barriales, que comenzaron a replicar la organización de los céntricos, restándoles convocatoria. Además de que las mismas obras eran puestas en las salas barriales con leves modificaciones para evitar el pago de derechos de autor, estos teatros eran alentados por una política impositiva desigual, hechos que fueron tempranamente denunciados (Caudarella, 2016). ${ }^{22}$

El surgimiento del teatro barrial se combinó además con el fenómeno de la radio: en efecto, los radioteatros de mayor convocatoria realizaban giras, generalmente los días lunes. Por otra parte, muchas salas se convirtieron exclusivamente a la exhibición de filmes:

\section{Si bien los cinematógrafos y los teatros competían por el favor del público, para muchos empresarios eran, en realidad, dos caras de la misma moneda [...] a juzgar por la cantidad de entradas que se vendían en los cinematógrafos y las ganan- cias que generaba, sin dudas era el negocio al cual había que apostar (González Velazco, 2012: 60).}

Ya en 1925 se contabilizaban treinta y nueve cinematógrafos, que paulatinamente comenzaron a acondicionarse para mejorar la calidad del servicio. También la producción cinematográfica nacional se acrecentó y se institucionalizó: ${ }^{23}$ en 1933 se crearon Argentina Sono Film y Lumiton. De este modo, la producción de filmes pasó de trece títulos en 1933 a medio centenar, hacia el final de la década.

Como corolario, numerosas publicaciones dedicadas al teatro desaparecieron: Bambalinas, La Escena, Anuario Teatral Argentino y Comoedia. La revista La Escena publicó el siguiente anuncio en 1933: "Debido a la persistente crisis teatral y a la escasa producción de obras de éxito, La Escena suspenderá las ediciones semanales que ha venido publicando, sin interrupción, desde hace dieciséis años" (La Escena, $\mathrm{N}^{\circ} 797$, 5/10/1933). En su lugar, surgieron y cobraron protagonismo diversas publicaciones que difundían la actividad cinematográfica y radiofónica, como Astrolandia, Micrófono, Sintonia, El Heraldo Cinematográfico, Antena, Film, Excelsior, etc. (González Velazco, 2012). Por último, y como dato significativo, en 1932 se inaugura el Luna Park, ámbito emblemático del boxeo, espectáculo deportivo de enorme convocatoria.

La gravedad de la situación no pasó desapercibida para los diversos agentes vinculados con las artes del espectáculo, ya desde finales de la década del 20. Aunque puede percibirse cierta desorientación respecto de las razones de la crisis y las posibles salidas de la misma. Así, el Anuario Teatral Argentino de 1927 responsabiliza a los empresarios:

Si el año 1926 se caracterizó por la vacilación de los empresarios en su conducta artística, el de 1927 no alcanzó a despejar la incertidumbre en esa conducta, y aún más: demostró la desorientación general, con el resultado desagradable de la deserción del público [...] Del panorama general surge la comprobación que no es dable esperar confiados mejores tiempos, sin la intervención de algo o de alguien; la reacción no podrá ya operarse por sí sola. Hacen falta resoluciones categóricas de entidades e individuos, si se quiere devolver al teatro nacional su público adicto y ya cansado de tanta tentativa vergonzosa, destinada únicamente a exprimirle los bolsillos (en Caudarella, 2016: 30-31, la cursiva es nuestra).

Se observa en estas afirmaciones una confusión entre motivos estéticos y económicos para explicar el cambio en las preferencias del público, al tiempo que se vislumbra, sin mencionarla explícitamente, la necesidad de la intervención del Estado.
22. Por ejemplo, en el diario $L a$ Argentina, 6 de abril de 1927.

23. Este aspecto es analizado en profundidad por Casale, “El actor en el star system argentino. ¿Trabajador privilegiado o mero producto?", en el presente dossier. 
Otros sectores les atribuyen la responsabilidad de la crisis a los autores. En 1927, el periódico Carátula publica un análisis en el que plantea que el conflicto entre los autores $^{24}$ se debió a la demagogia y vanidad de unos y otros, y al egoísmo poco inteligente de los empresarios y los actores-empresarios. Pero si el conflicto inicial había sido pequeño, se volvió más grande cuando se extendió a todos los gremios del quehacer teatral cristalizándose en la Federación Gente de Teatro (Caudarella, 2016). Según el diario, la Federación afectó muy ampliamente al teatro con consecuencias que fueron más allá de la temporada

Destruyó, y para siempre, el espíritu de cuerpo de toda una generación de autores. Viniéronse abajo la camaradería, la solidaridad intelectual, el sentimiento de comunidad en materia de intereses, la fuerza, la salud, la confianza y el optimismo que nacen de la unión confraternal [...] No previeron, posiblemente, el cariz que tomó aquella protesta. No sospecharon, seguramente, que el público, incapaz, por tendencia, de revolverse airado contra los insolentes que se atrevería a hacerle perder tiempo con sus remedos y refritos, iba a alejarse de las salas, dejando solos a los malos pero sin reponer en los carteles a los buenos (“El desbande”, Carátula, 3/12/1927)

Fue el propio Círculo de Autores el que en 1932, y ante la gravedad de la crisis, convocó a la organización de una Convención de Autores, Actores y Empresarios con el objeto de tratar los problemas que afectaban a la actividad y crear un frente único de gremios. El encuentro logró consensuar algunos puntos: reclamar por el alto precio de los alquileres de las salas y sustituir el alquiler por un sistema a porcentaje, solicitar al gobierno municipal una reforma de la Ordenanza General de Teatros en lo referente a las condiciones de habilitación, los impuestos cobrados y la aplicación de la censura, y reclamar por la inconveniencia de los espectáculos mixtos de cine y teatro (González Velazco, 2012). Sin embargo, no se llegó a un acuerdo acerca de la propuesta de los autores de que se considerara obligatoria la contratación de un director artístico, dado que los empresarios y los actores se negaron. Esto provocó que los autores se retiraran y el convenio se disolviera. En medio de la crisis, cada sector buscó entonces dar respuesta a sus propias dificultades.

En 1934, los autores lograron reunificar a las dos entidades en ARGENTORES. Además de la crisis, Baranchuk (2016) estima que esta fusión fue promovida por la sanción de la Ley de Propiedad Intelectual en 1933, que contemplaba a los autores, guionistas, directores, productores de cine y compositores musicales. ${ }^{25}$ Lo cierto es que, tal como lo señala Caudarella (2016), los autores se reunificaron cuando el teatro nacional ya estaba transitando una profunda declinación.

Este es un momento de crisis muy profunda dentro del gremio actoral, no sólo por los altísimos niveles de desocupación entre sus afiliados, sino por el surgimiento de ámbitos de trabajo que no contaban con representación sindical ni con normativa alguna, como la radio y el cine. Según Klein (1988), en 1933 sólo trabaja el 36\% de los mil ochocientos afiliados a la Sociedad Argentina de Actores, lo que no incluye a los setecientos artistas que se desempeñaban en la radio y en el cine.

En 1935, nuevamente surgen disputas acerca del perfil que la Sociedad Argentina de Actores debía adoptar. Habiendo ganado nuevamente la opción por el mutualismo, los grupos gremialistas organizan el Sindicato Argentino de Actores. El mismo tiene la particularidad de incluir como socios pasivos, sin voz ni voto, a los actores devenidos ocasionalmente en empresarios. El principal conflicto continúa siendo el del descanso semanal, que se consigue implementar a partir del $1^{\circ}$ de enero de 1936 en la Capital Federal y que luego buscará extenderse a las provincias. Sin embargo, en medio de la crisis la división dura sólo dos años, volviendo a fusionarse en 1937 en la Asociación Argentina de Actores (AAA), con el fin de fortalecer la lucha.
24. En referencia a la división de los mismos entre la Sociedad Argentina de Autores y el Círculo de Autores, analizado en profundidad en el artículo de nuestra autoría "Identidades y apelaciones antagónicas I ¿Artistas, productores o trabajadores? (1902 -1930)", en el presente dossier.

25. Lo que también propició la conformación de SADAIC, Sociedad Argentina de Autores Compositores de Música, que reunió a la Sociedad de Autores y Compositores de Música con el Círculo Argentino de Autores y Compositores de Música. 
En 1938, se inaugura finalmente la Casa del Teatro, que funcionará como paliativo a la falta de jubilación, y al tiempo, la Colonia de Vacaciones "Gente de Teatro", en la Ciudad de Villa María, construida conjuntamente por la AAA, ARGENTORES y la SADET (Sociedad Argentina de Empresarios Teatrales), con apoyo del gobierno de la provincia de Córdoba. La previsión social se intentará implementar dos años más tarde, al firmarse un acuerdo con los empresarios para destinar parte de la recaudación a tal fin.

Para la dirigencia de la AAA la solución a la situación imperante seguía consistiendo en la eliminación de la organización del teatro como actividad comercial comandada por el empresariado y su sustitución por una de carácter cooperativo. Para Héctor Ugazio, bibliotecario del gremio, la cooperativa constituye

Una fuerza de organización del trabajo en el aspecto artístico y económico (que) está por encima de cualquier empresa capitalista [...] que sin egoísmos... sin vanidad..., llegaremos a tener intérpretes para el autor; obras para el actor y teatro para el pueblo (Boletín de la Sociedad Argentina de Actores, № 7, 1/3/1929).

Es así como en 1943, la AAA tomó la iniciativa de organizar cooperativas que actúen por las provincias, para lo cual aportó \$20.000 de su caja social. Se formaron cuatro compañías con un total de noventa actores. El resultado arrojó una pérdida de \$31.500. El gremio evaluó que las causas de semejante fracaso consistieron en la imposibilidad de conseguir espacios teatrales, tomados por las empresas cinematográficas, y en la falta de apoyo de las autoridades locales (Klein: 1988). Vemos cómo nuevamente se adoptó la estrategia implementada durante las huelgas de los años $20,{ }^{26}$ pero con el agravante de que las cooperativas salieron a competir a un mercado que para estos años estaba en baja. El resultado fue, nuevamente, el fracaso económico.

Con respecto al Estado, éste persistió en su política de no intervención en las condiciones laborales de los artistas. De hecho, durante la década se registran dos intervenciones adversas a sus reclamos. Por un lado, la justicia excluye a los empresarios teatrales de la Ley de Quiebras, alegando que los mismos no lucran con el trabajo de los artistas (fallo publicado en El Cronista Comercial, 19/6/1936). Por otra parte, el Congreso Nacional no da tratamiento al proyecto de ley del diputado socialista Carlos Moret, que propone equiparar la condición del actor con la del empleado comercial (Klein, 1988).

El Estado municipal, por su parte, optó por brindar ventajas impositivas a las empresas teatrales. Es así como en 1937 sanciona dos ordenanzas al respecto. Una de ellas dispone le reducción del $90 \%$ de los impuestos a las compañías conformadas en sus dos terceras partes por artistas argentinos, y que ofrecieran un repertorio nacional en igual proporción que el extranjero (Pitaco, 1969). La otra, dispuso un recargo del 50\% de los impuestos para las compañías internacionales con más de 75 días de actuación, la mitad del cual se destinó proporcionalmente a la Caja de Socorros de la AAA y a la Casa del Teatro, que se inauguraría al año siguiente (Pitaco, 1969).

Estas disposiciones municipales se hallaban en consonancia con la dirigencia del gremio. En efecto, la propia AAA se manifestaba a favor de la obtención de beneficios en materia impositiva y edilicia, pero continuaba reivindicando a la actividad artística como autónoma respecto a cualquier política cultural estatal. De este modo, Orestes Caviglia afirma

Para mejorar el nivel artístico de nuestra escena, nos parecería oportuno separar netamente el arte del "negocio". Podría la municipalidad permitir la habilitación de salas menores (...) y destinaríamos esas salas al arte, sin el obstáculo que comporta un fuerte alquiler. Libre de impuestos, esas salas menores podrían cobijar iniciativas interesantes (Crítica, 2 de agosto de1932).
26. Aspecto analizado en profundidad en el presente dossier. Ver "Identidades y apelaciones antagónicas I ¿Artistas, productores o trabajadores? (1902 -1930)", de nuestra autoría. 
Es así como el 2 de agosto de 1940 el gremio solicita al Concejo Deliberante la cesión del solar de la Avenida Corrientes 1571, invocando la reciente pérdida de tres salas (Sarmiento, Buenos Aires y Comedia) debido al ensanche de la Avenida 9 de Julio, y el antecedente de la "eliminación comercial del 'Teatro Nuevo', adquirido por la Municipalidad y cedido graciablemente a otra institución" "Boletín oficial del HCD del 2 de agosto de 1940", reproducido en Máscara 1 (1), 17), en referencia al otorgamiento de dicha sala al Teatro del Pueblo en 1937.

No obstante, para 1942, se registrará un cambio significativo en la posición de los actores ante la intervención estatal. En primer lugar, y tras una dificultosa negociación con los empresarios, se establecieron nuevas Bases de Trabajo y el Contrato Único, largamente ansiado por la Asociación. Las nuevas cláusulas incluyen un número mínimo de trabajadores y la duración de la temporada, y días y horarios de ensayo. No obstante, una vez más las mismas son incumplidas, por lo que la Asociación recurre al Congreso Nacional. En efecto, la desigualdad de fuerzas entre los sectores en conflicto, lleva a la AAA a comprender finalmente, que sólo la intervención del Estado en favor de los trabajadores podría garantizar términos justos de negociación. El gremio reclama también por la situación del teatro en las provincias, exigiendo la rebaja en las tarifas ferroviarias y la exención de impuestos provinciales, apoyando el pedido con el ejemplo de las políticas aplicadas por los Estados de Brasil, Chile, México y Colombia.

Un año antes, y con motivo de la celebración del Primer Congreso de Teatro Rioplatense en Montevideo, la Asociación Argentina de Actores había presentado una serie de propuestas significativas en este sentido y que demuestran una clara sensibilidad para comprender la coyuntura. Se estima que la dirección e iniciativa de la escena nacional debe ponerse en manos del Estado, dado que la organización de la misma como actividad privada estaba agotada, incapaz de competir con el cine. Se toman como ejemplo los Teatros Federales de Norteamérica que, subvencionados por el Estado, recorren el país:

De esta manera se combate la desocupación, se fiscaliza el buen teatro, sustrayéndolo de las exigencias de boletería, y se utiliza muy bien un irremplazable instrumento de cultura popular ("Ponencia presentada por la AAA en el Primer Congreso de Teatro Rioplatense", Montevideo, 1941, cit. en Klein: 1988: 52)

De todos modos, es necesario hacer una salvedad en este sentido. Si bien el gremio actoral plantea la exigencia de una política estatal en materia de teatro, se deja en claro que la misma debe limitarse a la financiación de proyectos (fundamentalmente mediante la programación de los teatros oficiales) y a la implementación de medidas de fomento (exención de impuestos, rebaja en los transportes para las giras, sesión de salas municipales, otorgamiento de subsidios, etc.). Por consiguiente, en la inédita interpelación que la AAA dirige al Estado, dado que históricamente se había mostrado muy reticente a cualquier intervención en la actividad teatral, resulta ostensible la posición de la comisión directiva del gremio: el Estado debe aportar subsidios o beneficios económicos que permitan sostener una actividad teatral autogestionada por los trabajadores, pero de ninguna manera se tolerará la injerencia en la decisión sobre formas y contenidos, que debe quedar en la órbita de la creatividad e ideario de los artistas. Esta postura se halla en consonancia con lo que González Leandri (2001) caracteriza como una marcada relación pragmatista de los grupos medios con el Estado, que a partir de los años 30 deja de ser percibido como un enemigo para pasar a constituir un instrumento político del cual obtener beneficios.

Así, tanto para proteger la actividad teatral, como ya se estaba haciendo en otros países, como para obtener una legislación favorable, a principios de los 40 se vislumbra 
la necesidad del Estado. Pero al mismo tiempo, y muy influenciada por la tradición ideológica de la que provenía, la dirigencia de la Asociación Argentina de Actores se mantuvo muy reticente a la intervención estatal, conflicto que va a manifestarse explícitamente, por supuesto, con el surgimiento del primer peronismo.

\section{IV.}

Como ya ha sido señalado en numerosos estudios, el peronismo se propuso intervenir en todos los órdenes de la vida pública. En sintonía con un panorama internacional caracterizado por una tendencia intervencionista, que desembocará en la consolidación del estado de bienestar keynesiano durante la posguerra, la llegada de Juan Domingo Perón a la vida política argentina estará marcada por la conducción gubernamental del destino de una sociedad que ya poseía características de masas y que vivía un proceso de migraciones internas. En este contexto, el Estado asumió un proyecto de "democratización del bienestar" (Torre y Pastoriza, 2002) basado en el acceso de todos los sectores a los derechos y a los bienes, propugnando a la justicia social como argumento legitimante.

Para ello, el mundo del trabajo será, entonces, un sector clave. Es por este motivo que durante el primer peronismo se producirán numerosos avances en lo que respecta a la legislación laboral y al efectivo cumplimiento de la normativa existente previamente. Luego del golpe de estado de 1943 , y mediante el Decreto-Ley $\mathrm{N}^{\circ} 15074$, se creó la Secretaría de Trabajo y Previsión que suplantó al Departamento Nacional de Trabajo, y que será elevada a la categoría de Ministerio en 1949, con Perón ya como presidente. Durante su desempeño como Secretario, Perón impulsó la creación de sindicatos nuevos, la confección de estatutos especiales (los casos del Estatutos del Peón Rural y del Estatuto del Periodista, confeccionados en 1944, tuvieron además una fuerte implicancia simbólica), y reforzó las relaciones con la CGT No${ }^{\circ}$. Para 1947, el movimiento sindical se unifica y la CGT participa en la construcción de federaciones obreras y en la fusión de sindicatos autónomos con área de actuación nacional. Para 1949 el movimiento obrero organizado se consolida como rama y columna vertebral del peronismo (Baranchuk, 2016).

En cuanto a la legislación, podemos citar el Decreto-Ley 1740 de 1945, que dictamina el derecho a gozar de un período mínimo y continuado de vacaciones pagas, y el Decreto-Ley 33302 del mismo año, que impulsa el sueldo anual complementario y la creación del Instituto Nacional de Remuneraciones, encargado de adecuar los salarios al costo de vida, entre otras funciones (Baranchuk, 2016). En 1947, y ya con Perón en la presidencia, de proclama la Declaración de los Derechos del Trabajador, que incluye el derecho a trabajar, a la retribución justa, a la capacitación, a las condiciones dignas de trabajo, a la preservación de la salud, al bienestar, a la seguridad social, a la protección de la familia, al mejoramiento económico y a la defensa de los intereses profesionales. En 1949, estos derechos son incorporados a la nueva Constitución Nacional. En 1953, se sanciona la Ley $\mathrm{N}^{\circ} 14250$, que regula la negociación de los contratos colectivos de los trabajadores de la actividad pública y privada, instalando a las paritarias como núcleo central de la relación entre trabajo y capital (Baranchuk, 2016).

Por supuesto, el proyecto peronista también incluía a la cultura. ${ }^{27}$ De este modo, se implementaron políticas para promover que sectores sociales que hasta el momento no habían tenido acceso a determinados bienes culturales, se conviertan en consumidores y también, aunque en menor medida, en productores de los mismos. Las políticas en materia cultural se basaron fundamentalmente en el incremento del gasto público destinado al área y en la creación de una serie de dependencias estatales, que tenían por objeto instrumentar las diversas actividades planificadas, en pos de la
27. Esto también replicó lo sucedido en otros países. Entre 1935 y 1943 funcionó en los EEUU el primer programa federal de financiamiento de las artes, mientras que en Brasil la constitución del Estado Novo (1937) estipuló el deber estatal de contribuir al desenvolvimiento cultural. También en Inglaterra comenzó a discutirse el patronazgo estatal en la década del 30 (Fiorucci, 2008). 
democratización y federalización de la cultura: la Secretaría de Educación de la Nación, pronto convertida en Ministerio, y la Subsecretaría de Cultura, que luego pasaría a tener carácter de Dirección Nacional. Además, se realizaron cambios en la estructura organizativa de la Comisión Nacional de Cultura y en la Subsecretaría de Informaciones.

En un campo cultural que se había fundado en la tradición liberal y que asumía su autonomía como principio inalienable y valor supremo, este proyecto no podía suscitar más que conflictos. Coincidimos con Fiorucci (2008) cuando afirma que independientemente de los valores simbólicos en pugna, cualquier intento de organizar la cultura bajo la égida estatal implicaba arrebatarle dicha potestad a la élite que la había detentado hasta el momento y que contaba con un amplio acuerdo ideológico respecto a su centralidad. La autora sostiene que el patronazgo estatal de la cultura ha generado conflictos allí donde ha sido planteado, por el temor que suscita que la misma quede subsumida a una lógica político-instrumental. No obstante, agrega que la coordinación cultural estatal creció en paralelo con el surgimiento de los estados benefactores, porque ofrece ventajas financieras y de recursos, y porque permite poner en marcha un proyecto cultural capaz de representar a la nación y no tan sólo a una clase social.

El peronismo intentó que los intelectuales y artistas se sumaran a su gesta. Pretendía que su política cultural lograra, sino la centralidad del campo intelectual, cuando menos la aceptación del sector que la ostentaba. No obstante, la negativa del mismo fue mayoritaria y categórica, asumiendo en varios casos, una postura de oposición frontal. La suerte corrida por la Junta Nacional de Intelectuales es un elocuente ejemplo. La misma fue creada en 1948 con el objetivo de ampliar los beneficios laborales obtenidos por los trabajadores a quienes se desempeñaban en el ámbito de la cultura, para paliar así la "situación de injusta pobreza" en que los intelectuales desarrollaban su tarea, "rayana a menudo en la indigencia" (Decreto $\mathrm{N}^{\circ}$ 15484, 28/5/1948, Boletín del Ministerio de Educación, $\mathrm{N}^{\circ}$ 5: 1530). Sin embargo, la Junta nunca consiguió despertar la adhesión de sus potenciales beneficiaros y terminó disolviéndose en 1953, aunque habían sido los mismos intelectuales quienes habían reclamado a Perón por la precariedad de su situación (Fiorucci, 2008). Tal como lo señala Cadús, ${ }^{28}$ algo similar sucedió con el anteproyecto del Estatuto del Trabajador Intelectual, cuyas reminiscencias con el Estatuto del Peón Rural habrían provocado el rechazo de quienes serían favorecidos por el mismo. En ambos casos, resulta significativa la negativa de los intelectuales a responder a una interpelación que los identificaba como trabajadores, lo que se replicaría en el caso de los actores.

La política cultural peronista debe entenderse en el contexto de una sociedad de masas, en la que el espectáculo artístico en vivo ya no era una de las formas privilegiadas de entretenimiento. Es comprensible entonces que la radio y el cine fueran los ámbitos donde se produjo la mayor vinculación entre el colectivo artístico y el gobierno. Este apeló a los artistas en tanto trabajadores, convocándolos a participar en un proyecto colectivo en el que su especificidad laboral se enunciaba como necesaria. Este aspecto fue novedoso con respecto a la apelación del teatro independiente, que buscaba subordinar dicha especificidad a un fin didáctico-emancipatorio.

Como Secretario de Trabajo y Previsión (1943-1945), Perón intentó establecer vínculos con la colonia artística, iniciativa que se intensificará durante sus dos primeras presidencias (1946-1955). Son conocidas sus visitas a Radio Belgrano y a Argentina Sono Film, ${ }^{29}$ y su participación en la organización del evento realizado en el Luna Park con el fin de recaudar fondos para las víctimas del terremoto de San Juan, del
28. Ver "Las condiciones laborales de los/as bailarines/as durante la primera mitad del siglo XX", en el presente dossier.
29. Cabe destacar que concurrió allí invitado por sus propietarios, los hermanos Mentasti, y que Raúl Apold se desempeñaba como Jefe de Prensa de dicha empresa. 
que participaron varios artistas. Es en dicha oportunidad que conocerá a Eva Duarte, actriz con desempeño en teatro y cine, pero fundamentalmente, en radioteatros, quien se desempeñaba como presidenta de la ARA (Asociación Radial Argentina), fundada algunos meses antes. También como Secretario, Perón se acercó a sindicatos vinculados al mundo del espectáculo, como SADAIC (Sociedad Argentina de Autores y Compositores) y la misma AAA.

Incluso intervino en algunos conflictos. En noviembre de 1943, conminó a los empresarios teatrales a abonar sumas adeudadas a cuarenta afiliados de la AAA y, un mes más tarde, actuará como mediador en el conflicto surgido entre Actores, ARGENTORES y la SADET. El Secretario instó al cumplimiento de los pactos intergremiales, para lo cual se firmó un acuerdo conocido posteriormente como "el convenio Perón" (Klein, 1988). El convenio, cuya duración se fijó en diez años, disponía que las tres entidades se reconocieran mutuamente como representativas en futuros conflictos, lo cual desactivó la socorrida estrategia empresarial de negarle legitimidad al gremio actoral (tal como había sucedido en las huelgas de 1919 y 1921). Además, se conformó un tribunal con delegados de cada parte y presidido por un representante de la Secretaría, y se fijó una recaudación para ser destinada a la caja de jubilaciones y pensiones. En 1945, y ante la ausencia de la SADET ante reiteradas citaciones de la Secretaría, se firma un convenio en el que se incrementa la temporada mínima de cuarenta a noventa días, se fija el pago de un depósito de garantía por parte de las empresas teatrales y se aumenta el sueldo mínimo.

En 1944 y aprovechando el vínculo establecido con Perón, la AAA le presentó un informe de la precaria situación del teatro, en el que solicitaba la creación de fuentes de trabajo y la regulación oficial de las condiciones laborales (Klein, 1988). Poco después, el gremio le entregó un nuevo petitorio, instando a la regulación estatal de la actividad teatral y sugiriendo la eliminación del intermediario y su sustitución por un sistema de cooperativas, ideal largamente perseguido por el gremio a pesar de los resultados adversos obtenidos en los intentos de implementación anteriores (algunos de ellos, recientes, como el citado más arriba, que meses atrás había arrojado una importante pérdida monetaria). Otras propuestas incluidas en el documento fueron la constitución de dos elencos para el Teatro Nacional de Comedias y dos para el Teatro Municipal (uno en sala y otro en gira), el establecimiento de un plazo máximo para la presentación de compañías extranjeras (treinta días en Capital Federal y noventa en provincias), la regulación sobre el alquiler de salas y la supresión de impuestos para las empresas que realicen temporadas superiores a ocho meses. Si bien el petitorio no tuvo respuesta, las relaciones de la AAA con el Secretario de Trabajo y Previsión se mantuvieron cordiales, al punto que el mismo asistió al Festival organizado con motivo del $25^{\circ}$ aniversario del gremio (Klein, 1988).

Ahora bien, en este punto creemos oportuno profundizar en el modelo económico impulsado por el gobierno y en el lugar que les cabía a las cooperativas en el mismo. El peronismo histórico buscó impulsar la aplicación de la denominada economía social, "concebida como una tercera vía, en la que coexisten los sectores privado capitalista, cooperativo y público, bajo el arbitraje tutelar del Estado" (Mateo, 2013: 79). Al respecto, Rivera afirma:

Desde ya, una economía social no importa una economía sin capital o sin capitalistas [...] la economía social no propugna la desaparición del capitalista, sino la limitación de los poderes absolutos que se asignó bajo el pretexto de los principios liberales [...] Una ciencia o una política económica que prescinda de la apetencia humana por las riquezas materiales, será tan falsa e infructuosa como aquella que despoje al hombre de todo sentido de solidaridad o de todo otro impulso o razón de hacer que no sea el mero incremento de sus riquezas personales (1950: 127 y131). 
Aunque el gobierno peronista apoyó la formación y el funcionamiento de cooperativas de producción, sobre todo en el mundo agrario, ${ }^{30}$ resulta evidente que no estaba en el ánimo del -en ese entonces- Secretario de Trabajo y Previsión, promover la eliminación del capitalista en el teatro ni tampoco incentivar actividades que no resultaran económicamente viables o que no pudieran asegurar el sustento de sus propios trabajadores.

¿Cuál era entonces la postura del gobierno peronista respecto de los artistas? Regresando a nuestro anterior interrogante, ${ }^{31}$ para la política económica y cultural peronista, ¿los actores eran productores o trabajadores?: "Para nosotros el cooperativismo es, en los productores, lo que el sindicalismo en los trabajadores" (Juan Domingo Perón, "Discurso de Presentación del Segundo Plan Quinquenal", 1952). Resulta claro entonces, que Perón realizó una apelación hacia los actores en su calidad de trabajadores, por lo que instó a intensificar la autopercepción de los artistas como tales, reforzando la agremiación o impulsándola en los rubros artísticos donde la misma no existía hasta el momento.

De este modo, desde 1943 surgieron diversos sindicatos vinculados al quehacer artístico. La mencionada ARA (Asociación Radial Argentina) y la Asociación Gente de Radioteatro fueron fundadas el 3 de agosto de 1943, absorbiendo a la AGRA (Asociación Gente de Radio de la Argentina) fundada en 1939, y a la Asociación Argentina de Artistas de Radio, fundada en 1934, y ya fusionadas en Artistas Unidos de Argentina. La SAL (Sociedad Argentina de Locutores) fue fundada el 3 de julio de 1943, un mes después del golpe de estado y varios meses antes de que Perón asumiera como Secretario de Trabajo y Previsión. Su primer secretario fue el locutor Roberto Galán y rápidamente contó con seccionales en Mar del Plata, Bahía Blanca y Azul. El SADEM (Sindicato Argentino de Músicos) fue fundado el 21 de diciembre de 1945 y pronto contó con seccionales en Tandil y Junín. La UADAV (Unión Argentina de Artistas de Variedades) fue constituida el 5 de octubre de 1951 a través de un Acta firmada por cuarenta y siete miembros en la que se declara regida por los postulados que aconsejan Juan y Eva Perón. Cabe destacar que desde que la UADAV obtuvo su personería jurídica en 1953 , se suscitó un conflicto con la AAA por la representación de los bailarines, que se mantiene hasta nuestros días (Sousa, 2015). En 1953, la propia SADET obtiene su personería jurídica, pasando a denominarse APTA (Asociación de Promotores Teatrales Argentinos) mutual y gremial, hasta adoptar su denominación actual (AADET, Asociación Argentina de Empresarios Teatrales).

En 1944 obtiene su personería gremial el Sindicato del Espectáculo Público, cuyos antecedentes se remontan a diez años antes, cuando un grupo de trabajadores funda la Unión de Protección de Acomodadores (UPA). A partir de 1953, el Sindicato de Espectáculo Público suma a una serie de actividades que pueden quedar comprendidas bajo el abarcador concepto de "trabajadores del espectáculo público", y donde confluyeron sindicatos preexistentes, así como sectores que carecían de representación gremial: vendedores de golosinas, extras cinematográficos y de TV, radios de baja y alta potencia, juegos electrónicos, bowlings, controles de cine, teatros y parques de diversiones, electricistas de teatros, diversiones públicas, circos, natatorios, exhibidores cinematográficos, cines multipantallas, Stadium Luna Park Lectoure y Lectoure SRL (Baranchuk, 2016). La entidad, que pasa a denominarse SUTEP (Sindicato Único de Trabajadores del Espectáculo Público y Afines de la República Argentina) y obtiene su personería gremial en 1954, se constituyó por expreso pedido de Perón "como forma de dar contención a un grupo diverso de trabajadores que debido a su dispersión y tamaño quedaban en situación extremadamente desventajosa frente a determinadas patronales" (Baranchuk, 2016: 172).

También surgieron o se formalizaron sindicatos pertenecientes a rubros técnicos u otros trabajadores cuya lucha presentaba afinidad con los artistas, dado que combatían
30. Aspecto analizado en profundidad en Mateo, 2013.

31. Ver "Identidades y apelaciones antagónicas I ¿Artistas, productores o trabajadores? (1902-1930)", artículo de nuestra autoría en el presente dossier. 
con los mismos empleadores: AGICA (Asociación Gremial de la Industria Cinematográfica Argentina), luego denominado SICA (Sindicato de la Industria Cinematográfica Argentina), que agrupa a los técnicos de los principales estudios cinematográficos de la época, y el Sindicato Argentino de Periodistas, fundado en 1947.

La existencia de nuevos sindicatos permitía eventualmente fortalecer la lucha en conjunto, motivo por el cual surgió la FADEP (Federación Argentina del Espectáculo Público). Formada en 1943, la Federación nucleaba a la AAA, Asociación del Profesorado Orquestal, Asociación Gente de Radioteatro, AGICA, SADAIC, SAL, Sociedad Argentina de Técnicos Operadores Radiotelefónicos, ARGENTORES, Unión Electricistas de Teatro y Unión Maquinistas de Teatro. Paradójicamente, la FADEP, que terminará desintegrándose en 1947, tendrá una clara postura opositora al gobierno de Perón durante sus cuatro años de existencia.

El principal punto de conflicto surgió justamente alrededor de la constitución de nuevos sindicatos, puntualmente rechazan al incipiente Sindicato del Espectáculo Público, al que la AAA califica de "ignoto" (Klein, 1988: 56), y la manipulación en la concesión de la personería gremial de los mismos por parte del gobierno. La FADEP denuncia que éste pretende organizar gremios que ya están organizados, con el objeto de imponer un "gremialismo dirigido" (Máscara (62), noviembre de 1945). El enfrentamiento se intensifica cuando la Dirección de Espectáculos Públicos exige el envío previo de los textos de las obras a representarse (lo cual ya se implementaba en la radio). No obstante, la protesta conjunta de la AAA, ARGENTORES y la SADET obligó a la anulación de la medida (Klein, 1988).

Es notable observar las oscilantes posiciones de la AAA, ARGENTORES, SADET y FADEP frente a las políticas gubernamentales. Como ejemplo, citaremos un caso particular. A la oposición de la AAA y la FADEP al gobierno de Perón, los empresarios teatrales responden con una exhortación a mantener la histórica "imparcialidad a que siempre nos hemos atenido en las luchas políticas y sociales" (Klein, 1988: 59). No obstante, cuando el gobierno lanza el proyecto de implementación de un $50 \%$ obligatorio de textos nacionales y un 70\% de actores argentinos en las temporadas locales, la SADET reacciona violentamente, acusando a la AAA y a ARGENTORES de ser los impulsores ocultos de la iniciativa. De hecho, ambas agrupaciones están de acuerdo con la medida, largamente ansiada y, por otra parte, ya contemplada en la ordenanza municipal de 1937, que reducía los impuestos de las empresas que optaran por artistas y textos nacionales (citada más arriba). ${ }^{32}$

Teniendo en cuenta las históricas dificultades que los trabajadores del espectáculo habían tenido para defender sus derechos ante los empresarios, resulta por lo menos insólita la siguiente declaración de la FADEP: "Hasta 1943, las entidades que hoy integran esta Federación, disfrutaron de la más amplia libertad de acción para desarrollar su gestión gremial dentro de prácticas de entendimiento directo con los empleadores de cada uno de los sectores de trabajo" (Klein, 1988: 61, la cursiva es nuestra), tras lo cual acusa a Perón de perturbar la actividad gremial a través de la aparición de nuevos sindicatos con "decididas intenciones confusionistas" (Klein, 1988: 61). Más adelante, instan a abandonar posiciones políticas y religiosas al interior del gremio, pasando por alto la influencia que otras ideologías partidarias habían ejercido en el colectivo actoral hasta ese momento.

En efecto, a los vínculos con el socialismo durante los años 20 , consignados anteriormente, ${ }^{33}$ el gremio había mostrado recientemente explícitas simpatías por figuras políticas. Tal es el caso del radical Amadeo Sabattini, cuya foto es publicada en el primer número de la Revista Máscara, órgano oficial del gremio, con el siguiente epígrafe: "ex gobernador de Córdoba y gran amigo de los artistas, con cuya ayuda
32. En el mismo sentido pueden interpretarse las reacciones ante las mejoras impulsadas por el gobierno peronista frente al largo reclamo de los bailarines por la sala de ensayo La Rotonda en el Teatro Colón. Al respecto, ver Cadús, “Las condiciones laborales de los/as bailarines/ as durante la primera mitad del siglo XX", en el presente dossier.
33. Ver "Identidades y apelaciones antagónicas I ¿Artistas, productores o trabajadores? (1902-1930)", de nuestra autoría, en el presente dossier. 
eficaz pudo cristalizar el viejo sueño de la gente de teatro: La Casa de Descanso" (Máscara, I (1), 9/1940: 7). Más elocuente resulta, en el número siguiente, la página completa dedicada a Regina Pacini, esposa del ex presidente radical Marcelo T. de Alvear, en la que se reproduce su foto y el siguiente texto:

MADRE ESPIRITUAL DE LOS ARTISTAS. SEÑORA: si te dicen que somos un poco desamorados, créelo, si un poco tarambanas, también; mas si te dijeran que no amamos a nuestra madre, jura que no es verdad. Allá en el rinconcito más secreto de nuestro yo, hasta los que queremos pasar por más malos, llevamos como grabada a cincel esa palabra que aprendemos al nacer y a la que acudimos en los momentos más difíciles de nuestra vida. iMadre! Por eso y con la debida pleitesía que te debemos, acepta el homenaje de nuestra gratitud en esta santa palabra: ¡MADRE! (Máscara, I (2), octubre de 1940: 12).

Para las elecciones presidenciales de febrero de 1946, se torna evidente que el espíritu que rige la AAA no se corresponde con el ideario peronista. El colectivo actoral no fue ajeno a la polarización que suscitó la campaña electoral en la sociedad, en la que la polémica comenzó a exponerse en términos de defensa o ataque a la democracia. El elenco del Teatro Nacional de Comedia llegó a manifestar que: "Una actitud digna sería la de renunciar en masa. Permanecer es colaborar con el régimen" (Cit. en Insaurralde, 1997: 111). Mientras, las autoridades de la AAA hicieron explicita su oposición a Perón y su adhesión a la campaña presidencial de la Unión Democrática, que incluía la organización de actos políticos en su apoyo. Con este fin, en 1945 se forma la "Agrupación de Actores Democráticos", que reúne a actores profesionales e independientes, entre los cuales se encontraban Pablo Raccioppi, Lidia Lamayson, Pascual Nacaratti, Orestes Caviglia (Vicepresidente de la AAA), Francisco Petrone, Alberto Barcel, Domingo Mania, Niní Gambier, Amelia Bence, Miguel Faust Rocha, Margarita Corona, Blanca Tapia y Carlos Bellucci, entre otros. Según Baranchuk (2016), esta acción da inicio a las listas negras de artistas.

Por su parte, el vicepresidente de la AAA, Orestes Caviglia, proclamó en asamblea que "las actividades del espíritu sólo pueden llevarse a cabo en un clima de absoluta libertad", por lo que pidió que el país "retorne cuanto antes a las garantías que establecen las normas constitucionales", y agregó que "aun cuando el arte del actor ha de estar alejado de toda contingencia política", la condición de ciudadanos les impone el deber de manifestar sus convicciones civiles (Máscara (59), 8/1945).

Finalmente, la AAA terminará dividiéndose en agosto de 1946. El desprendimiento estuvo encabezado "por quienes simpatizaban con el peronismo y se oponían a las actitudes de las autoridades vigentes en Actores, quienes hacían extensivo su antiperonismo a toda la entidad" (Leonardi: 2009, 92). Esto dio lugar a la AGAA (Asociación Gremial Argentina de Actores), integrada por Enrique Muiño, Tito Lusiardo, Lea Conti, Malisa Zini, Eloy Álvarez, Pierina Dealessi, Virginia Luque, Pedro Aleandro y Pedro Maratea, entre otros. Los dirigentes de la Gremial afirmaron que con su fundación terminaban con veinticinco años de ostracismo, dado que el apoyo del actual gobierno era la oportunidad histórica de acceder a logros largamente ansiados (Klein, 1988). De hecho, la AGAA obtuvo su personaría gremial rápidamente (el $27 \mathrm{de}$ agosto de 1947), mientras que la solicitud de la AAA se postergó de manera indefinida (Baranchuk, 2016).

Lo cierto es que las reivindicaciones esgrimidas por la AGAA eran exactamente las mismas que las de la AAA: fuentes de trabajo y regulación de la actividad a través de un convenio. La diferencia radicaba en la postura esgrimida no sólo ante el gobierno peronista, sino también ante el rol del Estado. En efecto, aun cuando los conflictos con los empresarios obligaron a la AAA a requerir de la intervención estatal y a bregar 
por una política teatral, siempre dejaron en claro que las mismas debían obedecer a los lineamientos a los que la entidad adhería. Que el Estado fuera ocupado ahora por una figura como Perón, no hacía más que volver más rígida esta posición, por lo que la divergencia con el sector artístico que adhería al peronismo se profundizó, aunque esgrimieran las mismas reivindicaciones laborales.

Pronto se evidenció que la división debilitaba la posición de los artistas ante nuevos conflictos con el empresariado. En efecto, en septiembre de 1946, la FADEP decretó un paro de 24 hs. en solidaridad con los músicos y gremios radiales en huelga contra las emisoras. Al presentarse a los teatros para reanudar la actividad, los mismos estaban cerrados, debido a que la SADET había cancelado las temporadas. Dado que la Gremial no había apoyado la medida de fuerza, la AAA se vio obligada a negociar en inferioridad de condiciones. Tras un frustrado intento de reunificación en 1947, y merced a la mediación del gobierno, se acordó la libre afiliación y la asunción de un perfil estrictamente mutual para la AAA y gremial para la AGAA, al tiempo que se comprometieron a la mutua y cordial colaboración entre ambas. La AAA subsistió a través de la percepción en la recaudación indicada por el convenio Perón, pero al cumplirse el período de vigencia del mismo en 1953, la Gremial exigió ser considerada la única entidad representativa de actores, hecho que precipitó la reunificación un año más tarde, bajo el nombre de Sindicato de Actores de la República Argentina, que heredó la personería gremial de la AGAA, y pasó a ser gremial y mutual.

Ese mismo año, y a pedido de la CGT, Actores y la Asociación Gente de Radioteatro se unifican. Habrá que esperar a 1954 para que se modifiquen los estatutos de la AAA y los actores de cine también pueden ser representados por la entidad. Para 1955, ya funcionarán en el Sindicato secretarías por rama: Radio y TV, Cine, Cuerpos de baile y Coristas, Teatro, Circo, Apuntadores y Traspuntes.

Por consiguiente, se instala "de allí en más un criterio fuerte: el trabajo del actor es independiente del medio en el cual ejerce su actividad y, por ende, la organización apta para su defensa debe ser la misma, consolidándose de allí en más la sindicalización por oficio" (Baranchuk, 2016: 106). Baranchuk (2016) plantea que se registra así un movimiento inverso al de los otros sectores del trabajo, dado que en lugar de ir del gremio de oficio a la representación por rama, los artistas fueron de la rama al oficio. Por nuestra parte, consideramos que esto constituye un indicador de la percepción de la especificidad de la tarea de los artistas.

Durante su existencia, la Gremial propuso una serie de estrategias para reducir la desocupación, entre las que se encontraban la recuperación de las setenta salas perdidas a lo largo de veinte años, el incremento de elencos oficiales, la implementación del número vivo en las salas de cine y la eliminación de obstáculos para las compañías en gira por las provincias (Klein: 1988). Por supuesto, los vínculos de sus dirigentes con el gobierno promovieron la apertura de un canal de diálogo que redundó en logros concretos.

Además de que la mejora en el nivel de vida general se reflejó en un aumento de público, ${ }^{34}$ es mediante la representación sindical y la negociación con los empresarios que el gobierno peronista intervendrá en el sector artístico, lográndose por aquellos años diversas conquistas laborales. En 1948 se suprimió la función matinée y dos años después la controvertida función vermouth, que tantos conflictos había acarreado en los treinta y dos años de lucha desde su implementación. El contrato mínimo se extendió de tres a cinco meses y el elenco básico pasó de diez a doce integrantes. Se estipuló el pago por enfermedad durante treinta días y el pago del sueldo completo si los ensayos superaban los diez días. También se obtuvo el aguinaldo, concedido
34. Que pasó de dos millones en 1943, a tres millones y medio en 1951, según Klein (1988). Por su parte, Bayardo (1997) precisa 3.626.297 espectadores para 1950. 
por voluntad de los empresarios, y se acordó la retención de un porcentaje para la Obra Social. Para los elencos en gira se dispuso el descanso semanal obligatorio y la reducción del $25 \%$ en las tarifas ferroviarias.

Por otra parte, en 1953 se sancionó la Ley $\mathrm{N}^{\circ}$ 14226, que disponía la obligatoriedad del número vivo en las salas de cine. Esto no sólo implicaba una reivindicación laboral, sino también simbólica para los artistas de variedades, muchas veces relegados dentro del propio colectivo artístico. La UDAV declarará a Eva y Juan Perón como Socios Honorarios, dado que "nos ha entregado entre las muchas conquistas, esa magnífica Ley de los números 'vivos', en los cines que nos abrió la puerta del trabajo para todos" (Acta de la Asamblea Ordinaria de la UDAV, 2/12/1953). Sin embargo, los incumplimientos fueron moneda corriente. ${ }^{35}$

Además de los logros que atañen al teatro comercial, el Estado se convirtió en un importante organizador de actividades culturales que constituyeron fuentes de trabajo para los artistas. En primer lugar, hubo un fuerte impulso de la escena oficial. Durante el gobierno peronista, la actividad de este circuito fue intensa, empleando a gran cantidad de artistas. Cabe destacar que muchos de ellos trabajaban también en el circuito profesional culto y en el popular, y con anterioridad al gobierno peronista. El circuito teatral oficial estaba integrado por el Teatro Presidente Alvear (denominado Enrique Santos Discépolo, entre 1951 y 1955), el Teatro Nacional Cervantes (en el que funcionaba el Teatro Nacional de Comedia, que pasó a tener un elenco adicional que giraba por las provincias y territorios nacionales), el Anfiteatro Popular Eva Perón del Parque Centenario, el Teatro Colón y el Teatro Argentino de La Plata. Una mención especial requiere el caso del Teatro Municipal de la Ciudad de Buenos Aires. En 1943, el proyecto de creación de un Teatro Municipal en el solar de la Avenida Corrientes 1530 había funcionado como argumento para que el gobierno de facto de Pedro Pablo Ramírez impulsara el desalojo del Teatro del Pueblo de la sala que le había sido concedida por el Concejo Deliberante en 1937. En 1950, la sala pasó a denominarse Teatro Municipal General San Martín, y en 1954 se iniciaron las obras de construcción del edificio actual, inaugurado finalmente en 1960.

Por otra parte, el gobierno se propuso concretar la formación de un nuevo público, conformado por los migrantes internos y por zonas del país a los que determinados bienes culturales no habían llegado antes. Con este fin, organizó eventos masivos y representaciones teatrales para los obreros y sus familias, a precios populares 0 gratuitos, en los teatros oficiales y en el espacio público (Leonardi, 2009).

No sólo se implementó una política cultural en el teatro, en tanto ámbito de desempeño artístico. La industria cinematográfica recibió un notable apoyo a través de una serie de medidas que intentaron afianzar la producción, asegurando las fuentes de trabajo, no sólo de artistas, sino también de técnicos. Como consecuencia de estas políticas, el aumento en la producción de filmes nacionales fue notable, aspecto analizado en profundidad por Kriger (2009). Por último, cabe destacar que en 1951, y por iniciativa estatal, ingresa la televisión al país. En efecto, el 17 de octubre de ese año se realiza la primera transmisión con un discurso de Eva Perón en el Ministerio de Obras y Servicios Públicos. Si bien esto no se traduce en una generación inmediata de fuentes de trabajo para los artistas, a partir de la década siguiente pasará a constituir su campo laboral más importante y la principal fuente de financiación de su entidad sindical y de su obra social. De hecho, la primera Ley de Radiodifusión del país ( $\mathrm{N}^{\circ}$ 14241), que se sanciona en 1953 , organiza el sistema de medios en tres cadenas privadas y una estatal (pero dependiente de una de las cadenas comerciales), cada una de las cuales incluía radios y un canal de televisión (Baranchuk, 2016). Recién en 1954 se llaman a licitación las tres redes (Decreto $\mathrm{N}^{\circ}$ 9967/54).
35. De hecho, después del derrocamiento de Perón continuarían suscitándose conflictos al respecto. Como ejemplo podemos citar el caso de la intimación de la Dirección General de Empleo a la Sociedad Anónima Cinematográfica en 1956, con motivo del incumplimiento de la Ley por parte del Cine Callao, que llegó a la Corte Suprema de Justicia (Hechos y Fallo de la Corte Suprema de Justicia, 22 /6/ 1960: 121 y Ss.) Al respecto, ver Shirkin, "El artista de variedades en el Buenos Aires de principios del siglo XX" en el presente dossier. 
En lo que respecta a la formación artística, en 1947 se abrió el Seminario Dramático en el Teatro Cervantes. Creado por la Comisión Nacional de Cultura y dirigido por Juan Oscar Ponferrada, el Seminario estaba "destinado a la experimentación teatral y al estudio práctico de las materias inherentes al arte dramático y oficios afines" (Cuadernos de Cultura Teatral, $\mathrm{N}^{\circ}$ 23: 140). Posteriormente, se emprendió un proyecto más ambicioso: la Unidad Básica Cultural Eva Perón. Inaugurada el 18/9/1953, pertenecía al Partido Peronista Femenino y funcionaba en el centro porteño, entre Diagonal Norte y Florida. La institución, que asimiló al antiguo Ateneo Cultural Eva Perón, que funcionó entre 1950 y 1953, se proponía constituirse como un centro de irradiación a otras organizaciones culturales del país y contaba con diversas escuelas artísticas, como la de Arte Escénico, Cine, Folklore y Coral.

Para el ámbito de la cultura del momento, la adhesión de algunos artistas al peronismo tuvo fuertes implicancias simbólicas, dado que se planteó como una alternativa al ideal militante impartido desde el teatro independiente. De este modo, además de propiciar otro modelo de compromiso político, el gobierno adoptó la estrategia de generar una distinción clara entre el artista profesional y el aficionado, para lo cual promovió la creación de elencos vocacionales a nivel nacional y de experiencias teatrales educativas, que se plantearon como contrapartida de las formaciones independientes. Así, mientras éstas no sólo requerían de un compromiso ideológico antiperonista por parte de sus miembros, sino también de valores estéticos y culturales elitistas, en el corazón del concepto de las vocaciones residía, en cambio, la idea de que todos los ciudadanos podían convertirse en virtuales productores de arte. De este modo, el gobierno fomentó el surgimiento del Teatro Vocacional y del Teatro Obrero Argentino de la CGT, en el que los obreros participaban preferentemente en calidad de actores, aunque también lo hicieron como dramaturgos (Leonardi, 2009). Cabe destacar que en el programa de mano se detallaban los nombres de los actores, lo cual establecía una clara diferencia con el anonimato exigido dentro del movimiento independiente.

El teatro independiente, por su parte, ejerció una oposición abierta durante los dos primeros gobiernos peronistas, lo cual contribuyó a estrechar sus filas y a asumir una unívoca misión cultural y política junto con otros sectores, contra lo que consideraban un enemigo común. La respuesta del gobierno consistió en la clausura de algunas de las salas del movimiento argumentando la falta de cumplimiento de edictos municipales. La tensión entre el peronismo y el movimiento de teatro independiente no impidió, no obstante, que se realizaran algunos cruces significativos. Como ejemplo, baste el caso de El puente, de Carlos Gorostiza, estrenada por La Máscara en 1949. Obra marcadamente antiperonista, poco después fue reestrenada sin inconvenientes en el circuito comercial bajo la dirección de Armando Discépolo, lo cual provocó una fuerte polémica al interior de La Máscara e incluso el éxodo de algunos de sus integrantes (entre ellos, Alejandra Boero y Pedro Asquini). Más significativo aún resulta el hecho de que la obra fuera llevada al cine, teniendo en cuenta el apoyo oficial que las realizaciones cinematográficas tenían en ese momento, y que el autor participó en la adaptación y en la dirección de la misma. Evidentemente, la modificación de la historia original al incluir un cartel inicial en el que se señalaba que la historia transcurría en una época previa al peronismo, no resultó inaceptable para el propio Gorostiza, quien de otro modo no hubiera participado del proyecto. Y aún más, en 1954, adaptó El último perro de Guillermo House, para ser puesta por Armando Discépolo en el Teatro Nacional Cervantes, incorporándose así a la programación del circuito oficial.

Hemos visto cómo la estrategia del primer peronismo consistió en sumar a los artistas e intelectuales a su proyecto político. Si bien el gobierno buscó capitalizar la repercusión que podía suscitar la adhesión de grandes figuras, no construyó esta estrategia, sin embargo, sobre la base de beneficios individuales, sino mediante reivindicaciones para todo el colectivo (que incluía también a los grupos opositores), 
que muchas veces constituían reclamos de larguísima data. No obstante, analizado en perspectiva, el resultado fue negativo. Si bien una gran parte del colectivo artístico respondió a esta convocatoria, amplios sectores, entre los que se contaba la dirigencia de la AAA, declinaron la misma. En primer lugar, por el rechazo a la propia figura de Perón. Sin embargo, no hay que desdeñar el hecho de que la interpelación de los artistas como trabajadores realizada desde el peronismo, no estaba en consonancia con la figura del artista idealizado y militante que sostenía el gremio desde la época de las grandes huelgas.

Este ideal era refrendado por la propia existencia del movimiento independiente, que funcionaba como una especie de reservorio moral e instancia especular para los actores profesionales, y que ejerció una oposición abierta al peronismo, tal como lo destacan todos los estudios históricos al respecto. No ha sido señalado, en cambio, que, al posicionarse por fuera de la órbita de la política estatal, las iniciativas privadas independientes no fueron alcanzadas por ninguno de los avances en materia legislativa laboral, por lo que los artistas que se desempeñaron en ellas continuaron sumidos en una precariedad laboral notoria, al tiempo que esgrimían un imaginario emancipatorio completamente desvinculado y acrítico respecto de su propia situación.

Indudablemente, los sectores que detentan la centralidad del campo cultural han construido su versión de la relación entre artistas y peronismo. En todo estudio sobre las relaciones entre los artistas y el peronismo, no pueden soslayarse los rumores contradictorios y las acusaciones mutuas entre adherentes y detractores. A los casos documentados de censura, exilio y rehabilitación de figuras enemistadas con el gobierno, se le suman diversos relatos que ya forman parte de una suerte de leyenda, muchas veces incomprobable o legitimada por su sola reproducción. Estos relatos son prolíficos en episodios respecto de intervenciones gubernamentales para favorecer o perjudicar a artistas militantes $u$ opositores. Habiendo profundizado en este aspecto complejo en otras oportunidades (Mauro, 2015), nos limitaremos a señalar aquí que muchas de estas declaraciones se realizan luego del golpe de estado de 1955 y en los años de proscripción, durante los cuales mostrar algún tipo de simpatía con el peronismo podía resultar problemático para los artistas. En efecto, la censura y la condena moral dentro del propio campo cultural, e inclusive la persecución judicial y policial a los actores que habían adherido al peronismo, se prolongaron por años (durante el gobierno de facto, pero también en aquellos democráticos que le siguieron) $y$, en algunos casos, se mantuvieron de por vida. ${ }^{36}$ Sin duda, la aplicación de la autocensura y la sanción moral dentro del campo cultural en democracia es un tema complejo que aun reclama un trabajo sistemático y debidamente documentado.

En este sentido, es notable el caso de la propia AAA, que cuenta por lo menos con dos historias oficiales publicadas hasta el momento, ambas marcadamente críticas respecto del gobierno peronista. La primera data de 1969 y consiste en un artículo de María Delia Pitaco y Victoria Romero, publicado en el número de la revista Hechos de Máscara celebratorio del $50^{\circ}$ aniversario del gremio. Con respecto al período peronista y al golpe de estado de 1955, las autoras sostienen:

Hubo varios intentos de dominar la AAA, pero ninguno prosperó. Constreñida a una limitada actividad mutual, la veterana organización fue frenada en su evolución por quienes, en ese momento, ejercían un despiadado despotismo con el amparo del gobierno nacional. Esa increíble gremial llegó a actuar coercitivamente, exigiendo la afiliación como requisito para trabajar. Es una época de la cual los implicados prefieren no hacer comentarios, pero el cúmulo de atropellos cometidos contra los actores que no se plegaron al régimen imperante -algunos debieron trabajar en actividades ajenas a la profesión y hubo quienes recurrieron al forzoso exilioobliga a reflexionar sobre lo ocurrido y a extraer todavía conclusiones que sirvan
36. Tal es el caso de Fanny Navarro o el de Enrique Santos Discépolo, discriminado por el campo cultural hasta su muerte, acaecida cuando todavía gobernaba el peronismo. 
de experiencia [...] No pasaría mucho tiempo para que el statu quo variara. La Revolución Libertadora de setiembre de 1955 permitió que la AAA volviera a sus añejos fueros, al tomar posesión de ella y de su conducción, con carácter provisorio, un grupo de actores encabezados por Pedro Tocci. La intervención decretada por el gobierno en todos los sindicatos para investigar lo ocurrido durante 12 años y luego procurar la normalización de los mismos, mediante el llamado a elecciones, también se concretó en la AAA, en la que en mayo de 1956, el vicecomodoro doctor Diego Basilio Olmos, asumió esa difícil tarea (Pitaco, 1969: 104-105).

La segunda, el libro de Teodoro Klein publicado en 1988 por el propio gremio, si bien morigera sus dichos respecto de la autodenominada Revolución Libertadora y reconoce que las mejoras laborales durante el primer peronismo se obtuvieron mediante intervención estatal sin necesidad de confrontación sindical con los empresarios, no se aparta de la posición asumida por la dirigencia de la AAA cuarenta años antes.

\section{V.}

Luego del violento golpe de estado de 1955, las paritarias y la Constitución Nacional de 1949 fueron derogadas. Se inició la persecución a sindicalistas y se perdieron numerosas conquistas laborales, aunque en 1957 algunas normativas fueron anexadas a la rehabilitada Carta Magna de 1853, en el artículo 14bis: condiciones dignas y equitativas de labor, jornada limitada, descanso y vacaciones pagados, retribución justa, salario mínimo vital y móvil, igual remuneración por igual tarea, participación en las ganancias de las empresas con control de la producción y colaboración en la dirección, protección contra el despido arbitrario, estabilidad del empleo público y organización sindical libre y democrática reconocida por la simple inscripción en un registro especial (Baranchuk, 2016). Por otra parte, la Ley de Radiodifusión fue reemplazada por la $\mathrm{N}^{\circ} 15460$ de 1957 y las adjudicaciones de las redes de medios fueron declaradas nulas.

En lo que respecta a la AAA, ya se ha mencionado que la misma fue intervenida y su dirección pasó a manos de un marino. Por su parte, la producción cinematográfica se paralizó durante un año, al igual que la construcción del Teatro Municipal General San Martín. Las sanciones y reprimendas morales a los artistas que habían mostrado su adhesión al peronismo fueron muy duras, y como ya consignamos, se prolongaron más allá del gobierno de facto, originando listas negras que en algunos casos perduraron de por vida. Por otra parte, los actores en su conjunto perdieron muchas de las conquistas laborales y varias filiales provinciales de la AAA, cerraron (Klein, 1988).

No obstante, algunos dirigentes gremiales aceptaron desempeñar cargos públicos durante el gobierno de facto. De este modo, Orestes Caviglia, quien otrora se declarara defensor de la abstención política del gremio y que durante el gobierno peronista se había exiliado en Uruguay, acepta colocarse al frente de la Comedia Nacional Argentina, cargo que ocupa entre 1956 y 1960. Sólo luego de cuatro años presenta su renuncia aduciendo "cansancio moral" (Klein: 1988: 78), al igual que su elenco, integrado por Inda Ledesma, Ernesto Bianco, Corrado Corradi y Milagros de la Vega, entre otros.

Ya en el gobierno de Frondizi, y en plena proscripción del peronismo, se inicia un nuevo tipo de política cultural que incluye, entre otras medidas, la creación del Fondo Nacional de las Artes y del Instituto de Cinematografía. El caso del Fondo Nacional de las Artes constituye un claro ejemplo del tipo de política que se buscó implementar en la cultura. Ente autárquico integrado por comisiones honorarias asesoras y presidido por Victoria Ocampo durante catorce años (1958 a 1972), refrenda la hegemonía de los sectores que ocupaban la centralidad del campo cultural con anterioridad al peronismo. 
Por su parte, el teatro independiente asumió una posición ambigua respecto a la Revolución Libertadora (Pellettieri, 2003). Luego de la caída del peronismo, el movimiento independiente y principalmente, el Teatro del Pueblo, perdió la función política opositora que lo había sostenido durante los años precedentes, precipitando también cambios en su ubicación en el campo teatral, que pasó a ser marginal, aunque no sucedió lo mismo con las formaciones independientes que aparecieron posteriormente.

En efecto, en los años 50 surgió una segunda generación de grupos (como La Máscara, Nuevo Teatro, Fray Mocho, entre muchos otros) que emprendió la experimentación estética a partir de cambios en el espacio escénico y de la incorporación de metodologías de actuación novedosas, como el sistema Stanislavski, que promovió a su vez, el surgimiento de una nueva dramaturgia, el denominado realismo reflexivo. Aunque continuaron rigiendo en las mismas el cooperativismo anteriormente descripto, la prohibición de profesionalizarse ${ }^{37}$ y un fuerte personalismo, ${ }^{38}$ que paulatinamente ocasionaron tensiones internas y éxodos.

Con el correr del tiempo, esta modalidad se cristalizó como la única opción que permitía, no sólo la transmisión de ciertos contenidos, sino también la experimentación formal. De este modo, la autogestión pasó a significar, además de un refugio para ideas emancipadoras, una categoría estética que garantizaba la libertad y la experimentación creativa de los artistas. La gratuidad del trabajo inherente a esta versión de cooperativismo quedó, de esta manera, invisibilizada detrás de los logros estéticos y políticos. Así, la concepción didáctica que ostentaba este teatro se amalgamó con la noción de libertad creativa, por lo que la cooperativa se presentó como la organización más adecuada para la experimentación formal liberada de las exigencias de boletería, así como también de los reclamos sindicales.

Paradójicamente, el prestigio y legitimidad de este modo de hacer teatro se extendió a todo el campo cultural promoviendo que los actores y directores surgidos en el teatro independiente se profesionalizaran y emigraran a otros circuitos teatrales, a los medios de comunicación (como la televisión y el cine), y ocuparan posiciones dirigentes en las instituciones oficiales de formación para actuación, en los teatros dependientes de la Nación y la Municipalidad de la Ciudad de Buenos Aires e inclusive en el gremio, además de abrir sus propias instituciones de formación artística de carácter privado.

Esto ocasionó que el imaginario del teatro independiente se prolongara a la escena oficial, ejerciera un influjo notable en el teatro comercial culto y se utilizara como parámetro de conducta exigible a los artistas, además de actuar como criterio de evaluación de otras formas estéticas, que resultaron así desvalorizadas. Fue fundamentalmente la escena oficial la que terminó de delinearse a partir de los postulados de la escena independiente. En efecto, el Teatro Municipal General San Martín es, quizá, el espacio que más ha retomado los presupuestos de un teatro de arte con una función didáctica y política sobre el público. Su notable éxito y reconocimiento entre sectores de la clase media ilustrada y progresista atestiguan la confluencia de estos ideales.

De este modo, el imaginario del teatro independiente, en el que la gratuidad del trabajo en cooperativas, la ideología de carácter progresista y la experimentación formal se hallaban confundidos y entrelazados, se extendió a todos los circuitos y los medios en los que se desempeñan los artistas, como epítome de un arte auténtico, libre y de calidad. Si inicialmente los integrantes de las agrupaciones independientes no se relacionaban con los profesionales ni se afiliaban a la AAA, para los años 60, cuando el movimiento declina por los problemas económicos y el éxodo de los artistas, éstos se sindicalizan y surge la iniciativa de redactar la Reglamentación Laboral para Sociedades Accidentales de Trabajo que rige actualmente (Bayardo, 1990): 39
37. Un caso significativo es el de Héctor Alterio, quien mientras formaba parte de Nuevo Teatro debió trabajar como corredor de galletitas. Sólo luego de abandonar la agrupación pudo trabajar profesionalmente, convirtiéndose en uno de los actores emblemáticos del cine nacional.

38. Tríbulo (2006) describe los problemas suscitados en Nuevo Teatro: no se permitía ninguna ausencia en los ensayos y no se admitía que los actores hicieran otro tipo de teatro. Agrega que nunca se leía el reglamento interno y que los actores se enteraban del contenido del mismo a través de las clases, y que la rigidez de la organización era tal, que quienes que decidían abandonar la agrupación mentían, aduciendo problemas de salud.
39. Que analizamos en profundidad en el artículo de nuestra autoría, "Entre el mundo del arte y el mundo del trabajo. Herramientas conceptuales para comprender la dimensión laboral del trabajo artístico", en el presente dossier. 
No necesariamente las cooperativas se constituyen por una voluntaria adscripción a la tradición independiente. Sin embargo, la emergencia legalmente institucionalizada de estas como una forma de producción alternativa a la empresarial en el teatro coincide con la declinación del Movimiento Teatral Independiente y retoma en buena medida sus postulados (Bayardo, 1990: 35)

Finalmente, este sistema de producción, entendido como el motor dinamizador y la reserva ética del campo teatral (e incluso de los medios de comunicación), se cristalizó en la Ley Nacional de Teatro de 1997 y en las legislaciones municipales confeccionadas según ese modelo.

\section{VI.}

En el presente artículo hemos analizado las condiciones laborales de los artistas del espectáculo entre 1930 y 1955 . Hemos observado que los actores oscilaban entre una conflictiva identificación como trabajadores y una apelación, realizada desde el campo intelectual, que los instaba a asumir un rol militante en un teatro cuya función social y política prevaleciera por sobre cualquier otra instancia, lo cual presuponía el abandono de la profesionalización y el consiguiente desdén por la lucha sindical. Por otra parte, la existencia de características específicas en el ejercicio de la actuación, reclamaba una organización gremial adaptada a estas circunstancias. Frente a la necesidad de desarrollo de una identidad laboral novedosa y compleja, las acuciantes necesidades económicas y la falta de legislación atentaban contra este proceso, obligando a los artistas a soluciones desventajosas o al simple y llano abandono de la lucha. Esto se torna aún más significativo si tenemos en cuenta las mejoras laborales conseguidas por los trabajadores calificados durante la década del 30, indicador de que los artistas no eran considerados como parte de los mismos.

Ante el avance del empresariado y la crisis sobrevenida por la situación económica, pero además, por el surgimiento de nuevas formas de entretenimiento, se hacía necesaria la intervención estatal en favor de los trabajadores de la cultura, que hasta los propios actores reclamaron. No obstante, las posiciones se retrajeron cuando esa intervención fue asumida por un movimiento que no se correspondía con los valores que ocupaban la centralidad del campo cultural.

La relación entre los artistas y el primer peronismo debe ser revisada a la luz de los procesos históricos, situando la problemática del actor desde los años previos a la irrupción del movimiento y analizando el derrotero de la misma en los años posteriores. En este contexto, la apelación del peronismo a los artistas del espectáculo en tanto trabajadores fue novedosa. No obstante, amplios sectores del colectivo artístico mostraron una apasionada negativa a abandonar el carácter misional de su tarea, idea respecto de una supuesta función del arte que en definitiva era tan sesgada como la peronista.

Si bien la irrupción del peronismo constituyó una bisagra para el mundo del trabajo en la Argentina, el campo del arte y la cultura se autoexcluyó de dicho escenario. No obstante, en las artes del espectáculo se produjo un cambio significativo luego de este período: nunca más el gremio intentaría llevar adelante la sustitución de la organización comercial de la actividad por una de tipo cooperativo. Esto implica que, desde la segunda mitad del siglo XX, quedaron completamente escindidas dos formas de producción y, por consiguiente, dos modos posibles de desempeño artístico: uno bajo relación de dependencia y otro, autogestivo. Dadas las características de ambos, las reivindicaciones sindicales sólo serán pertinentes en el primero, al que el campo cultural le aplicará además un fuerte desprecio ideológico y estético debido su afán 
de lucro. El circuito independiente, por su parte, mantuvo su postura de estricta separación entre el mundo de la cultura y el mundo del trabajo, situándose al margen de todo tipo de retribución económica para sus artistas, pero siendo objeto, a cambio, de una alta valorización estética y sobre todo, ideológica. De este modo, logró imponerse una concepción respecto del mundo del arte y de la cultura, y de las relaciones que el mismo debe establecer (o permitir) con el Estado. En dicho imaginario, el rol de éste último se reduce a brindar beneficios económicos (ya sea en forma de subsidios, rebajas impositivas y/o concesiones edilicias), excluyendo tajantemente toda intervención en formas y contenidos, que quedarían así librados a las preferencias de los artistas. Aunque, dada la dinámica del propio campo cultural (Bourdieu, 1967), dichas elecciones sean perfiladas de forma endógena por los agentes que ocupan la centralidad del mismo. En este sentido, la concepción de un Estado cuya obligación es responder a los lineamientos culturales marcados por el propio campo artístico en virtud de los altos ideales y de la importancia social que el sector que ocupa la centralidad del mismo se auto atribuye, es hegemónica.

Por consiguiente, aunque el imaginario del sector cristalizó la idea de un Estado cuya intervención es siempre amenazante, en largos y significativos períodos de nuestra historia cultural se registra el caso inverso: han sido los sectores que ocuparon y ocupan la centralidad del campo cultural los que le han impuesto al Estado sus ideas del arte y de la cultura, estableciendo así una hegemonía o tutelaje sobre otros sectores con menos o nula representación en las políticas culturales o el quehacer artístico. Este hecho, que merece un estudio específico y pormenorizado, ha tenido numerosas consecuencias en las artes del espectáculo, que van desde la adopción acrítica de estéticas de moda, hasta la utilización de fondos públicos en producciones con nóminas de artistas recurrentes; desde la pérdida de patrimonio cultural material e intangible, hasta la autoprecarización de los trabajadores del arte y de la cultura. 


\section{Bibliografía}

》 AAVV (1983). “Editorial: Cultura Nacional, Cultura Popular. Definiciones y problemas de la política y la historia cultural en la Argentina”. Punto de Vista, VI (18), 1.

» ATA (1928). Anuario Teatral Argentino 1926-1927/1927-1928, Buenos Aires: ATA.

"Baranchuk, M. (2016). Los trabajadores de los medios y sus organizaciones, C.A.B.A.: Patria Grande.

"Barletta, L. (1961). Manual del actor, Buenos Aires: Ediciones del Teatro del Pueblo.

"Bayardo, R. (1990). "Economía de la escena. Las cooperativas de teatro" y “La tradición teatral independiente y las tensiones del asalariamiento". Cuadernos de Teatro, 8, 27-40.

» Bayardo, R. (1997). El teatro "off corrientes": ¿una alternativa estético-cultural?, Tesis de Doctorado.

» Bottini, E. (1950). “Las sociedades cooperativas”. Hechos e Ideas, X (71), 155-168

» Bourdieu, P. (1967). “Campo intelectual y proyecto creador”. En AAVV, Problemas del estructuralismo (135-182). México: Siglo XXI

»Carranza Torres, M. (2011) “Un francés pionero de la propiedad intelectual argentina", Comercio y Justicia, 24 de mayo [en línea] Consultado el 17 de enero de 2018 en www.comercioyjusticia.info

»Caudarella, M.F. (2016). La necesidad del espectáculo. Aspectos sociales del teatro porteño (1918-1920), Rosario: Prohistoria.

» Falcón, R. (1986). El mundo del trabajo urbano (1890-1914), Buenos Aires: CEAL.

"Fiorucci, F. (2008). "Reflexiones sobre la gestión cultural bajo el Peronismo". Nuevo Mundo, Mundos Nuevos [en línea] Consultado el 15 de abril de 2014 en http: //nuevomundo.revues.org/24372

» Ford, A., J. Rivera y E. Romano (1984). Medios de comunicación y cultura popular, Buenos Aires: Legasa

»González Leandri, R. (2001). "La nueva identidad de los sectores populares". En AAVV (Dir. A. Cattaruzza), Nueva Historia Argentina. Tomo 7. Crisis económica, avance del Estado e incertidumbre política (1930-1943), (201-238). Buenos Aires: Sudamericana.

"González Velazco, C. (2012). Gente de teatro: ocio y espectáculos en la Buenos Aires de los años veinte, Bs. As.: Siglo XXI.

»Insaurralde, A. y C. Maranghello (1997). Fanny Navarro o Un melodrama argentino. Buenos Aires: Ediciones del Jilguero.

» Jauss, H. (1976). La literatura como provocación, Barcelona: Península.

》 Klein, T. (1988). Una historia de luchas. La AAA, Buenos Aires: AAA.

» Kogan, G., C. Ulanovsky, S. Pelayes y M. López (2012). Los Productores. Historias de los empresarios teatrales argentinos de todos los tiempos, Buenos Aires: AADET.

» Kriger, C. (2009). Cine y peronismo: el Estado en escena, Buenos Aires: Siglo XXI

"Leonardi, Y. (2009). Representaciones del peronismo en el Teatro Argentino (19451976), Tesis de Doctorado. 
"Mateo, G y X. Carreras Doallo (2013). "La economía social en la Argentina peronista (1946-1955) Una mirada desde el discurso oficial”. E.I.A.L., 24, 2.

" Mauro, K. (2015). “La actuación durante el primer peronismo. Políticas laborales y procedimientos estéticos". En AAVV, Teatro y cultura durante el peronismo en la Provincia de Buenos Aires, La Plata: Instituto Cultural de la Provincia de Buenos Aires - Archivo Histórico de la Provincia de Buenos Aires "Dr. Ricardo Levene"

»Pellettieri, O. (Dir.) (2003). Historia del teatro argentino en Buenos Aires, Tomo IV, La segunda modernidad (1949-1976), Buenos Aires: Galerna.

» Pitaco, M.D. y V. Romero (1969). "5o años de la Asociación Argentina de Actores”. En Hechos de Máscara, I (4), 92-106.

" Rivera, J. M. (1950). “Economía capitalista y economía social”, Hechos e Ideas, $X, 71$.

"Sarlo, B. (1983). “La perseverancia de un debate”. Punto de Vista, VI (18), 3-5.

»Sarlo, B. (1984). "La izquierda ante la cultura: del dogmatismo al populismo". Punto de Vista, VII (20), 22-25.

"Seibel, B. (2002). Historia del teatro argentino: desde los rituales hasta 1930, Bs As: Corregidor.

»Sigal, S. (2002). Intelectuales y poder en Argentina. La década del 6o, Buenos Aires: Siglo XXI.

"Sousa, D. (2015). “¿Cuánto ganan los bailarines?”. Balletin Dance. La revista argentina de danza, 22, 247, 10 de enero [en línea] Consultado el 30 de noviembre de 2017 en www.balletindance.com.ar/index.php?option=com_content\&task=v iew\&id $=945 \&$ ltemid $=1163$

» Torre, J. C. y E. Pastoriza (2002). “La democratización del bienestar”. En AAVV, Nueva Historia Argentina. Tomo 13, Buenos Aires: Sudamericana

»Tríbulo, J.A. (2006). Stanislavski-Strasberg. Mi experiencia de actor con la emoción en escena, Buenos Aires: Atuel.

\section{Otras fuentes}

»Boletín de la Sociedad Argentina de Actores

"Boletín de la Sociedad Argentina de Autores

»Boletín del Ministerio de Educación

"Boletín Informativo. Órgano de la Federación Gente de Teatro

"Cuadernos de Cultura Teatral

»Periódicos: Última Hora, La Nación, La Censura, La Vanguardia, Crítica, La Montaña, Idea Nacional.

»Renovación. Revista de la Sociedad Argentina de Actores

»Revista Máscara

»Versiones taquigráficas del HCD 